\title{
Wave length of the cardiac impulse and reentrant arrhythmias
}

Citation for published version (APA):

Smeets, J. L. R. M. (1983). Wave length of the cardiac impulse and reentrant arrhythmias. [Doctoral Thesis, Maastricht University]. Rijksuniversiteit Limburg. https://doi.org/10.26481/dis.19830513js

Document status and date:

Published: 01/01/1983

DOI:

10.26481/dis.19830513js

Document Version:

Publisher's PDF, also known as Version of record

\section{Please check the document version of this publication:}

- A submitted manuscript is the version of the article upon submission and before peer-review. There can be important differences between the submitted version and the official published version of record.

People interested in the research are advised to contact the author for the final version of the publication, or visit the DOI to the publisher's website.

- The final author version and the galley proof are versions of the publication after peer review.

- The final published version features the final layout of the paper including the volume, issue and page numbers.

Link to publication

\footnotetext{
General rights rights.

- You may freely distribute the URL identifying the publication in the public portal. please follow below link for the End User Agreement:

www.umlib.nl/taverne-license

Take down policy

If you believe that this document breaches copyright please contact us at:

repository@maastrichtuniversity.nl

providing details and we will investigate your claim.
}

Copyright and moral rights for the publications made accessible in the public portal are retained by the authors and/or other copyright owners and it is a condition of accessing publications that users recognise and abide by the legal requirements associated with these

- Users may download and print one copy of any publication from the public portal for the purpose of private study or research.

- You may not further distribute the material or use it for any profit-making activity or commercial gain

If the publication is distributed under the terms of Article $25 \mathrm{fa}$ of the Dutch Copyright Act, indicated by the "Taverne" license above, 
Wave length of the cardiac impulse and reentrant arrhythmias

Joseph Léon Robert Marie Smeets 



\section{Wave length of the cardiac impulse and reentrant arrhythmias}

Proefschrift

ter verkrijging van de graad van Doctor in de

Geneeskunde aan de Rijksuniversiteit Limburg

te Maastricht op gezag van de Rector Magnificus

Prof. Dr. H.C. Hemker volgens het besluit

van het College van Dekanen in het openbaar te

verdedigen in de Aula van de Universiteit op

vriijdag 13 mei 1983

des namiddags te 16.00 uur

door

Jaseph Léon Robert Marie Smeets

geboren te Heerlen 
Promotor: Prof. Dr. F.I.M. Bonke, Rijksuniversiteit Limburg, Maastricht.

Co-promotor: Dr. M.A. Allessie, Rijksuniversiteit Limburg, Maastricht

Referenten: Dr. M.J. Janse, Universiteit van Amsterdam, Amsterdam.

Prof. Dr. H.J.J. Wellens, Rijksuniversiteit Limburg, Maastricht.

Prof. A.L. Wit, PhD, Columbia University, New York.

Het verschijnen van dit proefschrift werd mede mogelijk gemaakt door steun van de Nederlandse Hartstichting.

Financial support by the Netherlands Heart Foundation for the publication of this thesis is gratefully acknowledged. 

Ne 11 a 

2.2 Superfusing and experimental equipment

2.4 Measurement of the conduction velocity

2.5 Homogeneity in conduction

2.6 Characteristics of conduction block

2.7 Measurement of the refractory period

2.8 Measurement of the maximum pacing rate 29

2.9 Calculation of the length of the 29 excitation wave

3. INFLUENCE OF RATE AND RHYTHM ON THE LENGTH OF THE EXCITATION WAVE

4. THE EFFECTS OF TEMPERATURE ON THE LENGTH 
$S$ OF NEUROTRANSMITTORS ON THE LENGTH

ITATION WAVE

Experimental protocol $\quad 57$

Results 58

Discussion $\quad 67$

:TS OF CHANGES IN EXTRACELLULAR

1 CONCENTRATION

L Experimental protocal $\quad 71$

? Results 72

3 Discussion 78

:TS OF L IDOCAINE

1 Experimental protocol 83

2 Results 84

3 Discussion $\quad 88$

CTS OF QUINID INE

1 Experimental protocol 93

2 Results 94

3 Discussion 99 
9. THE EFFECTS OF DUABAIN

9.1 Experimental protocol 105

9.2 Results 107

9.3 Discussion 111

10. THE EFFECTS OF VERAPAMIL 115

10.1 Experimental protocol 115

10.2 Results $\quad 117$

10.3 Discussion 119

11. THE EFFECTS OF AMIODARONE 123

11.1 Methods 123

11.2 Results 124

11.3 Discussion 132

$\begin{array}{ll}\text { SUMMARY AND CONCLUSIONS } & 139\end{array}$

$\begin{array}{ll}\text { SAMENVATTING EN CONCLUSIES } & 143\end{array}$

$\begin{array}{ll}\text { NAWOORD } & 145\end{array}$

$\begin{array}{ll}\text { CURRICULUM VITAE } & 146\end{array}$ 
1. INTRODUCTION.

\section{Historical background.}

Tachyarrhythmias can be divided in those based on abnormal impulse formation and those based on abnormal impulse conduction, leading to circulating excitation in the heart (Wit and Cranefield 1978, Hoffman and Rosen 1981). The existence of circulating excitation was already discovered in the beginning of this century. Mayer (1906) demonstrated that in a ring, cut from the paralyzed jelly-fish, rhythmic activity could be initiated if only ane stimulus was given. This regular activity was based on the occurrence of one contraction wave, which circulated in this ring. The first to describe circulating excitation in cardiac tissue was Mines (1913). In a ring structure, made from atrial and ventricular muscle of the tortolse heart, a rhythm was originated in which the activation went from atrium to vertricle and back to atrium and so on. This was described as a "reciprocating rhythm". It is essential for the initiation of such a recipracating rhythm or circus movement that the stimulated impulse is blacked in one direction of the ring structure (unidirectional block). Furthermore the impulse, going in the opposite direction, must travel along such a route that the area of block has enough time to restore its excitability to be activated in a retrograde fashion by the circulating impulse.

Lewis et a1. (1920) demonstrated that atrial flutter initiated in a canine heart was based on a circulating excitation around the superior and inferior caval veins. Further evidence that this arrhythmia was based upom circus movement around the orifices in the atrium was obtained by Rosenblueth and Garcia Ramos (1947). They showed that induction of atrial flutter was markedly facilitated if the muscular area between superior and inferior caval vein was crushed. The importance of the size of the anatomical obstacle around which the impulse is circulating was further elucidated by the fact that the cycle length prolonged if the anatomical obstacle was enlarged (Kimura et a1. 1954). An additional argument for circus movement as the underlying mechanism, was the sudden termination of the arrhythmia if the anatomical obstacle was enlarged in the direction of the atrio-ventricular groove, resulting in an interruption of the pathway. 


\section{CIRCUS MOVEMENT}

Anatomical iy determined

(Mines, 1913)

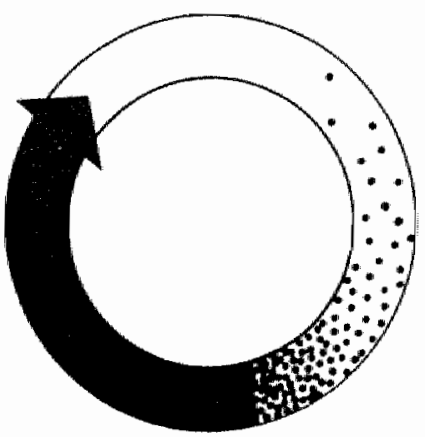

1) Fixed length of circuit

2) Circuit length equal to aratomical pathway

3) Excitable gap between head and tail of impulse

4) Rate proportional to conduction velocity and length of pathway
Functionally determined

(Allessie et a ", 1977)

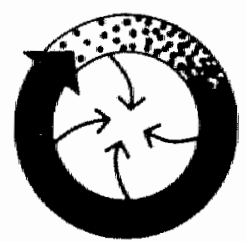

1) Variable size
of circuit

2) Circuit Iength equal to length of the excitation wave

3) No gap of full excitability

4) Rate proportional to refractory period 
An example of a clinical arrhythmia which is based on a circus movement in an anatomically determined pathway is the Wolff-Parkinson-White-syndrome. In this arrhythmia the anatomically determined pathway consists of atrium, atrio-ventricular node, bundle of $\mathrm{His}$, bundle branch, ventricle and accessory pathway (Durrer and Wellens 1974).

Wwo types of circus movement.

In addition to circulating excitation in an anatomically determined pathway, circus movement also can exist without involvement of an anatomical obstacle. It was first shown by Allessie et al. (1973, 1976, 1977a) that a rapid circus movement could be initiated in an isolated atrium of the rabbit which did not contain any anatomical obstacle. This kind of circus movement without an anatomically preformed pathway is fully determined by the electrophysiological properties of the myocardium. The circulating wave will take the shortest possible route in which the impulse just can activate the tissue ahead, which is recovering from the previous activation. In this situation a tight fit exists between the head and tail of the wave front. The central area is continuously invaded by centripetal wavelets, which collide on each other and thus prevent a short-cut of the circuit. In other words this central area acts as a functional block, around which the impulse revolves. If the electrophysiological properties of the tissue change, the pathway of the impulse changes too. As a consequence the localization and size of this functionally determined circuit is not fixed and can change from moment to moment. For instance if the refractory period is shortened the tissue in the center will recover its excitability earlier and thus allows an impulse to take a shorter route, eventually resulting in a short-cut of the circuit. On the other hand if the conduction velocity is increased the impulse is forced to take a longer way since the tissue is not yet restored from the previous activation. However the time needed to complete one revolution will not be affected. From this it follows that the rate of this circus movement is related to the refractory period of the myocardium. In figure 1.1 the properties of an anatomically determined and a functionally determined circuit are compared. 
Arrhythmias based on intra-myocardial reentry.

Arrhythmias which might be based on such functionally determined circuit are atrial flutter and fibrillation. It was proposed by Moe and Abildskow (1959) that fibrillation could be based on the simultaneous wandering of multiple wavelets, changing continuously in width, position and number. Recently Allessie et al. (1982) provided experimental evidence for this hypothesis. Using an extensive mapping technique they demonstrated that during atrial fibrillation in an isolated blood perfused canine heart several functionally determined circuits were present simultaneously. These reentrant circuits continuously changed in size and position. The number of simultaneously present circuits depends on the size of the circuits relative to the size of the part of the heart in which they are circulating. If the size of the circuit is small in relation to the heart, there might be room for many circuits. In this situation the statistical chance that all wavelets die out at the same time is small and spontaneous termination of fibrillation is unlikely. On the other hand if the size of the circuit is large, only a limited number of wave fronts can be present simultaneously and termination of fibrillation becomes more likely.

The role of inhomogeneity in conduction and refractoriness for the initiation and continuation of fibrillation.

Measurement of the refractory period at several sites in atrial and ventricular myocardium have revealed considerable differences in the rate of recovery of excitability (Alessi et a1. 1958, Han and Moe 1964, Janse 1971, Allessie et a1. 1976). In general if the heart rate is low these differences play no role because the myocardium has sufficient time to restore its excitability completely before the next impulse arrives. As a consequence the activation front is conducted uniformally in all directions. If however an extrasystole arises in the relative refractory period the conduction is less. uniform since not all fibers have completely regained their excitability. The activation front is conducted in fibers, which have recovered from the previous activation, whereas in neighboring fibers the conduction is blocked because they did not yet restore their excitability. As a consequence the activation front will have an irregular contour and becomes fractionated. From this it follows that if the dispersion in recovery of excitability is large, the likelihood of occurrence of areas of block is high. As a result 
fractionation of the wave fronts will occur frequently, making degeneration into arrhythmias likely. Interventions which increase the inhomogeneity in conduction and refractoriness, are associated with an increased risk of fibrillation. It was demonstrated that vagal stimulation enthances the non-uniform recovery of excitability in the atrium (Alessi et al. 1958), and increased sympathetic activity increases the dispersion of recovery of the excitability of ventricular myocardium (Han and Moe 1964). However not only local inhomogeneities in refractoriness and conduction but also the dimension of an intra-myocardial circuit determines whether or not an impulse can be trapped in a circuitous route.

The role of the length of the excitation wave for the initiation and continuation of fibrillation.

In considering the occurrence of a circus movement three factors have to be taken into account, as was already described by Lewis (1925): the length of the pathway, the conduction velocity of the impulse and the duration of the refractory period. In an anatomically determined circuit the length of the pathway is larger than the length of the excitation wave (product of conduction velocity and refractory period). Under these circumstances a gap of full excitability exists between head and tail of the wave front. However, in a functionally determined circuit there is a tight fit between head and tail of the wave front and no gap of full excitability is present. Then the length of the pathway is equal to the wave length of the circulating impulse.

In figure 1.2 the prerequisite conditions for the initiation of a functionally determined circuit are depicted. In general the activation front will propagate uniformally from the point of origin to all directions, as illustrated in panel $A$. If due to inhomogeneity in excitability the impulse is blocked, the activation front circumvents this area. By doing so the myocardium at the other side of the block is activated (panel $B$ and $C$ ). If the impulse travelled such a route that the myocardium which was previously blocked had enough time to restore its excitability, the block area can be activated in a retrograde fashion (panel D) and the impulse can accomplish the first reentrant loop. 


\section{A}

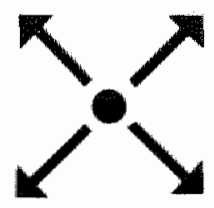

C

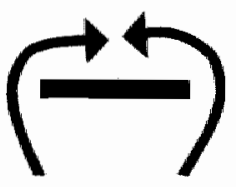

B
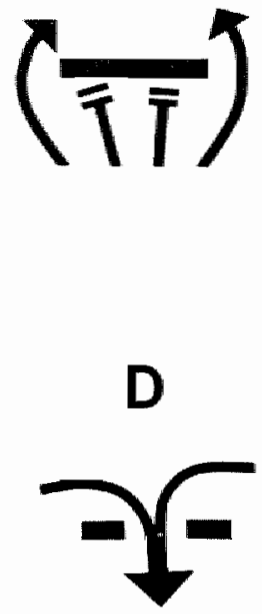

FIGURE 1.2: Prepequigite conditions for initiation of reentry. In generaz an activation front is conducted unifomally in alt directione (panel A). Sometimes however the impulee is blocked (panet B) and the activation front circumvents this area of block panet $B$ and $C$. If the impulse arrives at the backside of the block area at the moment the myocardium has restored its excitability, metrograde activation of this area occurs (panel D).

Whether such a reentrant circuit occurs depends on a delicate interplay between the size of the block and the length of the excitation wave. If the route the impulse must travel to reach the backside of the block area is shorter than the length of the excitation wave, no circuit can be established because the myocardium had not yet restored its excitability. Only if the pathway is equal to the length of the excitation wave, the block area can be invaded and a circuit can be completed since the myocardium has just regained its excitability. If the pathway which the impulse travels around the block area becomes larger than the length of the excitation wave the activation front will activate the block area as soon as the myocardium becomes 
excitable again. From this it follows that if the wave length is relatively short, a small area of block will be sufficient to set the stage for a reentrant circuit. Since small areas of block can accur rather frequently in the myocardium initiation of these circuits becomes more likely. On the other hand if the wave length is relatively long, reentry only can occur if a large arc of conduction black will be present. However occurrence of a large area of block is unlikely, making the chance on initiation of a reentrant circuit low.

Measurement of the length of the excitation wave.

In figure 1.3 a functionally determined circuit is schematically represented. The black area indicates the myocardium which is in the absolute refractory phase, whereas the dotted area indicates the relative refractory tissue. Since a tight fit exists between the head and tail of the wave fronts, the size of the reentrant circuit is equal to the length of the circulating wave. Measurement of the wave length can be done in two ways. The wave length of the circulating impulse can be measured directly by mapping the activation pathway during an intra-myocardial reentry. Allessie et al (1977b) showed that under the influence of acetylcholine the minimal dimension of this functionaliy determined circuit diminished considerably due to a change in refractoriness. However measurement of changes in the minimal dimension by mapping the activation pathway is a rather time consuming investigation.

The wave length can also be measured in a narrow bundle of myocardium, as if the circuit is opened and unrolled. If one knows the conduction velocity and the refractory period under conditions comparable with that of the tachycardia the length of the excitation wave can be calculated from the product of these two parameters. The advantage of this method is that the measurement of the wave length can be done quickly and no elaborate equipment is needed. 

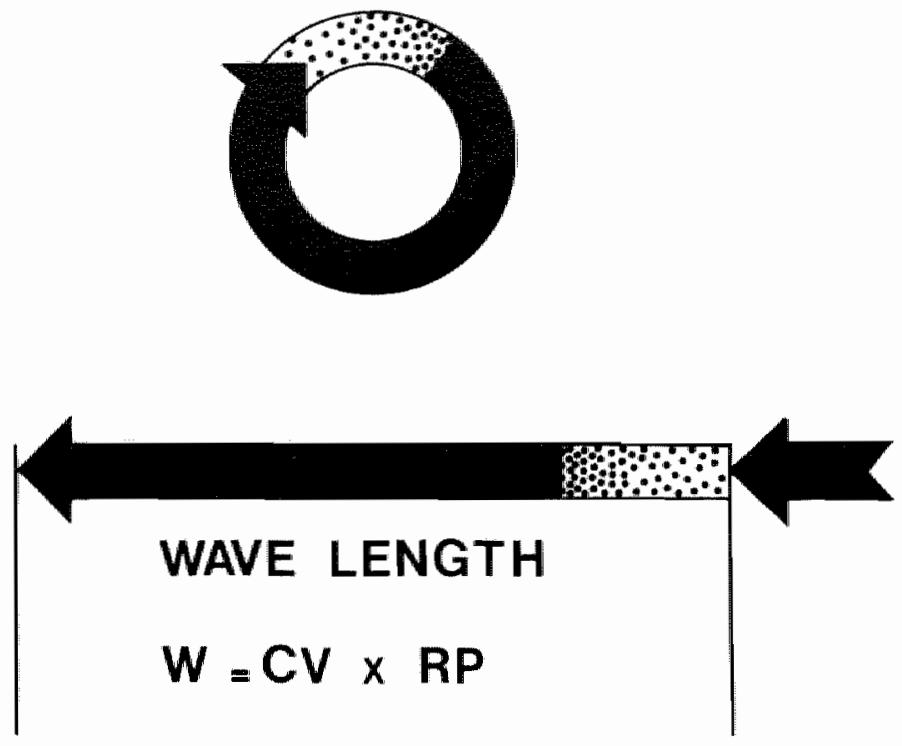

FIGURE 1.3: Sehematic representation of a functionally determined eireut. The biack area indicates the tissue which is in its absolute refractory phase, whereas the dotted area represents the relative refractory tissue. Since a tight fit exists between the head and tail of the circulating activation wave, the size of the circuit is equat to the wave length of the imputse. The wave length can be measured by mapping the activation cequenee of a reentrant arrhythmia, or by calculating the product of conduction velocity and refractory period, measured under conditions comparable with that of the reentrant armythmia.

Possible mode of action of some arrhythmogenic and antiarrhythmic interventions in relation to reentrant arrhythmias.

If our hypothesis is correct that the size of the circuit cq. the wave length is one of the factors determining the chance of initiation and continuation of fibriliation we should expect that interventions which influence the occurrence of fibrillation will also change the length of the excitation wave. To test this hypothesis we measured the wave length in the isolated atrium of the rabbit during arrhythmogenic and antiarrhythmic interventions. 
It is a well known fact that atrial fibrillation can easily be induced when the vagal nerve is stimulated or when the atrium is exposed to acetylcholine. According to our hypothesis we expect that acetylcholine shortens the length of the excitation wave. In this case the induction of fibrillation would be facilitated (only a small area of block is needed), and persistence of fibrillation becomes more likely (many circuits can be present simultaneously).

On the other hand drugs which can terminate atrial fibrillation (quinidine, digitalis, amiodarone) are expected to prolomg the length of the excitation wave. When the excitation wave is long the induction of fibrillation would be more difficult (a large block area is needed) and the termination of fibrillation more likely (only a limited number of wavelets can be present).

In addition we tested this hypothesis by measuring the effects of antiarrhythmic drugs, which do not influence the occurrence of atrial fibrillation (verapamil, lidocaine). If no change in the length of the excitation wave was observed during administration of these drugs, this would support our hypothesis.

\section{REFERENCES}

Alessi R, Musynowitz M, Abildskov JA, Moe GK: Nonuniform distribution of vagal effects on the atrial refractory period.

Am U Physiol, 194: 406-410, 1958.

Allessie MA, Bonke FIM, Schopman FJG: Circus movement in rabbit atrial muscle as a mechanism of tachycardia.

Circ Res, 32: 54-62, 1973.

Allessie MA, Bonke FIM., Schopman FJG: Circus movement in rabbit atrial muscle as a mechanism of tachycardia. II. The role of nonuniform recovery of excitability in the occurrence of unidirectional block, as studied with multiple microelectrodes.

Circ Res, 39: 168-177, 1976. 
Allessie MA, Bonke FIM, Schopman FJG: Circus movement in rabbit atrial muscle as a mechanism of tachycardia. III. The "leading circle" concept: A new model of circus movement in cardiac tissue without the involvement of an anatomic obstacle.

Circ Res, 41: 9-18, 1977a.

Allessie MA, Bonke FIM, Lammers WJEP: The effects of Carbamylcholine, Adrenaline, Ouabain, Quinidine and Verapamil on Circus Movement Tachycardia in isolated segments of rabbit atrial myocardium.

In: Re-entrant Arrhythmias. Mechanisms and treatment. Edited by: H.E. Kulbertus, MTP Press Limited, Lancaster, 63-71, $1977 \mathrm{~b}$.

Allessie MA, Lammers WJEP, Smeets JLRM, Bonke FIM, Hollen SJ: Total mapping of atrial excitation during acetylcholine-induced atrial flutter and fibrillation in the isolated canine heart.

In: Atrial Fibrillation. Edited by Kulbertus HE, 01sson SB, Schlepper M, Publ Hassle, Molndal Sweden, 44-61, 1982.

Durrer D, Wellens HJJ: The Wolff-Parkinson-White syndrome: anno 1973. Eur J Cardio1, 1/4: 347-367, 1974.

Han J, Moe GK: Nomuniform recovery of excitability in ventricular muscle. Circ Res, 14: 44-60, 1964.

Hoffman BF, Rosen MR: Cellular mechanisms of cardiac arrhythmias. Circ Res, 49: 1-15, 1981

Janse MU: The effect of changes in heart rate on the refractory period of the heart. Thesis, Mondeel-offsetdrukkery, Amsterdam, 1971.

Kimura E, Kato K, Murao S, Ajisaka H, Koyama S, Omiya Z: Experimental studies on the mechanism of the auricular flutter. Tohoku J Exp Med, 60: 197-207, 1954. 
Lewis T, Feil HS, Stroud WD: Observations upon flutter and fibrillation. Part II. The nature of auricular flutter. Heart, 7: 191-246, 1920.

Lewis $T$ : The mechanism and graphic registration of the heart beat. Shaw and Sons Ltd.London, $3^{\text {rd }}$ edition, 1925.

Mayer AG: Rhythmical pulsation in the scyphomedusae. Publication no 47, Carnegie institutions of Washington, 1906.

Mines GR: On the dynamic equilibrium in the heart. J Physiol, 46: 349-383, 1913.

Moe GK, Abildskov JA: Atrial fibrillation as a self-sustaining arrhythmia independent of focal discharge.

Am Heart J, 58: 59-70, 1959.

Rosenblueth A, Garcia Ramos J: Studies on flutter and fibrillation. II. The influence of artificial obstacles on experimental auricular flutter. Am Heart J, 33: 677-684, 1947.

Wit AL, Cranefield PF: Reentrant excitation as a cause of cardiac arrhythmias. Am J Physiol, 255: H1-H17, 1978. 

2. METHODS

\subsection{Preparation}

Young New Zealand rabbits of both sexes weighing between 1.5 and $2.0 \mathrm{~kg}$ were stunned with a blow in the neck and the thorax was opened by a midsternal incision. The heart was rapidly excised and transferred to a tissue bath where further dissection was performed. A left oblique lateral view of the rabbit heart is shown in figure 2.1 panel $A$. The hatched area of the left atrium indicates the part of the heart which was used for these studies. The atria and ventricles were separated by a cut along the atrial side of the atrio-ventricular groove. Another cut was made along the border of the atrial appendage, removing the floor of the atrium. After this procedure the oxygenated Tyrode solution could reach freely the endocardial surface of the left atrium. This part of the operation - from the cervical dislocation till the opening of the left atrium - was done as quickly as possible to prevent hypoxic damage of the endocardial cells and was accomplished within 2 minutes. Figure 2.1 parel $B$ is a view of the atria as seen from below. The right atrium is still intact, showing the atrio-ventricular orifice. In the left atrium the floor has been removed showing the complete endocardial surface of the roof. The last part of the operation was to jsolate a long and narrow strip of atrial myocardium. In figure 2.1 panel $C$ the actual form of the left atrial preparation is shown which was used for our experiments as seen from the endacardial side. The L-shaped strip is about $20 \mathrm{~mm}$ long, $2-3 \mathrm{~mm}$ in width and not more than $0.5 \mathrm{~mm}$ thick. After isolation from the rest of the atria, the preparation becomes quiescent. The short "leg" was used for stimulation, whereas in the lang part the conduction characteristics were measured.

\subsection{Superfusing- and experimental equipment.}

The strip of left atrial myocardium was placed in a $50 \mathrm{ml}$ tissue bath which is perfused at a rate of $100 \mathrm{ml}$ per minute. The Tyrode solution had the following composition (mM): $\mathrm{MaCl} 130, \mathrm{KCl} 4.5, \mathrm{CaCl}_{2} 2.2, \mathrm{MgCl}_{2} 0.6, \mathrm{NaHCO}_{3}$ 24.2, $\mathrm{NaH}_{2} \mathrm{PO}_{4} 1.2$, glucose 11 and sucrose 13. The perfusion fluid was saturated by a mixture of $95 \% \mathrm{O}_{2}$ and $5 \% \mathrm{CO}_{2}$. The pH of the Tyrode was 

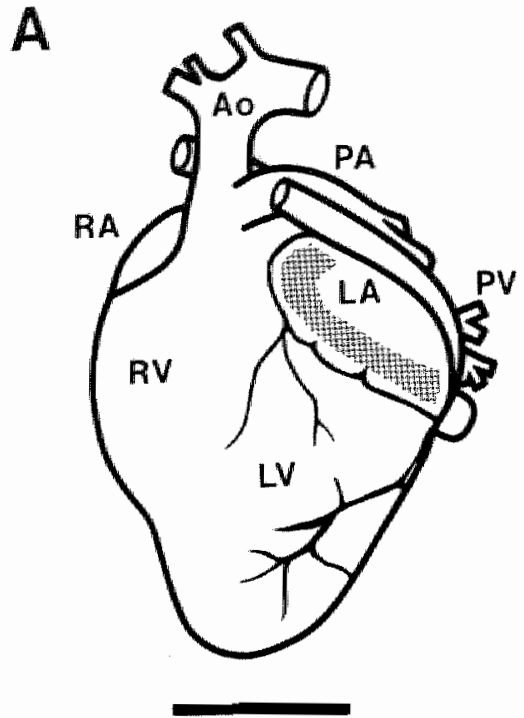

$10 \mathrm{~mm}$
B
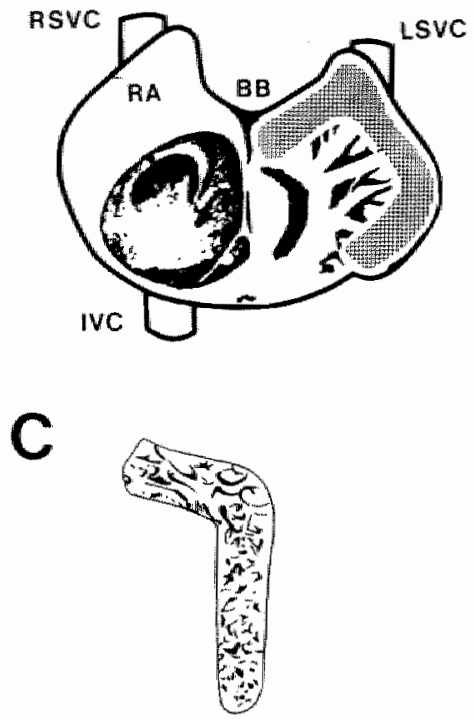

FIGURE 2.1 Schematic dratings of the different stages of dissection of the preparation. Panel A show the rabbit heart from a left obitiue lateral view. The hatched area in the left atrium indicates the part that wizl be isolated. In parel $B$ the left and might atrium are seen from below. The right atrium is still intact, whemeas the floor of the left atmilm has been removed. In panel $C$ the preparation is shown as it appears after the hatched area in paret $B$ hol been excised. The stmp is t-rhaped, about $20 \mathrm{~mm}$ zong, $2-3$ mon in width and not more than $0.5 \mathrm{~mm}$ thick. The shom part of the L-ahaped atmip tis used to etimulate the preparation, whereas in the long part the conduction velootty is measured. $A O=$ aorta, $B B=$ Bundle of Bachmann, IVC = inferior vena cava, $L A=$ Left atmium, LSVC = Left Guperior vena cava, LV = Left ventmite, $P A=$ pulmonary artery, $P V=$ pulmonary veins, $R A=$ might atmium, RSVC = might auperior vena cava, $R V=$ might ventmicle.

maintained at $7.35 \pm 0.05$. After being oxygenated in a 10 liter reserwoir the Tyrade solution was transported by a roller pump to an airchamber, where the pulsatile flow was changed to a more continuous flow. Before entering the tissue bath the fluid was warmed in a heating coil to a temperature of $37^{\circ} \mathrm{C} \pm$ 0.1 . After coming out of the tissue bath the Tyrode is led back again to the 10 liter reservoir.

Figure 2.2 gives a schematic drawing of the experimental set-up. 
A programable stimulator delivers constant current pulses (duration 1-2 msec, strength 2-5 times diastolic threshold) to the strip of left atritum through 2 platinum plates $(2 \times 4 \mathrm{~mm})$ embracing the short leg of the bundle. The stimulating electrode is positioned in such a way that the preparation can move freely between the 2 plates. From the point of stimulation the impulse is propagated along the bundle. The fact that the strip is so narrow guarantees that the pathway of activation can show only minor variations. The activation sequence was recorded with a multiple unipolar recording electrode, consisting of a row of 8 teflon coated silver wires $0.3 \mathrm{~mm}$ in diameter. The distance between the recording electrodes is fixed at $2 \mathrm{~mm}$. A minimum distance of $3 \mathrm{~mm}$ was kept between the point of stimulation and the

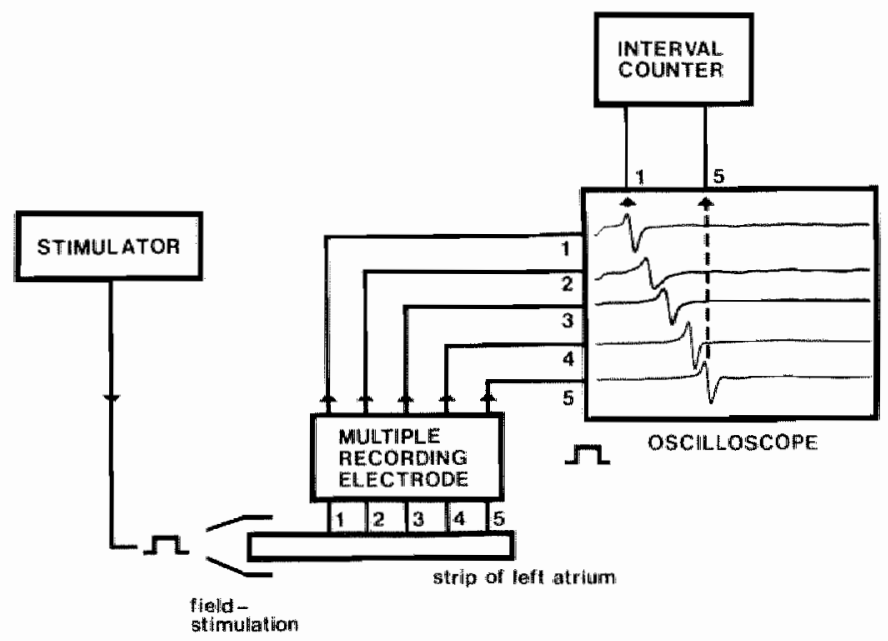

FIGURE 2.2 Schematic representation of the experimental set- up. A stmp of left atrial myocardium is mounted in a tiseue bath. A programabie stimulator delivers equare wave pulses, 1 or 2 msec in duration, through a set of platinum plates placed just above and beneath one end of the left atrial strip. A row of $B$ unipolar recording electrodes is gently positioned on the remaining part of the bundle. The electrograme are individually amplified and displayed on an oscilloscope. An example of the recorded activation sequence is shown at the right. The beam of the oscilloscope is started on the stimulue artefact. The time between activation of the first and last electrode on the atrial stmip is displayed on an interval counter. In this case five etectrodes fitted on the preparation, the distance between the firet and last recording electrodes being $8 \mathrm{~mm}$. 
first recording electrode. A large silver plate in the tissue bath was used as indifferent electrode. The unipolar electrograms recorded with this multiple recording electrode were individually amplified (bandwith $5-400$ $\mathrm{Hz}$ ) and displayed on an oscilloscope (Tektronix 1503N). In this way the activation sequence all along the strip of left atrium can be easily monitored. The fast part of the intrinsic deflection of the unipolar electrogram, representing the moment of activation of the tissue beneath the recording electrode, was detected by a trigger unit designed by our electronic workshop. The time difference between arrival of the activation front at the first and last recording electrode was continuously measured with an interval counter (Hewlett Packard 5300B)

\subsection{Electrical stimulation}

Point-versus field-stimulation.

Stimulation of the myocardium with extracellular electrodes can be done either locally, using a point electrode, or more regionally, using a large electrode (field stimulation). To evaluate which way of stimulation should be used in our studies, we compared both ways of stimulation in 12 preparations. Table 2. I gives the individual values of these experiments. For both ways of stimulation the shortest possible pacing interval and the conduction velocity at that rate are plotted. Note that, compared to point stimulation, during field stimulation the average minimal pacing interval is shorter (90.4 versus $110.4 \mathrm{msec})$ and the conduction is 51 ower $(32.8$ versus $36.3 \mathrm{~cm} / \mathrm{sec})$. These differences can be explained by the different amount of tissue, which is stimulated. In case of a point electrode the electrophysiological properties of a small amount of tissue determines whether or not a propagated response will be initiated. If at the spot of stimulation the refractory period is long, the maximum pacing rate will be found to be relatively low. On the other hand if the local refractory period is short a higher maximum pacing rate will be measured. In case of field stimulation the area of myocardium, which is exposed to the electrical stimulus, is larger. Therefore the localisation of the stimulating electrodes is less critical. The part of the tissue between the plates with the shortest refractory period will determine the maximum pacing rate. As a consequence the minimal pacing cycle length is 
TABLE 2. I

POINT-ST IMLATION

Preparation
Interval

Fmax (ms) Velocity $(\mathrm{cm} / \mathrm{sec})$
FIELD-STIMULATION

Interval Conduction

Fmax (ms) Velocity ( $\mathrm{cm} / \mathrm{sec})$

\begin{tabular}{r|rl|rl}
\hline & 110 & 29 & 100 & 34 \\
1 & 125 & 24 & 90 & 35 \\
3 & 80 & 24 & 80 & 40 \\
4 & 125 & 27 & 85 & 34 \\
5 & 110 & 55 & 100 & 33 \\
6 & 110 & 37 & 80 & 33 \\
7 & 105 & 40 & 80 & 28 \\
8 & 95 & 43 & 100 & 33 \\
9 & 120 & 57 & 90 & 33 \\
10 & 110 & 21 & 95 & 32 \\
11 & 130 & 43 & 85 & 31 \\
12 & 105 & 35 & 100 & 28 \\
\hline MEAN & 110.4 & 36.3 & & \\
SD & \pm 13.9 & \pm 11.9 & 90.4 & 32.8 \\
& & & \pm 8.4 & \pm 3.2
\end{tabular}

shorter, and also the conduction at this higher pacing rate is slower. Furthermore the variability between the different preparations, as indicated by the standard deviation is smaller for field stimulation. Because of these reasons we decided to use field stimulation in these studies.

Release of neurotransmitters by field stimulation

It has been described that electrical stimulation of the heart can liberate neurotransmitters like acetylcholine and/or (nor)epinephrine from the cardiac nerve terminals (Vincenzi and West 1963, Spear et al. 1979). To check whether the field stimulation we wanted to use could release acetylcholine and (nor)epinephrine, we applied this kind of stimulation on the isolated rabbit sinus node. It is well known that in the sinus node area a large number of both sympathetic and parasympathetic nerve terminals are present. If the stimulation procedure releases one or both neurotransmitters this should become apparent by a change in sinus rhythm. In figure 2.3 an example is shown of the effects of electrical stimulation on the rate of spontaneous discharge of the isolated sinus node. Two platinum plates were 
SINUS NODE CYCLE LENGTH

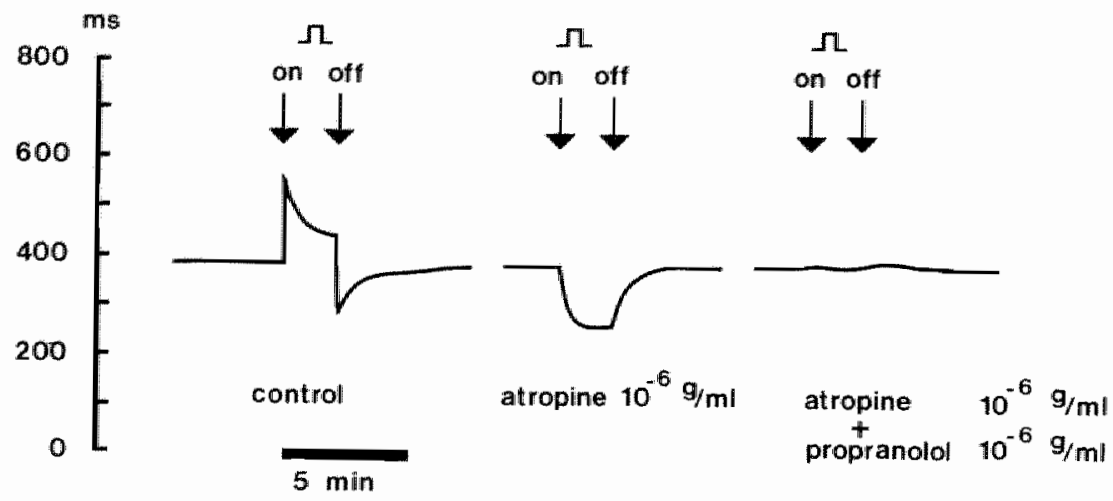

FIGURE 2.3 The effects of electrical stimulation of the Einus node. The apontaneous cycle tength of the sinus node ie plotted on the ordinate. The effects of electrical stimulation are shown during control, during administration of atropine $\left(10^{-6} \mathrm{gr} / \mathrm{ml}\right)$ and duming administration of atropine together with propranolol $\left(10^{-6} \mathrm{gr} / \mathrm{ml}\right)$. During the period delineated by the arrows, a train of 7 stimuli (duration 1 msec, interval 2 msec, strength 10 $\mathrm{mA})$ is applied to the sinus node region after every spontaneous discharge. During contmol, stimilation resulted in a prolongation of the sinus node cycle length. In contrast after administration of atropine a marked shortening of cycle length was observed. When in addition propranotol was added no effect of the electrical stimuli was observed at alt.

positioned at each side of the opened superior Vena Cava, at the area where the sinus node is located. After every spontaneous discharge of the sinus node a train of 7-10 stimuli (duration $1 \mathrm{msec}$, interval $2 \mathrm{msec}$, strength 10 mA) are given through the two plates. Because the atrium has been depolarized by the sinus node just before this train of stimuli is given, the myocardium is still in its absolute refractory phase and can not be excited. However the nerwe fibers, having a very short refractory period, will be stimulated. In figure 2.3 the effects during control, after administration of atropine and after atropine together with propranolol are illustrated. During control electrical stimulation clearly prolonged the spontaneous sinus node cycle length. This phase of slowing was preceded by a decelaration directly after initiation of stimulation, and was followed by an acceleration after termination. After administration of atropine no increase in cycle length was 
observed anymore. Instead the cycle length decreased from about 400 to 300 msec. If atropine and propranolol were administered the sinus node cycle length was not changed at all during the stimulation procedure. These results indicate that field stimulation indeed can release both (nor)epinephrine and acetylcholine from the nerve terminals.

To check whether also in the isolated ieft atrium acetylcholine and (nor)epinephrine are released, we applied the same stimulation protocol to the atrium. However instead of using the rate of spontaneous discharge of the sinus node, we used the refractory period as an indicator for the liberation of neurotransmitters. Acetylcholine shortens the refractory period at 500 msec pacing interval $(2 \mathrm{~Hz}$ ) in the rabbit atrium whereas epinephrine prolongs refractoriness (see chapter 5). As can be seen in table 2. I no differences in refractory period mere detected with or without electrical stimulation. Al so addition of atropine in a concentration of $10^{-6} \mathrm{~g} / \mathrm{ml}$ did not change the refractory period. These results indicate that even strong stimulation of the

TABLE 2.II

REFRACTORY PERIOD

(ms)
INTERVAL Fmax

(ms)

\begin{tabular}{|c|c|c|c|c|c|}
\hline $\begin{array}{l}\text { Prepa- } \\
\text { ration }\end{array}$ & Control & $\begin{array}{l}\text { St imula- } \\
\text { tion* }\end{array}$ & $\begin{array}{l}\text { Atro- } \\
\text { pine** }\end{array}$ & Control & $\begin{array}{l}\text { Atro- } \\
\text { pinex }\end{array}$ \\
\hline $\begin{array}{l}1 \\
2 \\
3 \\
4 \\
5\end{array}$ & $\begin{array}{l}70 \\
60 \\
45 \\
60 \\
70\end{array}$ & $\begin{array}{l}70 \\
60 \\
45 \\
60 \\
65\end{array}$ & $\begin{array}{l}85 \\
65 \\
45 \\
60 \\
70\end{array}$ & $\begin{array}{r}100 \\
90 \\
95 \\
85 \\
-\end{array}$ & $\begin{array}{r}100 \\
90 \\
90 \\
95 \\
-\end{array}$ \\
\hline $\begin{array}{l}\text { MEAN } \\
\text { SD }\end{array}$ & $\begin{array}{l}61.0 \\
+10.3\end{array}$ & $\begin{array}{l}60 \\
+9.4\end{array}$ & $\begin{array}{l}65 \\
\pm 14.6\end{array}$ & $\begin{array}{r}92.5 \\
+6.5\end{array}$ & $\begin{array}{r}93.8 \\
+4.8\end{array}$ \\
\hline
\end{tabular}

* train of $7 \mathrm{stimuli,} \mathrm{duration} 1 \mathrm{msec}$, interval $2 \mathrm{msec}$, strength $10 \mathrm{~mA}$ ** $10^{-6} \mathrm{~g} / \mathrm{ml}$ atropine 
isolated left atrium does not cause a major release of neurotransmitters and will not influence the values of refractoriness and conduction velocity.

\section{The stimulus strength}

Since the measured value of the refractory periad may strongly depend on the stimulus intensity used, an appropriate stimulus strength has to be chosen. The relation between stimulus strength and shortest possible coupling interval (strength-interval curve) is shown in figure 2.4. At lower stimulus

\section{STIMULUS STRENGTH}

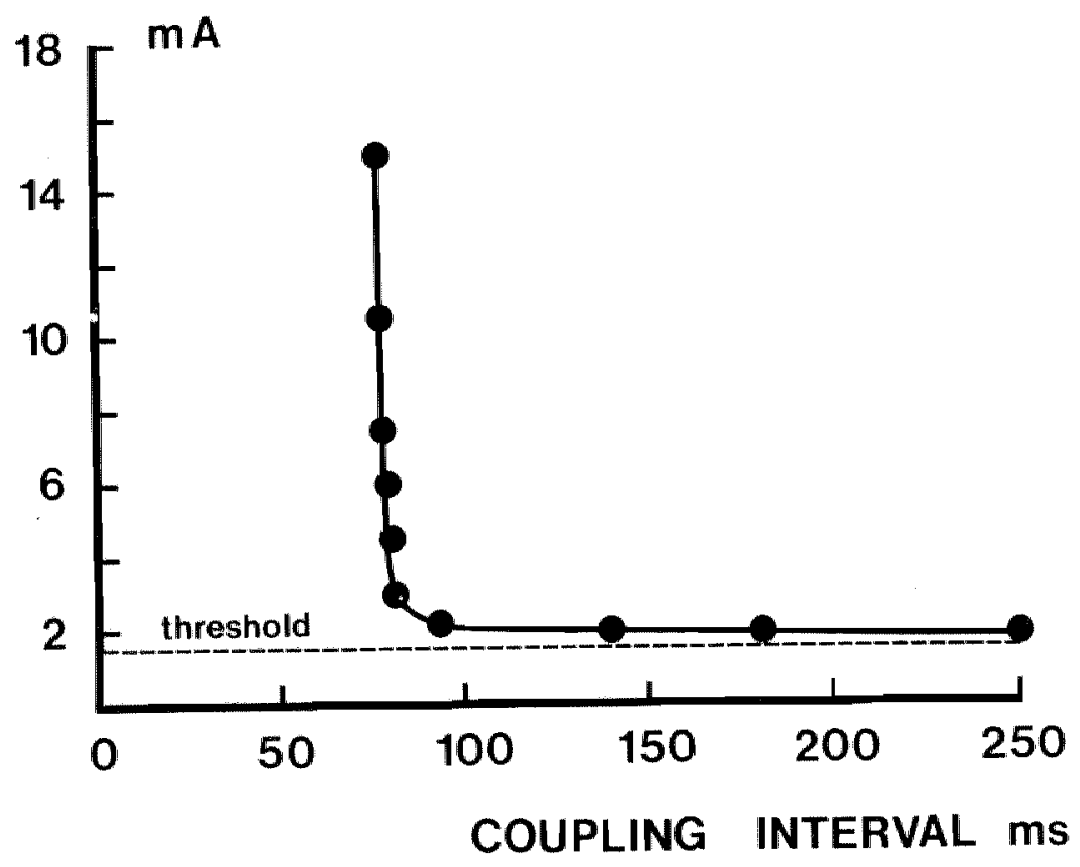

FIGURE 2.4 The strength-interval curve of isotated left atrial myoaradium uing field stimulation. The refractory period the shortest possible A1-A2 interval) it shortened markedly when the etimulue strongth is increased from threshold to about 2 times threshold $(3 \mathrm{~mA})$. Fumther increase to 10 times dastotio threshotd (15 mA) hardiy affects the A1-A2 intemal. Eor the determination of the refractory period we used a stimulus atrength of $4-5$ time diastotic threshota (pacing rate $2 \mathrm{~Hz}$ ). 
intensities minor changes in stimulus strength result in large differences in the measured refractoriness. However at a higher stimulus strength, starting from 3 times diastolic threshold $(4.5 \mathrm{~mA})$ the refractory period is hardly affected by the stimulus strength. For this reason a stimulus of 4 to 5 times diastolic threshold was used for the measurement of the refractory period.

\subsection{Measurement of the conduction velocity.}

The conduction velocity of the electrical impulse in the heart can be calculated if one knows the conduction time of the activation wave over a certain distance. There are two different ways which are used to measure the conduction time. The simplest and most widely used method is to measure the time between delivery of a stimulus through a pair of stimulating electrodes and the arrival of the activation front at a remote recording electrode. Another method uses an additional recording electrode between the point of stimulation and the remote recording electrode. The time lapse between the arrival of the activation front at the first and second recording electrode is taken as the conduction time required to cover the distance between the electrodes. To evaluate which of the methods is to be prefered, we compared both ways of conduction time measurement in a isolated piece of atrial myocardium. Figure 2.5 gives an example. The conduction time was measured pacing the preparation at a rate of $10 \mathrm{~Hz}$ at different stimulus strengths. The conduction time measured betweem the stimulus artefact and the remote recording electrode is plotted as solid circles, whereas the squares indicate the conduction time measured between the proximal and distal recording electrode. The inset of the figure shows the experimental set-up. The conduction time shortened with increasing stimulus strength, if measured between stimulus artefact and the remote recording electrode. However, if the conduction time is measured between two recording electrodes it was found to be almost independent of the stimulus strength. Because a reproducible and accurate measurement of the conduction time can only be done if it is independent of the stimulus intensities used, we decided to measure the conduction time using two recording electrodes. 


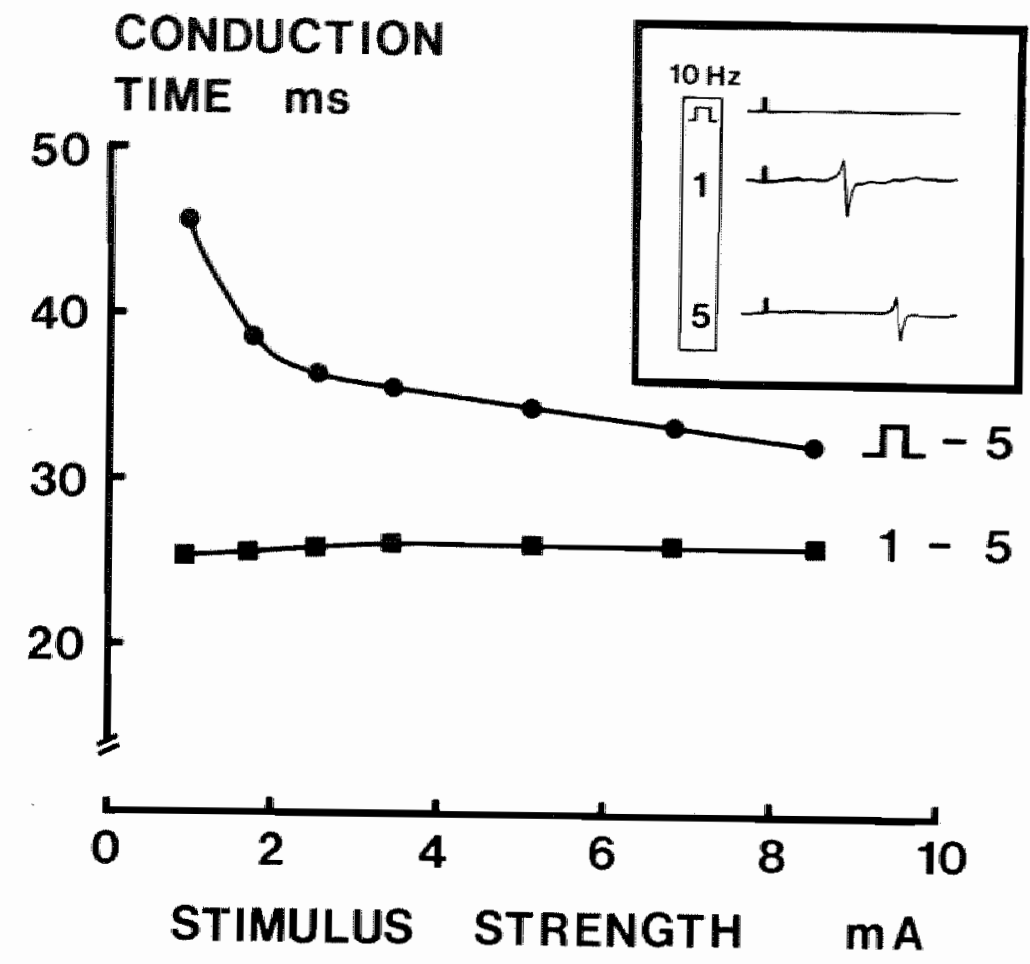

FIGURE 2.5 Conduction time along a bundze of atrial myocardium as a function of stimulus strength. Tho methods to measure the conduction time are compared. If the conduction time is expresied as the time difference between the stimulus artefact and the moment of arrival at a remote recording eleatrode, the values indicated by the filled circtes are found. If the oonduction time is measured between two recording electrodes, in this example between the first and fifth lead of a multiple recoraing electrode, the value indicated by the filled squares are found. The inset at the top gives a chematic representation of the experiment. In this case the preparation was paced at a frequency of $10 \mathrm{~Hz}$. It is clear that using the stimulus artefact to determine the conduction velocity, the measured value of the conduction time is not independent of the stimulus strength used.

2.5. Homogeneity in conduction.

Figure 2.6 gives an example of the activation sequence in a strip of atrial myocardium at a pacing rate of $2 \mathrm{~Hz}$ (500 $\mathrm{msec}$ pacing interval). Recording electrode 1 was about $3 \mathrm{~mm}$ from the site of stimulation and the distance between the recording electrodes was $2 \mathrm{~mm}$. In the left panel the 
simultaneously recorded unipolar electrograms of electrodes 1 to 5 are displayed, whereas in the right panel the conduction time is plotted as a function of distance. During this slow rhythm the impulse propagates at a constant speed, the conduction time showing a linear relationship with distance. Also at higher pacing rates the conduction remained homogeneous. Figure 2.7 shows the conduction in another strip of atrial myocardium measured at 4 different pacing rates. At the top of each panel the conduction time over a distance of $8 \mathrm{~mm}$ between the first and fifth recording electrode is indicated. An increase of the pacing rate from 2 to $4 \mathrm{~Hz}$ causes a mimor increase in conduction time from 12 to $13 \mathrm{msec}$. Increasing the pacing rate to $8 \mathrm{~Hz}$ causes a further prolongation of the conduction time to $14 \mathrm{msec}$, whereas a lengthening to $16 \mathrm{msec}$ is observed when the pacing rate is increased to 12 $\mathrm{Hz}$. Even at this high rate there is still a uniform conduction.
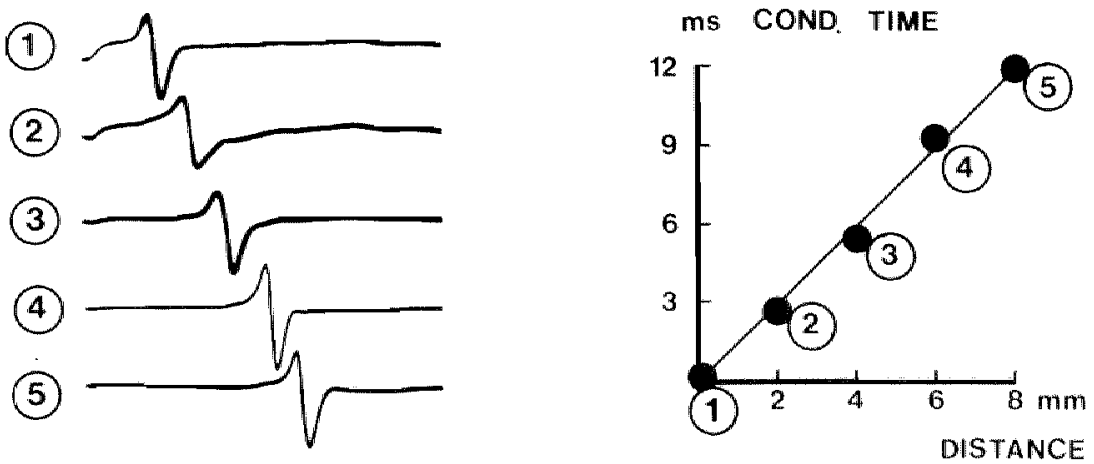

$10 \mathrm{~ms}$

EIGURE 2.6 Conduction characteristics in a bundie of icolated atrial myocardium. In the left panel the activation sequence at a constant pacing intervat of 500 msec is shoum. The electrodes are indicated by the enciralied numbers. It is clear that the conduction between the different electroded it vemy uniform. At the might, the conduction time is plotted as a function of the recording distance. Here again it can be noted that the conduction in this strip of atmial myacardium at a pacing intervat of 500 meec is highty uniform. The conduction time between two bucceive recording electrudea (inter-electrode distance $2 \mathrm{~mm}$ ) was 3 maec. 
$12 \mathrm{~ms}$

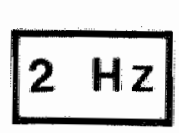

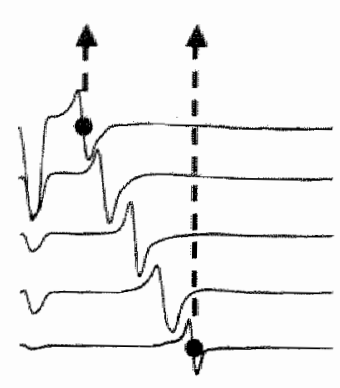

$14 \mathrm{~ms}$

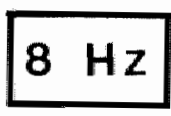

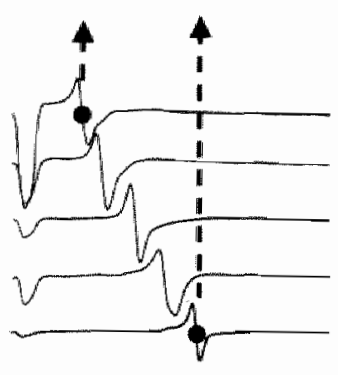

$13 \mathrm{~ms}$

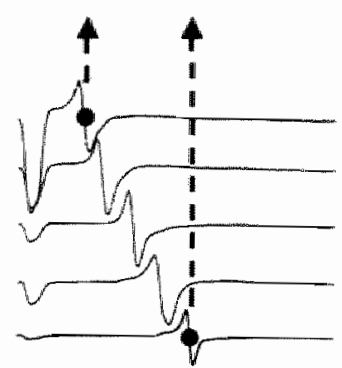

$16 \mathrm{~ms}$

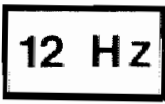

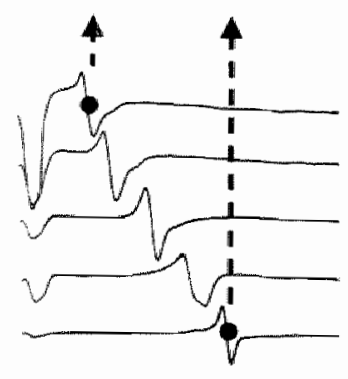

$10 \mathrm{~ms}$

FIGURE 2.7 Influence of rate on conduction in the atrium. In the 4 panels the conduction is shown over a distance of $8 \mathrm{~mm}$ at the following pacing rates: $2,4,8$ and $12 \mathrm{~Hz}$. The conduction time was 12 msec at a pacing rate of $2 \mathrm{~Hz}$ (left top pane l). Increasing the pacing rate to 4,8 and $12 \mathrm{~Hz}$ caused a protongation of the condiation time to 13,14 and 16 mbee respectively. It may be noted that at this high rate the conduction is still highly homogeneous.

2.6. Characteristics of conduction black.

Figure 2.8 is taken from the same experiment as figure 2.7. The pacing rate has been increased to $13 \mathrm{~Hz}$ and every impulse is still conducted along the bundle. If the pacing rate is further increased to $14 \mathrm{~Hz}$ conduction block occurred at the end of the strip between the fourth and fifth recording electrode. At this high rate not every impulse could be conducted all along 


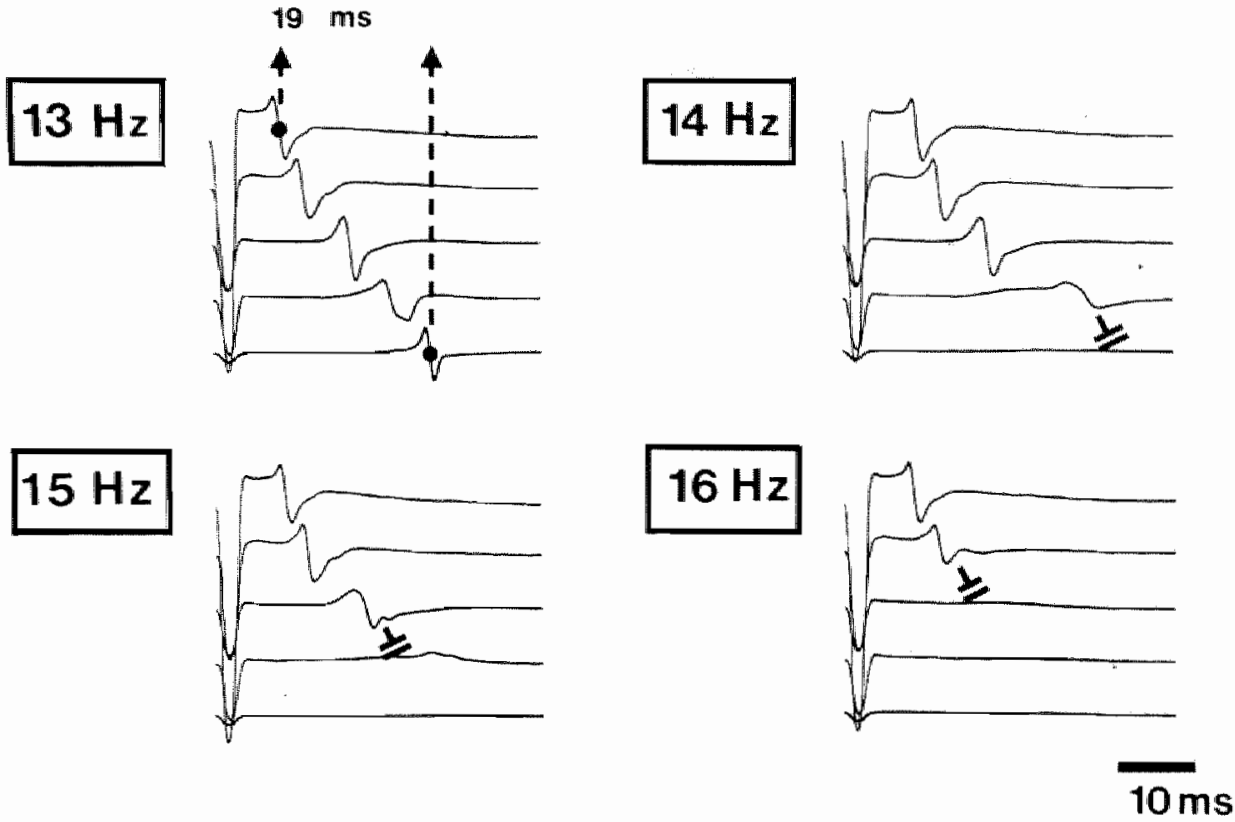

FIGURE 2.8 Intra-atrial conduction block at high pacing rates. Impulse propagation along the bundle of atrial myocardium during constant pacing with $13,14,15$ and $16 \mathrm{~Hz}$ is shown. The data are taken from the same preparation as figure 2.7. At a pacing rate of $13 \mathrm{~Hz}$ every impulse is conducted throughout the bundle as show in the top left panel. If however the pacing rate is increased to $14 \mathrm{~Hz}$ conduction black is observed between the fourth and fifth electrode. At pacing rates of 15 and $16 \mathrm{~Hz}$ the impulse already dies out closer to the eite of stimulation, between the third and fourth electrode and between the second and third electrode respectively.

the bundle. When the pacing rate is increased to as high as 15 and $16 \mathrm{~Hz}$, the conduction was blocked at progressively shorter distances from the site of stimulation. During pacing with $15 \mathrm{~Hz}$ the impulse died out between the third and fourth electrode and at $16 \mathrm{~Hz}$ conduction block accurred between the secand and third recording electrode. The site where conduction is blocked differed from preparation to preparation and was closer to the site of stimulation at increasing pacing rates. This indicates that the locallisation of block is determined by functional properties of the myocardium, making an anatomically determined "weak link" within the bundle unlikely.

Intra-atrial conduction block as found during rapid pacing is mot observed during propagation of a premature impulse. An early premature beat 
will either be conducted all along the bundle or not be conducted at all, not even to the first recording electrode. A possible explanation for the fact that rapid pacing may lead to conduction block whereas a single premature beat does not, is offered in figure 2.9. The $A_{1}-A_{2}$ intervals as measured with the row of recording electrodes are given for the shortest possible premature beat $\left(s_{1}-s_{2}\right.$ is $\left.62 \mathrm{msec}\right)$. At this coupling interval the time between the basic and premature response at the dffferent recording electrodes was $64,66,69$, 72 and 74 msec respectively. It is clear that the $A_{1}-A_{2}$ interval is getting longer as the distance from the site of stimulation increases. In other

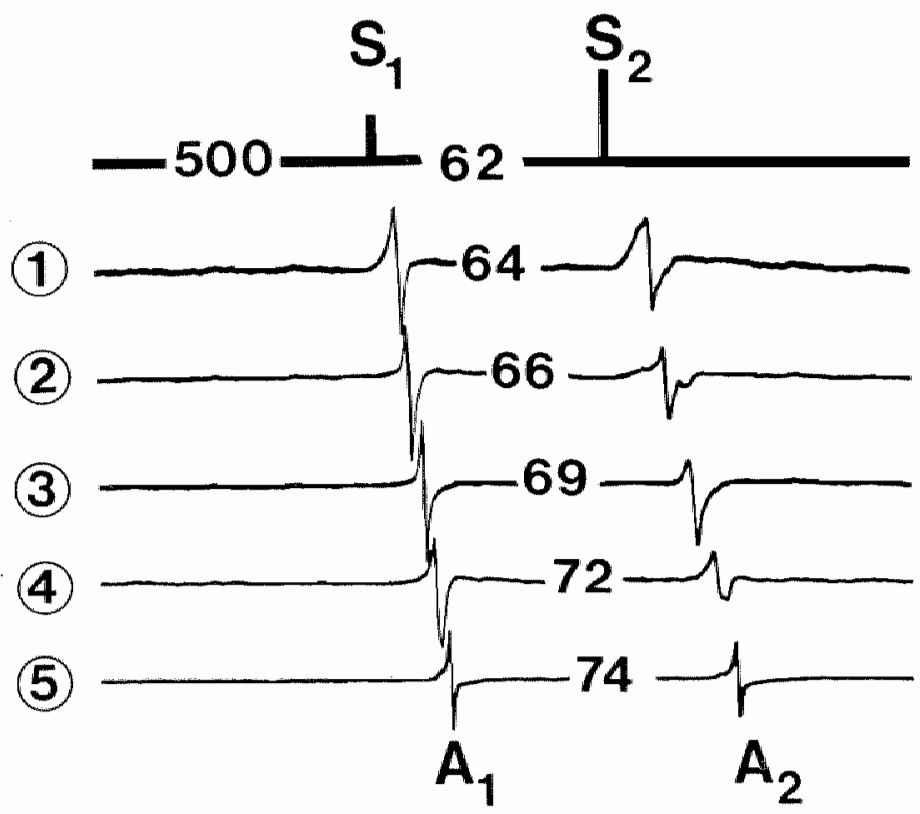

PIGURE 2.9 The prematumity of an extrasystole at increasing distance from the site of stimulation. Conduction of the last basic beat and the earitiest poseible premature beat in atrial myocardium are shoum as recorded with the brush electrode. The top tracing indicates the stimulue protocot, the axbsequent tracings represent the electrograns 1 to 5 . The shortest possible SI-S2 which provoked a propagated response was 62 meec. At the first recording electrode, near the site of stimulation, the A1-A2 interval is 64 msec. At the second, thimd, fourth and fifth electrode the A1-A2 interval increased to $66,69,72$ and 74 msec. It is clear that the prematumity decreases with increasing distance from the site of origin of the premature beat. This increase in the AI-AI interval $i s$ caused by the fact that the premature impulse is conducted alower than the basic impulse. 
words, at greater distance the degree of prematurity is less than in the direct vicinity of the site of origin of a premature beat. This decrease in prematurity, caused by the fact that the premature impulse conducts more slowly than the basic impuise, makes it more unlikely that the impulse is being blocked.

On the other hand, during rapid pacing there is no sudden change in conduction velocity. Thus all along the bundle the cycle length is equal to the pacing interval and not dependent on the distance from the site of stimulation. Consequently during maximum pacing, minor differences in local excitability may cause intra-atrial conduction block.

\subsection{Measurement of the refractory period.}

During programmed electrical stimulation of the heart, refractoriness of the myocardium can be measured with the extra stimulus technique. The actual value of the refractory period at well defined stimulus qualities depends on the criteria used to determine the refractory period. Some widely used definitions of refractoriness of atrial or ventricular myocardium are:

Absolute refractory period (ARP): the longest coupling interval between a basic stimulus and a premature stimulus at which the atrial or ventricular myocardium is not captured.

Effective refractory periad (ERP): the shortest coupling interval $\left(S_{1}-S_{2}\right)$ eliciting a propagated response in the nyocardium.

Functional refractory period (FRP): the shortest intervall between two induced and propagated responses.

In figure 2.10 the $A_{1}-A_{2}$ interval is platted as a function of the $S_{1}-S_{2}$ interval as measured with field stimulation in a bundle of left atrium. It is clear that the $A_{1}-A_{2}$ interval is equal to the $S_{1}-S_{2}$ interval at long coupling intervals. However if the coupling interval is progressively shortened the $A_{1}-A_{2}$ interval is shortened to a lesser extent, and at the shortest $S_{1}-S_{2}$ intervals the $A_{1}-A_{2}$ interval even prolongs. This prolangation of the interval between successive responses is caused by an increased latency between 


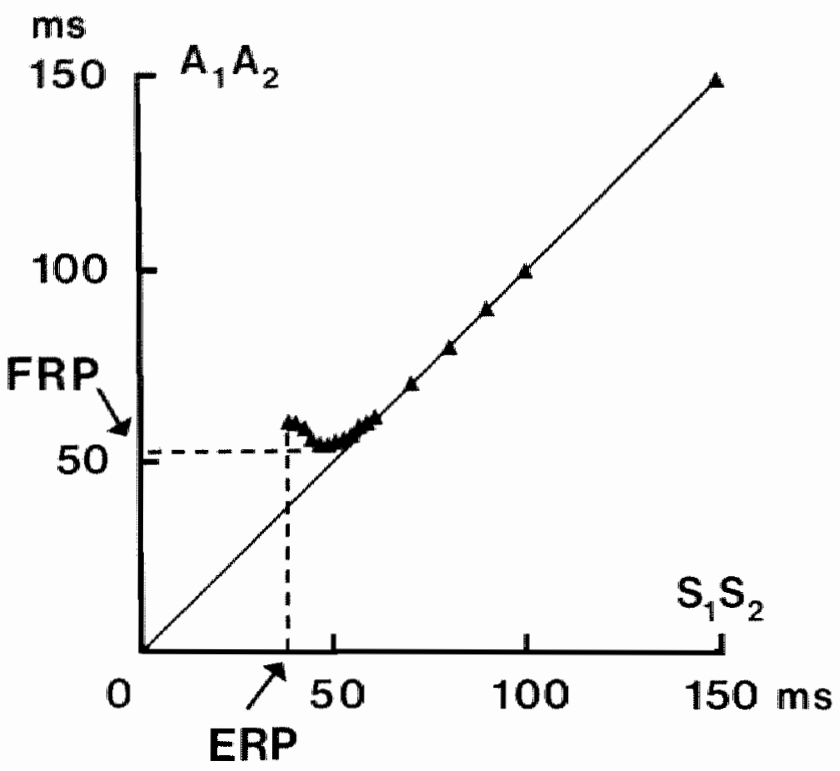

FIGURE 2.10 The relationship between AI-A.2 and S1-S2 interal. The AI-A2 intemat, measured on the recording electrode near the site of stimulation, is plotted as a function of the coupling interval S1-SZ. At coupling intervate tonger than 70 msec the S1-S2 and A1-A2 interval are equat. If the S1-S2 is shortened the A1-A2 intervat shortens also but to a lesser extent and becomes longer than the coupling interval. The ehortest possible S1-S2 interval is the effective refractory period, the shortest atiainable $A 1-A 2$ interval is the functional refractory period.

stimulation and initiation of a response. This explains why in this case the ERP is shorter than the FRP. To avoid this kind of measuring faults we decided to use the shortest possible interval between two successive responses as criterium for refractoriness (FRP).

since the distance from the site of stimulation influences the prematurity (see 2.6) we measured the refractory period close to the site of stimulation at the first recording electrode (distance $3 \mathrm{~mm}$ ). Thus the functional refractory period is defined as the shortest possible $A_{1}=A_{2}$ interval, measured at the first recording electrode at a stimulus strength of 4 times diastolic threshold, which is conducted throughout the bundle of atrial myocardium. The actual measurement was done by selecting a premature stimulus $S_{2}$ which did not capture the atrium, followed by increasing the 
$S_{1}-S_{2}$ interval in steps of $2 \mathrm{msec}$ until the shortest possible $A_{1}-A_{2}$ interval was measured.

2.8. Measurement of the maximum pacing rate.

Figure 2.11 (top panel) gives the protocol of incremental pacing used to determine the highest possible pacing rate. The top tracing indicates the conduction time between the first and last recording electrode on the atrial strip, the bottom tracing gives the pacing interval. The pacing interval is initially decreased with big steps from 500 to 400 to 300 to 200 to 170 and $150 \mathrm{msec}$. These changes in pacing interval only caused a minor prolongation in conduction time. At pacing rates above 400 beats per minute (interval less than $150 \mathrm{msec}$ ) the cycle length is shortened in steps of $10 \mathrm{msec}$ and above 600 beats per minute (interval less than $100 \mathrm{msec}$ ) in steps of $5 \mathrm{msec}$. At these high pacing rates small changes in pacing interval caused a considerable prolongation in conduction time. The shortest possible pacing interval at which every impulse was still conducted all along the atrial myocardium during at least 400 to 500 consecutive beats is indicated by an arrow. If the pacing interval was further decreased with $5 \mathrm{msec}$ intra-atrial conduction block occurred.

In figure 2.11 (bottom panel) the conduction time is plotted as a function of the pacing interval. Here again it is clear that at pacing intervals longer than about $150 \mathrm{msec}$ variations in rate hardly affect conduction velocity. However at pacing intervals shorter than 150 msec a marked prolongation of the conduction time is seen. In this example the conduction time during the highest pacing frequency (Fmax) was more than $50 \%$ longer than during the slow rate of $2 \mathrm{~Hz}$.

\subsection{Calculation of the length of the excitation wave.}

The term wave length in cardiac electrophysiology indicates the distance travelled by the impulse during the time the myacardium needs to restore its excitability. This distance is given by the product of conduction velocity and refractory period. Whether an impulse can be trapped in a circuitous route depends on the length of the reentrant pathway in relation to the wave 

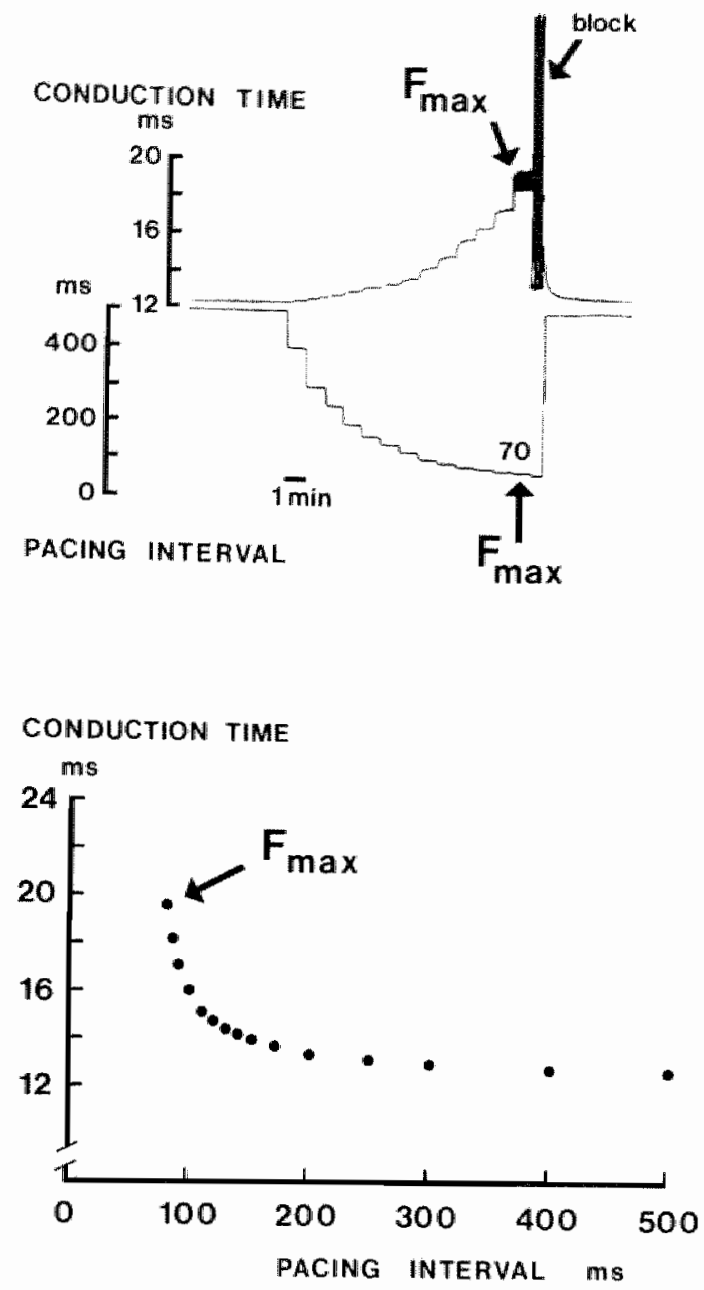

FICURE 2.11 Measumement of the maximm pacing rate. In the top panet the conduction time (top tracting) is show at different pacing intervat (bottom tracingl. Shortening of the pacing interval from 500 to 150 msec in big cteps. prolongs the conduction time onty sightly. However, at intervale ehorter tham 150 meed a smalt decrease of the pacing intervat (5 or 10 mbec) causes a manked prolongation in the conduction time. The shortest possible pacing intervat (max) at which every impulse was conducted atl atong the atmat atrip was in this preparation 70 msec. The conduction time at this pacing intervat wa about 19 mbee. If the pacing interval tis shortened further from 20 to 65 meec the conduction is blocked in the bundle. In the bottom panet the conduction time is plotted as a function of the pacing interval. Here again it is show that the conduction time only increases sightly at pactng intemat longer than 150 msec. At pacing intervals shorter than 150 msec a marked increase in conduction time can be observed. The shortest possible pacing interval and conduction time at this rate is indicated by the arrow. 
length. A continuous circus movement can only be established if the pathway of the reentrant loop is equal to or larger than the wave length. Thus the wave length is defined as the distance the impulse travels during the time the myocardium restores its excitability to such a level that a second wave can just be propagated. It can be calculated as follows:

WAVE LENGTH $(\mathrm{mm})=$ CONDUCTION VEL OCITY $(\mathrm{mm} / \mathrm{mseC}) \times$ REFRACTORY PERIOD (msec)

The wave length during a regular rhythm.

An example of the simultaneous determination of conduction velocity and refractory period during regular pacing is shown in figure 2.12 . The electrograms numbered 1 and 5 are taken from the first and last electrode on the bundle. The distance between these recording electrodes is $8 \mathrm{~mm}$. The bottom tracing gives the stimulation protocol. The left panel shows the 14th and 15 th basic stimulus and the premature stimulus, while in the right panel the last basic impulse and the premature response are given at a higher sweep speed. In this example the basic pacing interval $\left(S_{1}-S_{1}\right)$ is 500 msec. The
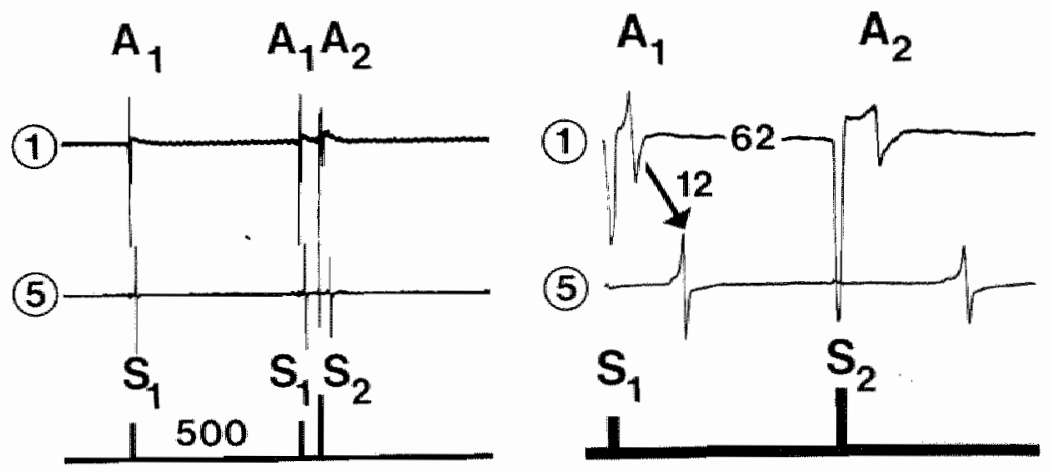

FIGURE 2.12 The calculation of the wave length of a regular impulse. In the left panel the 14th and 15 th basic beat and the premature beat are shown at a slow sweep speed. At the might the last basic beat and the premature beat are depicted at a fast sweep speed. The tracinge numbered 1 and 5 are from the recording electrodes 1 and 5 of the brush electrode and the bottom tracing gives the stimulation protocol. The conduction time of the basic beat (S1-S1 is 500 meec) is 12 meec over a distance of a mim (conduction velocity is 0.87 momsecl. The shortest poseible $A 1-A 2$ interval is 62 msec. The wave length, being the product of the conduction velocity and the refractory period ite calculated to be $42 \mathrm{~mm}$. 
conduction time of this regular impulse as measured between the intrinsic deflection of electrograms 1 and 5 was $12 \mathrm{msec}$. Since the distance between electrode 1 and 5 was 8 mm the conduction velocity during this slow rhythm was $67 \mathrm{~cm} / \mathrm{sec}(0.67 \mathrm{~mm} / \mathrm{msec})$. The shortest possible $A_{1}-A_{2}$ interval at this rate was $62 \mathrm{msec}$. Thus the wave length could be calculated to be $42 \mathrm{~mm}(0.67$ $\mathrm{mm} / \mathrm{msec} \times 62 \mathrm{msec}$ ).

The wave length of a premature impulse.

The length of the excitation wave of a premature impulse is calculated in an analogous way as the wave length of a regular impulse. An example is shown in figure 2.13. It is taken from the same experiment used for figure 2.12. Again the left panel shows the electrograms 1 and 5 and the stimulation protocol at a slow time base, the right panel at a fast time base. The canduction time of the premature impulse $\left(A_{2}\right)$ was $22 \mathrm{msec}$ over a distance of $8 \mathrm{~mm}$, the conduction velocity being $36 \mathrm{~cm} / \mathrm{sec}(0.36 \mathrm{~mm} / \mathrm{msec})$. The refractory period of this premature impulse was measured by giving a third stimulus $\left(s_{3}\right)$. The shortest possible $A_{2}-A_{3}$ interval, indicating the functional refractory period of the $A_{2}$ impulse, turned out to be $58 \mathrm{msec}$. Thus the
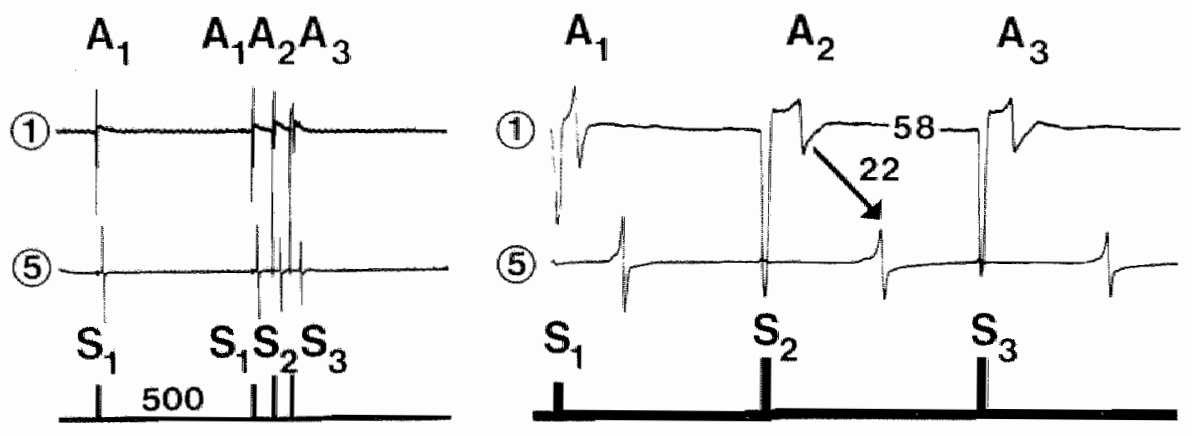

FIGURE 2.13 The calcutation of the wave length of a premature beat. At the Left bide the etectrogmans 1 and 5 and the stimitation protocot are giver at a slaw weep speed. In the might panel the last baste beat and the premature beat are shown at a fast sweep speed. The conduction time of the premature response A2 over $8 \mathrm{~mm}$ is in this example 22 meec (conduction veloctity is 0.36 $\mathrm{mm} / \mathrm{msec}$. To measure the refractory period of the $A 2$ impulse a third impulse has to be evoked as short as possibte after A2. In this example the shortest attatnable $A 2-A 3$ intemat was 58 msec. The wave length of this premature impulse is 21 mon. 
length of the excitation wave of this premature beat was $21 \mathrm{~mm}(0.36 \mathrm{~mm} / \mathrm{msec}$ $x 58 \mathrm{msec}$ ).

The wave length during maximum pacing.

As illustrated in figure 2.11 the conduction of the excitation wave slows progressively during incremental pacing. Also the time needed for restoration of excitability shortens. Figure 2.14 gives an example of the conduction during the highest pacing rate (cycle length $75 \mathrm{msec}$ ) at two different time scales. As shown in the left panel every impulse is conducted all along the bundle. The conduction time between electrodes 1 and 5 (right panel) was 20 msec. Therefore the conduction velocity can be calculated to be $40 \mathrm{~cm} / \mathrm{sec}$ $(0.40 \mathrm{~mm} / \mathrm{msec})$. Since the shortest possible interval between two impulses was $75 \mathrm{msec}$ the wave length was calculated to be $30 \mathrm{~mm}\left(0.40 \mathrm{~mm} / \mathrm{msec} \times 75^{\circ}\right)$.

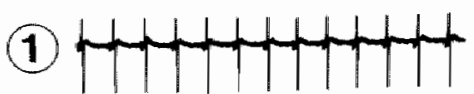

(5)
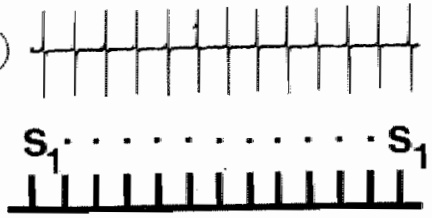

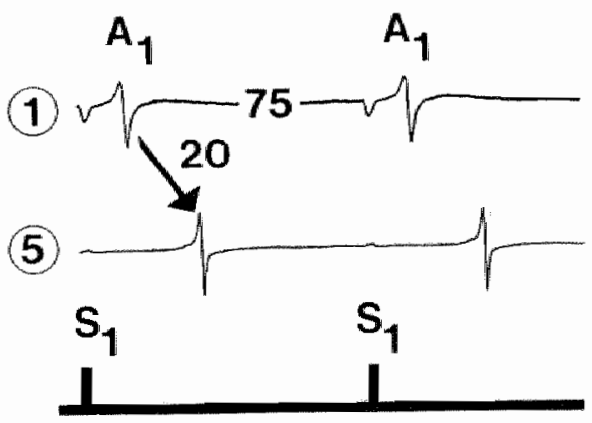

FIGURE 2.14 The calculation of the wave length at the maximum pacing rate. The left panel gives the recordings of electrode 1 and 5 during the shortest possible pacing interval and the stimulation protocol at a slow aweep speed, the right panel showe 2 beats at a fast sweep speed. The conduction time over $8 \mathrm{~mm}$ is $20 \mathrm{msec}$ (conduction velocity is $0.4 \mathrm{~mm} / \mathrm{msec}$. The shortest possible pacing intemal is 75 msec. The wave length, being the product of the conduction velocity and this pacing interval is 30 nm. 


\section{REFERENCES}

Spear JF, Kronhaus KD, Moore EN, Kline RP: The effect of brief vagal stimulation on the isolated rabbit sinus node.

Circ Res, 44: 75-88, 1979.

Vincenzi FF, West TC: Release of autonomic mediators in cardiac tissue by direct subthreshold stimulation.

W Pharmacol Exp Ther, 141: 185-194, 1963. 
3. INRLUENCE OF RATE AND RHYTHM ON THE LENGTH OF THE EXCITATION WAVE.

It is now widely recognized that reentrant arrhythmias can be initiated and terminated by programmed electrical stimulation. One, two or more premature impulses, if properly timed, can initiate reentrant arrhythmias in the heart. Only premature stimuli within a narrow zone of short coupling intervals will initiate a reentrant rhythm. Besides the timing of a premature beat its site of origin is also a critical factor for the initiation of reentrant arrhythmias (Wellens 1978). Furthermore the success rate for induction of arrhythmias increases if more premature stimuli (2, 3 or 4$)$ are given. Finally also heart rate itself influences the chances for reentry.

If our hypothesis is correct that the wave length is an indicator for the chance on initiation and continuation of reentrant arrhythmias, we must expect that programmed electrical stimulation, leading to the induction of reentrant arrhythmias, should be associated with a shortening of the wave length. To test whether this hypothesis is correct we determined the wave length during changes in rate and rhythm. We measured the wave length of a basic beat at different pacing rates, and the wave length of premature beats at different prematurities and at different pacing rates.

\subsection{Experimental protocol.}

The effects of changes in rate and rhythm were investigated in 30 left atrial preparations. In all preparations the wave length of the basic impulse and the wave length of the earliest premature impulse was measured during incremental pacing. Additionally in 7 experiments we measured the wave iength of premature beats of different prematurities as induced during a fixed pacing rate of $2 \mathrm{~Hz}$. In two studies an extensive stimulation protocol was performed in which both the effect of pacing rate and the degree of prematurity of a single premature beat on the wave length was studied.

Figure 3.1 gives an example of the effects of 4 different pacing rates on refractoriness and conduction of a regularly driven impulse $\left(A_{1}\right)$. The top left panel gives the contral situation at a basic pacing interval of 500 msec. Only electrogram 1 and 5 of the multiple recording electrode are displayed. The conduction time of the basic impulse $\left(A_{1}\right)$ at this rate of $2 \mathrm{~Hz}$ was $12 \mathrm{msec}$. After every 15 th $A_{1}$ impulse a premature impulse $A_{2}$ was 

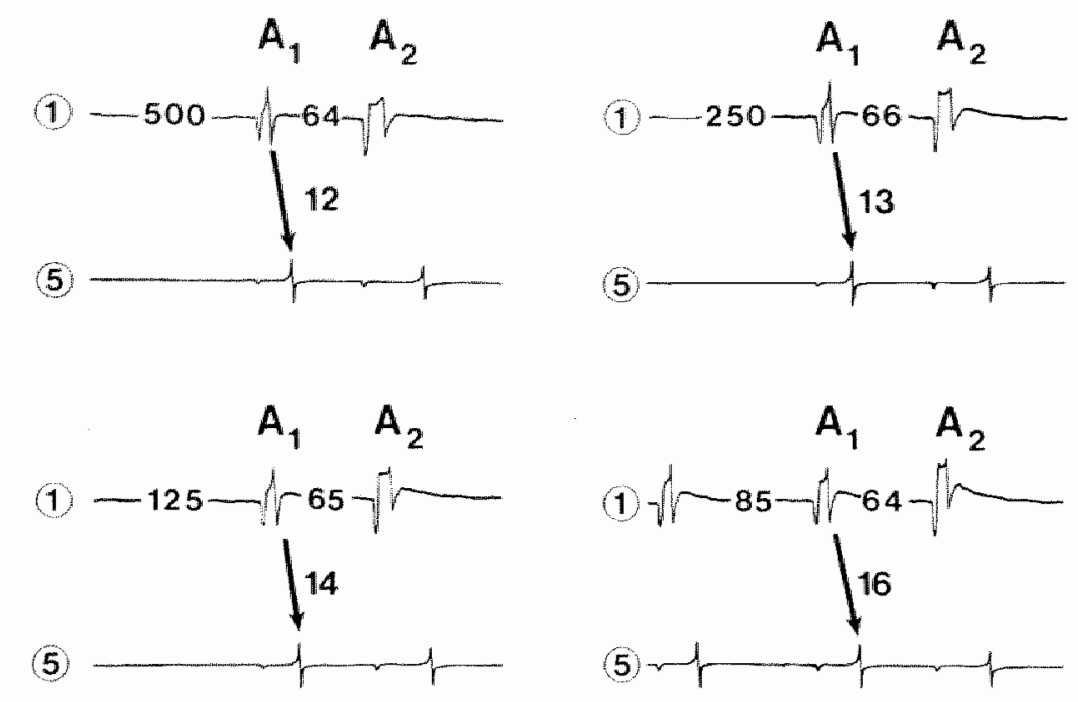

FIGURE 3.1 The effects of incrementat pacing on the wave length of a basic impulse. The 4 panels show the effeats of shortening of the paring interval from 500 to 250,125 and $85 \mathrm{msec}$ on refractominess and conduction. The distance between the recording electrodes 1 and 5 is $8 \mathrm{~mm}$. The condution time of the A1 impulse prolongs from 12 to 13,14 and 16 msec if the pacing interval is shortened. Simultaneously the functional refractory pemod is almost unchanged $164,66,65$ and 64 respectivelyl. calculation of the wave tength of the basic impulee reveated a progressive shortentng from 43 to 41 , 37 and $32 \mathrm{~mm}$.

introduced. The shortest $A_{1}-A_{2}$ interval at this rate was 64 msec and the wave length could be callculated to be $43 \mathrm{~mm}$. A progressive, gradual shortening of the pacing interwal to 250,125 and 85 msec, as depicted in the next three panels, caused a prolongation of the conduction time to 13,14 and 16 msec. The refractory perfod changed only slightly. Calculation af the wave length revealled a progressive shortening from 43 to 41,37 and $32 \mathrm{~mm}$ respectivelly.

Figure 3.2 shows the effects of 4 degrees of prematurity on refractoriness and conduction of a premature beat. The shortest $A_{1}-A_{2}$ impulse was 63 msec (top left panel). The other panels show premature beats with an $A_{1}-A_{2}$ interval of 73,98 , and $120 \mathrm{msec}$. The conduction time of the earliest premature impulse was $22 \mathrm{msec}$. Its refractory period was 59 msec (shortest $A_{2}-A_{3}$ interval). Thus the wave length of the earliest possible premature beat was 22 mm. A premature beat induced $10 \mathrm{msec}$ after the functional refractory period (top right panel) showed a conduction time of $17 \mathrm{msec}$ and a refractory 


\section{$\begin{array}{lll}A_{1} & A_{2} & A_{3}\end{array}$}

(1)

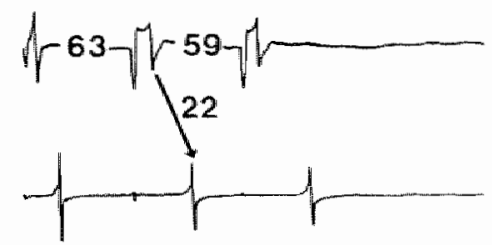

$A_{1}$

(1)

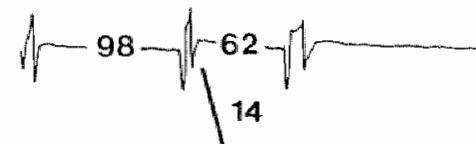

(5)

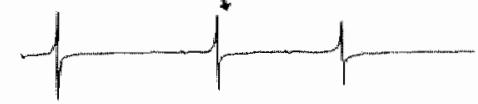

$\begin{array}{lll}A_{1} & A_{2} & A_{3}\end{array}$

(1)

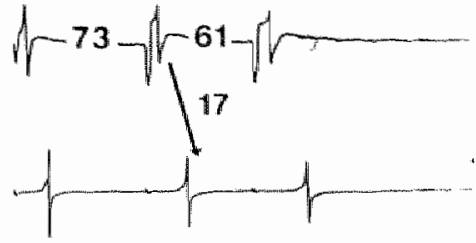

(1)

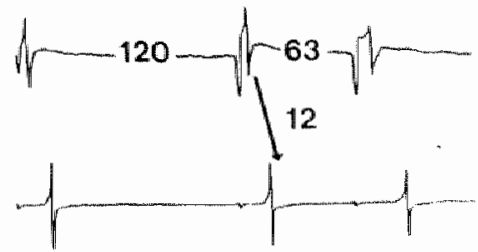

FIGURE 3.2 The effects of the degree of prematumity on the wave length of a premature beat. The effeets of 4 different timings of the $A 2$ inpulae 163 mbeo (FRP), $73 \mathrm{msec}$ (ERP $+10 \mathrm{mgec}), 98(F R P+35 \mathrm{msec})$ and $120 \mathrm{msec}$ (FRP +57 mbec)) on conduction and refractoriness are shown. The diatance between the recording electrodes 1 and 5 is $8 \mathrm{~mm}$. The basic intervat $A 1-A 1$ is fixed at 500 msec. Decreasing the prematurity by prolonging the A1-A2 intervat from 63 to $73,98,120$ msec caused a shortening of the conduction time from 22 to 17 , 14, 12 msec respectively. The mefractory periad (the shortest A2-A3 interval, is prolonged sight $y$ from 59 to 61,62 and $63 \mathrm{msec}$. As a consequence the wave length of these premature beats is $23,29,35$ and 43 mm respectively. These recorde are taken from the same experiment as was used for figure 3.1 .

period of $61 \mathrm{msec}$ (wave length $=29 \mathrm{~mm}$ ). Further prolongation of the wave length to $35 \mathrm{~mm}$ and $42 \mathrm{~mm}$ was observed when the $A_{1}-A_{2}$ interval was prolonged to 98 and $120 \mathrm{msec}$.

\subsection{RESULTS.}

3.2.1 The influence of rate on the length of the excitation wave.

The effects of incremental pacing on refractoriness, conduction velocity and wave length of a regularly driven impulse are shown in figure 3.3 . The mean values of 30 atrial preparations are plotted. The length of the excitation wave is clearly affected at higher pacing rates. Shortening of the 


\section{WAVE LENGTH DURING A REGULAR RHYTHM}

REF. PER.

ms

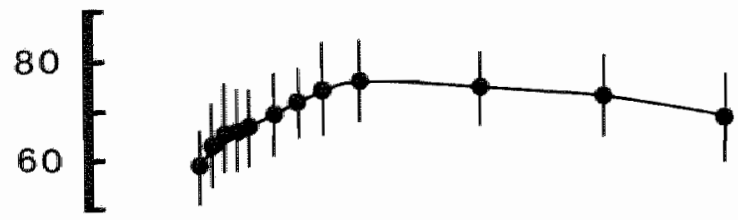

COND. VEL.

$\mathrm{cm} / \mathrm{sec}$
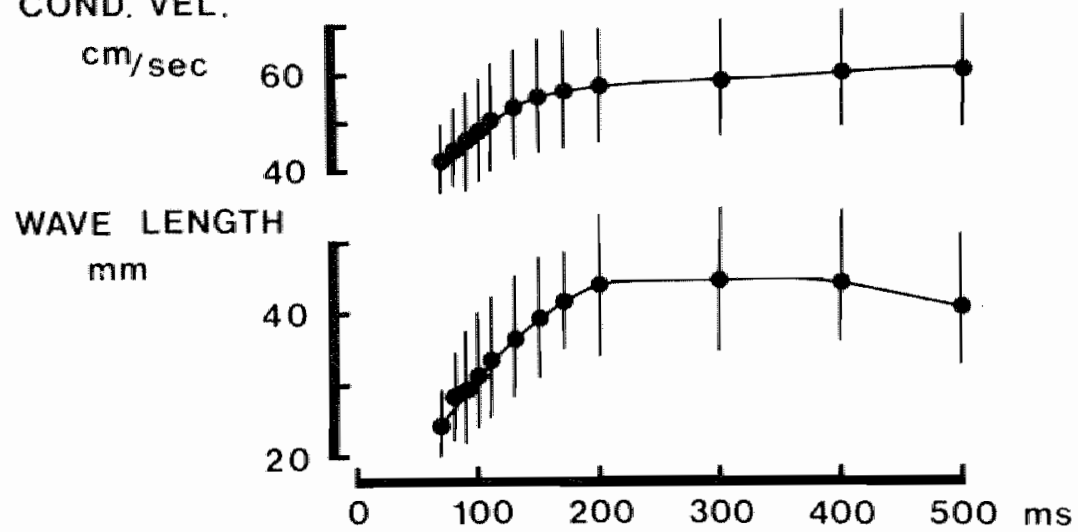

PACING INTERVAL

FIGURE 3.3 The effects of ineremental pacing on the wave iength of a regularty driven impulse. The mean value and standard deviation ( $n=30$ ) of refractory period, conduction velocity and wave tength are plotted as a function of the paing intermat. The wave length of a basic beat is progresotwely shortened if the pacing intemal is shorter than 200 msec. The length of the exctation uave $i s$ constant between 200 and 400 msec. The shortening of the wave length is caused by both a shortering of the refractory period and a depression in conduction. The refratory period of the regutar impules ehartens at pacing intervals shorter than 200 meec. The conduction velocity is depreased at pacing intervals shorter than 130 mbec.

pacing interval from 200 msec to the shortest possible pacing interval (70-90 msec) causes a gradual, progressive shortening of the length of the excitation wave of the basic impulse from 44 to an average of $28 \mathrm{~mm}$. If the pacing interval is varied between 400 and $200 \mathrm{msec}$ the wave length is not changed, whereas at a pacing interval of $500 \mathrm{msec}$ the mean wave length is slightly shorter. The shortening of the wave length at the highest rate with 
$40 \%$ is caused both by a shortening of the refractory period and by a slowing of the conduction velocity at these high rates. The refractory period of the basic impulse (the shortest possible $A_{1}-A_{2}$ interval) is shortened from 76 msec at $200 \mathrm{msec}$ pacing interval to $63 \mathrm{msec}$ at $80 \mathrm{msec}$ pacing interval. The conduction velocity at $200 \mathrm{msec}$ pacing interval was $54 \mathrm{~cm} / \mathrm{sec}$. It was depressed to $42 \mathrm{~cm} / \mathrm{sec}$ at the highest possible pacing rate.

At relatively slow rates (slower than $5 \mathrm{~Hz}$ ) the length of the excitation wave was constant. This was true although the values for the refractory period and conduction velocity were not. The refractory period prolonged slightly at pacing intervals from 500 to $200 \mathrm{msec}$, whereas the speed of propagation was somewhat $\mathrm{slowed.} \mathrm{Because} \mathrm{refractoriness} \mathrm{and} \mathrm{conduction}$ velocity changed in a different direction their effects on the length of the excitation wave were opposite, resulting in a complete cancellation of their effects on the wave length.

\subsubsection{The wave length of a premature impulse.}

The effect of the degree of prematurity of an impulse on refractoriness, conduction velocity and wave length during a stable rhythm of $2 \mathrm{~Hz}$ (500 $\mathrm{msec}$ interval) are shown in figure 3.4. The abscissa gives the timing of the premature impilse relative to the functional refractory period of the basic beat $\left(A_{1}\right)$, starting with the shortest possible $A_{1}-A_{2}$ interval (FRP) at the left, followed by FRP $+5 \mathrm{msec}$, FRP $+10 \mathrm{msec}$ and so on. Premature beats occurring more than $40 \mathrm{msec}$ after the refractory period were not different from a basic impulse with respect to both conduction velocity and refractoriness. Consequently also the wave length was unchanged.

However if premature beats are giwen in a small range of 40 msec after the refractory period, marked changes in refractoriness and conduction velocity occurred. The most outspoken changes in electrophysiological properties of these early premature beats are a pronounced slowing of the speed of propagation together with a slight shortening of the refractory periad. Compared to a premature beat elicited late in the atrial cycle, the conduction of the earliest premature beat was depressed from 55 to $33 \mathrm{~cm} / \mathrm{sec}$, whereas the refractory periad was shortened from 68 to $61 \mathrm{msec}$. Because both a shortening of the refractory period as well as a slowing in conduction exerts their effects on the wave length in the same direction, a marked shortening of the length of the excitation wave was observed. The wave length 


\section{EFFECT OF PREMATURITY}

REF. PER.

msec

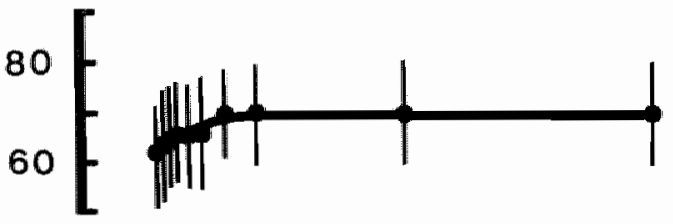

COND. VEL.

$\mathrm{cm} / \mathrm{sec}$

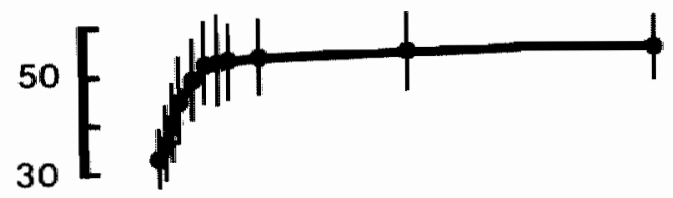

\section{WAVE LENGTH}

$\mathrm{mm}$

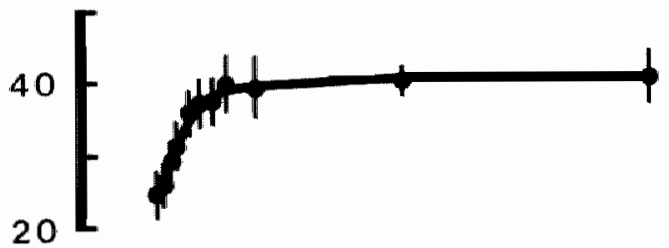

FIGURE 3.4 The effects of the degree of prematurity on the wave length of a premature beat. The mean value and standard deviation $(n=7)$ of refractory pemiod, conduction velocity and wave length are plotted as a function of the prematurity of the A2 impulse relative to the FRP of the basic beat. The absciesa atarts at the shortest posible A1-A2 interval (FRP) followed by FRP +5 meec, $E R P+10$ msee and so on. The wave length of a premature beat is constant over a wide range of $A 1-A 2$ intervals. A marked shortening is observed if a premature beat amises within 30 msec after the shortest possible A1-A2 interval. The wave length is shortest at the shortest A1-A2 interval. This shortening $i s$ caused by a marked depression of the conduction and a elight shortening of the refractory period at these earty premature beate. 
of an extrasystole arising 40 msec after the shortest possible $A_{1}-A_{2}$ interval was $37 \mathrm{~mm}$, whereas the earliest possible premature beat had a wave length of only $23 \mathrm{~mm}$. Thus an abrupt shortening of the length of the excitation wave of a premature beat with $38 \%$ is achieved in a narrow zone of 40 msec of $A_{1}-A_{2}$ intervals. Note that during a regular rhythm a comparabie shortening of the wave length was observed if the pacing interval was lowered from 200 to $80 \mathrm{msec}$, thus over a range of $120 \mathrm{msec}$.

3.2.3 The influence of rate on the wawe length of the earliest premature impulse.

After having studied the effects of rate and the degree of prematurity on the length of the electrical impulse we investigated the effects of incremental pacing on the wave length of the earliest possible premature beat. In figure 3.5 the mean values of refractory period, conduction velocity and wave length $(n=30)$ of the earliest premature impulse are given at a wide range of pacing intervals. The refractory period (the shortest $A_{2}-A_{3}$ interval) is shown in the top panel. Shortening of the pacing interval slightiy shortened the refractory period of the earliest premature impulse, reaching a minimum value at a pacing interval of $100 \mathrm{msec}$. A further shortening of the pacing interval, up to the maximum rate, caused a slight prolongation.

The conduction velocity of the earliest prenature impulse $\left(A_{2}\right.$, middle panel) is constant at almost all pacing intervals. Only at intervals sharter than $130 \mathrm{msec}$ the conduction of the earliest premature impulse is somewhat slowed.

As a consequence the wave length of the earliest premature impulse is hardly affected by changes in pacing rate. Only at pacing intervals shorter than $170 \mathrm{msec}$ it is 51 ightly shortened. At the highest pacing rate the length of the shortest impulse was $18-19 \mathrm{~mm}$, compared to $23 \mathrm{~mm}$ at a slow pacing rate.

In figure 3.6 the effects of changes in rate and rhythm on the wave length are illustrated. In this experiment an extensive stimulation protocol was done. Not onlly the wave length during regular pacing (top thick curve) and the wave length of the earliest possible premature beat (bottom thick curve) were measured at different pacing rates, but in addition also the degree of prematurity was varied (thin curves). It is clear that an increase 


\section{WAVE LENGTH OF EARLIEST PREMATURE BEAT}

REF. PER.

ms

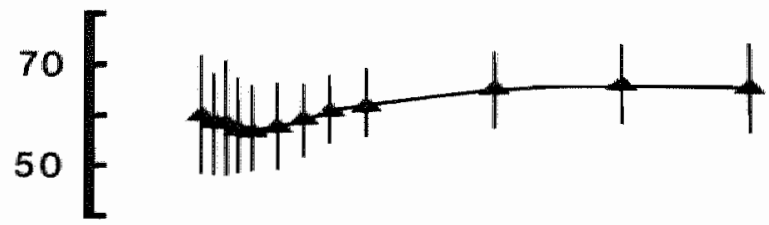

COND. VEL.

$\mathrm{cm}_{/ \mathrm{sec}}$

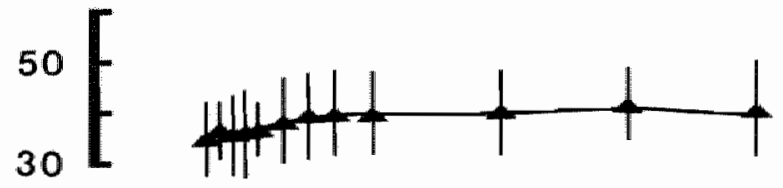

WAVE LENGTH

$\mathrm{mm}$

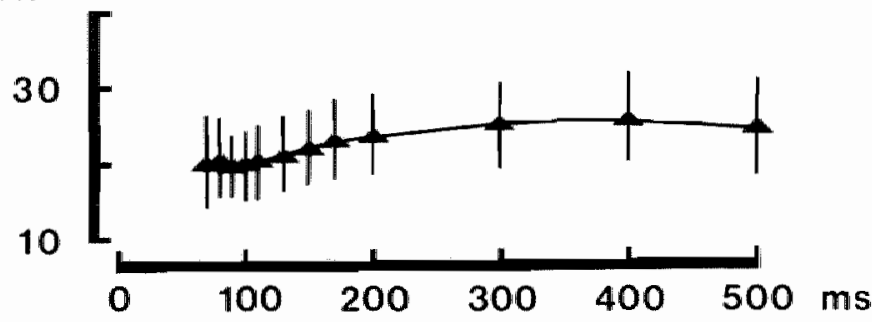

PACING INTERVAL

IIGURE 3.5 The effects of incrementat pacing on the wave length of the earliest premature beat. The mean value and standard deviation $(n=30)$ of the refractory period, the conduction velocity and the wave length of the earliest premature inpulse are shoum. The length of the excitation wave of the earliest premature beat shortens sight ly at pacing intervals shomier than 170 meec. The ahortening can be attributed to a stight shortening of the refractory period and a elight depression of the conduction.

in pacing rate above $5 \mathrm{~Hz}$ always resulted in a shortening of the length of the excitation wave. This is true for regular pacing, the earliest premature beat and also for premature beats coming later in the cycle. At a11 pacing rates the length of the earliest premature impulse was about half the wave length during the underlying regular rhythm. The wave length of a premature beat prolongs steadily at decreasing prematurity. Premature beats coming 20 msec later than the earliest premature beat have a wave length which is almost similar to the wave length of a basic impulse. In other words only very early premature beats have a shortened wave length. 


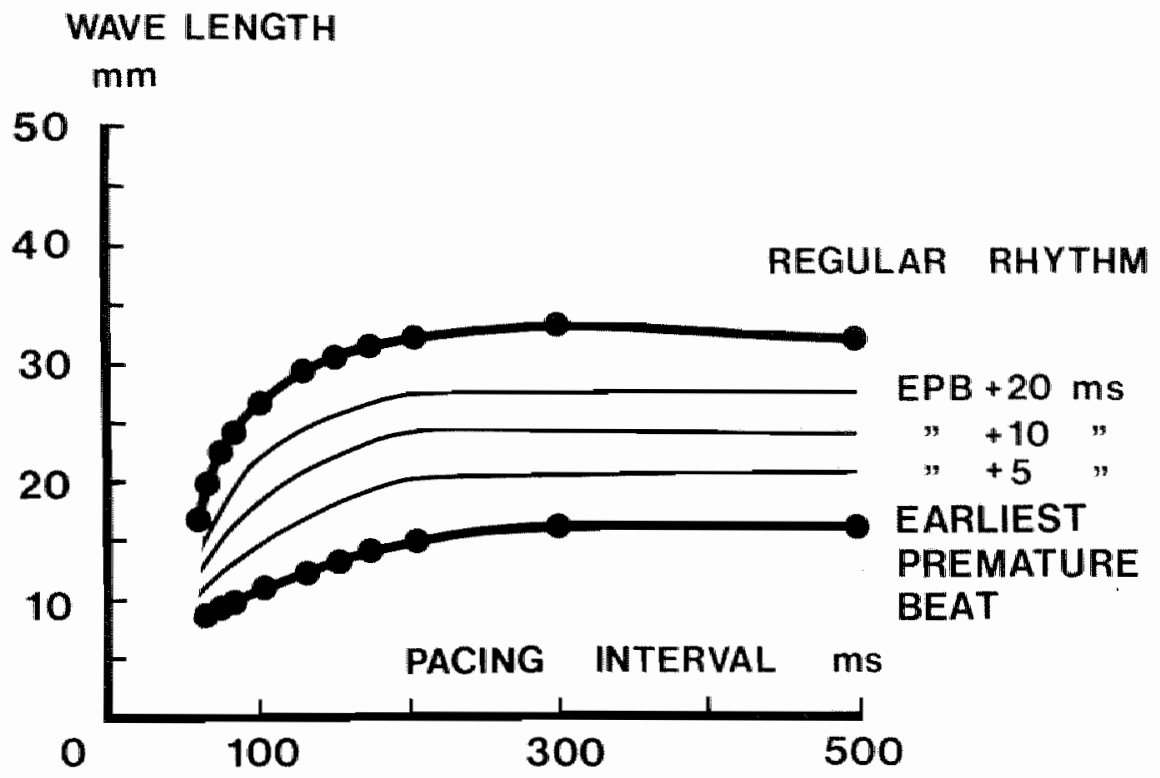

FIGURE 3.6 Effects of rate and rhythm on the length of the excitation wave. The wave length of a regular imputse (top thick curve), of the earliest premature beat (lower thick curvel and of a premature beat coming $5,10,20$ msec later than the earliest premature beat are plotted as a function of the pacing interval. It is clear that the wave length of a regutar impulse and of the earitiest premature beat shorten markedty at pacing cycle length's of lesis than 200 msec. Aleo premature beats elicited later in the cycle have a shortened wave length at increasing pacing rates. Note that the wave length of the earliest premature beat is almost half the wave length of a basic impulse.

\subsection{DISCUSSION}

Effects of changes in rate on refractory period and conduction velocity.

An increase in heart rate causes a shortening of the refractory period both in the atrium (Hoffman and Cranefield 1960) as well as in the ventricle (Janse 1971). However, the amount of shortening differs from tissue to tissue, and from species to species (Hoffman and Cranefield 1960). In our experiments an increase in pacing rate in the rabbit atrium initially results in a slight prolongation of the refractory period, followed by a marked shortening at higher pacing rates. The slight prolongation of the refractory period at relatively slow rates, as found in our studies, is probably 
specific for the rabbit atrium. This phenomenon was no longer observed after the induction of a single premature beat.

The conduction was depressed at increasing pacing rates. Here again the silowing is initially moderate, but at pacing intervals shorter than $200 \mathrm{msec}$ the speed of propagation is depressed progressively until conduction block accurs. The conduction velocity at the highest pacing rate was about $60 \%$ of the value at $2 \mathrm{~Hz}$.

Relation to reentrant arrhythmias.

The ralle of $s$ llow conduction for the occurrence of reentry has been stressed by many authors (Schmitt and Erlanger 1928, Hoffman and Cranefield 1960, Wit et a1. 1972a, Wit et a1. 1972b, Cranefield 1975). Another condition which can facilitate the occurrence of reentry is a short refractory period (Moe and Abildskov 1959, Hoffman and Cranefield 1960). The interplay of both the speed of propagation and the rate of recovery of excitability is expressed in the length of the excitation wave. Initiation and continuation of a reentrant circuit can be considered to be related to the length of the excitation wave. Normaliy the length of the excitation wave is relatively long, preventing reentrant excitation within the myocardium. However if the wave length of the impulse is short the chances for initiation of reentry become higher.

Measurement of the wave length of premature impulses showed that early premature impulses have a markedly shortened length of their excitation wave. However the zone of coupling intervals in which the wave length is shortened was rather narrow. The shortest premature beat had an average wave length of $23 \mathrm{~mm}$. The wave length of a premature impulse coming $10 \mathrm{msec}$ later was $28 \mathrm{~mm}$ lang, whereas premature impulses induced 25 and $45 \mathrm{msec}$ after the refractory period had a length of 33 and $34 \mathrm{~nm}$. It was shown by Allessie et al.(1973) that initiation of a reentrant circuit in the isolated left atrium of the rabbit was only possible with premature stimuli given within about $10 \mathrm{msec}$ after the refractory period. There is a striking correlation between this narrow echo-zone and the range of prematurity in which the excitation wave was shortened. If one accepts the hypothesis that the dimension of reentrant circuits in the myocardium is equal to the length of the circulating excitation wave, the size of the first reentrant circuit must be between 20 and $30 \mathrm{~mm}$. 
An alternative way to induce reentrant arrhythmias is rapid pacing. We found that the wave length during regular rhythm is shortened at pacing rates higher than $5 \mathrm{~Hz}$. At the highest pacing rate the length of the impulse was shortened to $28 \mathrm{~mm}$. Here again there is a good correlation between the inducibility of reentrant arrhythmias and the shortening of the wave length. It may be noted that the shortening of the wave length due to incremental pacing is more gradual and takes place over a larger range of pacing intervals than the shortening of the wave length of a premature beat. This indicates that the coupling interval of a premature beat is more critical than the cycle length of rapid pacing.

Allessie et al. (1973) observed that a reentrant tachycardia initiated with a single premature stimulus gradually increased in cycle length during the first 100 revolutions before a steady state was reached. However, very often the tachycardia stopped spontaneously during this initial phase. our studies on the influence of heart rate on the length of the impulse offers a possible explanation for this phenomenon. The length of the excitation wave of the earliest premature impulse, equal to the size of the first reentrant loop, is smaller $(23 \mathrm{~mm})$ than the wave length at the highest pacing rate $(28$ $\mathrm{mm})$. One can imagine that the size of the reentrant circuits, gradually increases after initiation of the tachycardia. This enlargement of the reentrant loop may be of significance for termination of the arrhythmia.

\section{REFERENCES}

Allessie MA, Bonke FIM, Schopman FJG: Circus movement in rabbit atrial muscle as a mechanism of tachycardia.

Circ Res, 32: 54-62, 1973.

Cranefield PF: The conduction of the cardiac impulse. The slow response and cardiac arrhythmias.

Futura Publishing Company, Mount Kisco, New York, 1975. 
Hoffman BF, Cranefield PF: Electrophysiology of the heart.

McGraw-Hi11, New York, 1960, (Futura Publishing Company, Mount Kisco, kew York 1976 (reprint edition)).

Janse M: The effect of changes in heart rate on the refractory period of the heart.

Thes is, Mondeel-offsetdrukkery, Ansterdam, 1971.

Moe GK, Abildskov JA: Atrial fibrillation as a self-sustaining arrhythmia independent of focal discharge.

Am Heart J, 58: 59-70, 1959.

Schmitt FO, Erlanger $J$ : Directional differences in the conduction of the impulse through the heart muscle and their possible relation to extrasystolic and fibrillary contractions.

An J Physiol, 87: 326-347, 1928.

Wellens HJd: Value and limitations of programmed electrical stimulation of the heart in the study and treatment of tachycardias.

Circulation, 57: 845-853, 1978.

Wit AL, Hoffman BF, Cranefield PF: Slow conduction and reentry in the ventricular conducting system. I Return extrasystole in canine Purkinje fibers.

Circ Res, 30: 1-10, 1972a.

Wit AL, Cranefield PF, Hoffman BF: Slow conduction and reentry in the ventricular conducting system. II single and sustained circus movement in networks of canine and bovine Purkinje fibers.

Circ Res, 30: 11-22, $1972 b$. 


\section{THE EFFECTS OF TEMPERATURE ON THE LENGTH OF THE EXCITATION WAVE.}

It is generally agreed that hypothermia increases the chance on fibrillation. When patients are cooled during open heart surgery ventricular fibrillation frequently develops. Also experimental animal studies report an increased incidence of fibrillation during hypothermia (Cavino and D Amato 1962).

The electrophysiological changes which at low temperatures make the heart more susceptible to fibrillation are not completely understood. An increased dispersion in refractoriness (Han and Moe 1964), as well as slowed conduction (Covino and D'Amato 1962, Yamagishi and Sano 1967) may favor the occurrence of reentrant arrhythmias. But on the other hand the prolongation of the refractory periad (Angelakos et al. 1957, Covino and D'Amato 1962) may diminish the chance of fibrillation.

It has been proposed that fibrillation is based on the existence of multiple reentrant circuits within the myocardium (Moe and Abildskov 1959, Allessie et al. 1982). Furthermore Allessie et al. (1977) intraduced the hypothesis that the size of such intra-myocardial circuit has to be equal to the wave length of the circulating impulse. A possible explanation for the increased risk of fibrillation at lower temperatures is that, as a result of depressed conduction, the wave length of the impulse shortens. To test this hypothesis we measured the length of the excitation wave during rapid pacing at temperatures from 38 to $21{ }^{\circ} \mathrm{C}$.

To correlate changes in wave length directly with changes in size of a reentrant circuit we mapped the activation pattern of a circusmovement tachycardia in the left atrium during a decrease in temperature.

\section{1 EXPERIMENTAL PROTOCOL.}

The effects of changes in temperature of the Tyrode solution were studied in 13 left atrial preparations. The temperature was varied in steps of $2{ }^{\circ} \mathrm{C}$ between 38 and $26{ }^{\circ} \mathrm{C}$ in a 11 preparations and in 2 experiments the temperature was further lowered to $21{ }^{\circ} \mathrm{C}$. The temperature changes were achieved by switching from one heating system (Tamson TC 9) to another which was prewarmed cq. precooled to the desired temperature. By switching forth and back between the two separate heating systems any temperature step could be selected. The preparation was allowed to accomodate to the new temperature 
for at least 5 minutes before the measurements were made. Besides the conduction velocity at $2 \mathrm{~Hz}$, the conduction velocity and the wave length at the shortest possible pacing interval were measured. The potassium concentration in the Tyrode solution was $5.6 \mathrm{mmol}$.

In additional experiments we studied the effects of changes in temperature on intra-atrial reentry. We isolated pieces of atrial myocardium consisting of the roof of the left atrium and left atrial appendage. After addition of carbamylcholine $\left(4 \times 10^{-7} \mathrm{~g} / \mathrm{ml}\right)$, long lasting periods of atrial flutter can be induced in these pieces of atrium $(20 \times 20 \mathrm{~mm})$. The sequence of excitation during this arrhythmia was mapped by simultaneously recording of 192 electrograms. The recording equipment is described in detail by Allessie et a1. (1982) and wit et al. (1982). In the present study we used a multiple recording dewice, in which the recording electrodes (teflon coated sillver wire, diameter $0.3 \mathrm{~mm})$ were arranged in a regular array (14x14 electrodes ( 4 electrodes were not connected), interelectrode distance 1.4 mmi). With this mapping technique it was possible to wisualize the reentrant circuit responsible for the atrial fiutter, and to study directly the effects of changes in temperature on cycle length and size of these intma-atrial circuits.

\subsection{RESULTS.}

The effects of temperature on conduction velocity, maximum pacing rate and wave length of all experiments are given in table 4 . I and figure 4.1. It is clear that changes in temperature have pronounced effects on both conduction velocity and maximum pacing rate. A minor decrease in temperature of the superfusing solution from 37 to $35^{\circ} \mathrm{C}$ already caused a statistically significant $(P<0.05)$ slowing of the conduction velocity both at $2 \mathrm{~Hz}$ and at the highest pacing rate (table 4. I). The shortest possible pacing interval is even more sensitive for changes in temperature, significant changes occurring already at temperature steps of $1^{\circ} \mathrm{C}$. At a temperature range fram 37 to $27^{\circ} \mathrm{C}$ the slowing in conduction and the prolongation of the mimimum pacing interval were almost linear with changes in temperature (figure 4.1). The shortest possible pacing interval was doubled from $86 \mathrm{msec}$ at $37{ }^{\circ} \mathrm{C}$ to $167 \mathrm{msec}$ at 27 ${ }^{\circ}$. The conduction welocity at the highest possible pacing rate was also markedly depressed $\left(21 \mathrm{~cm} / \mathrm{sec}\right.$ at $27^{\circ} \mathrm{C}$ versus $34 \mathrm{~cm} / \mathrm{sec}$ at $37^{\circ} \mathrm{C}$ ). Cooling 
TABLE 4.1

TEMPERATURE CONDUCTION INTERVAL CONDUCTION VELOCITY $2 \mathrm{~Hz}$

FMAX

VELOCITY

WAVE

n

FMAX

LENGTH

FMAX

${ }^{0} \mathrm{C}$

$\mathrm{cm} / \mathrm{sec}$

mS

$\mathrm{cm} / \mathrm{sec}$

min

\begin{tabular}{|c|c|c|c|c|c|}
\hline 37 & 62.1 & 85.9 & 34.5 & 29.5 & 13 \\
\hline 36 & $\begin{array}{l}7.0 \\
58.7\end{array}$ & $\begin{array}{l}9.5 \\
97.5\end{array}$ & $\begin{array}{l}4.5 \\
31.8\end{array}$ & $\begin{array}{l}4.4 \\
31.3\end{array}$ & 6 \\
\hline & 5.3 & 7.6 & 4.3 & 5.4 & \\
\hline 35 & $\begin{array}{l}58.6^{*} \\
6.9\end{array}$ & $\begin{array}{l}96.9^{*} \\
12.8\end{array}$ & $\begin{array}{l}30.0^{*} \\
5.1\end{array}$ & $\begin{array}{l}28.7 \\
3.1\end{array}$ & 8 \\
\hline 34 & $55.6^{* *}$ & $101.8^{\star \star *}$ & $30.7^{\star \star}$ & 31.4 & 10 \\
\hline 33 & $\begin{array}{l}6.0 \\
55.9 * *\end{array}$ & $\begin{array}{l}11.4 \\
107.2 * * *\end{array}$ & $\begin{array}{l}4.4 \\
30.4^{\star}\end{array}$ & $\begin{array}{l}4.7 \\
32.6\end{array}$ & 8 \\
\hline & 5.5 & 13.7 & 4.5 & 5.0 & \\
\hline 32 & $\begin{array}{l}49.4^{* *} \\
5.2^{*}\end{array}$ & $\begin{array}{l}113.9 * * * \\
9.9\end{array}$ & $\begin{array}{l}27.6^{\star \star *} \\
3.0\end{array}$ & $\begin{array}{l}31.3 \\
4.6\end{array}$ & 8 \\
\hline 31 & $\begin{array}{l}50.6^{* *} \\
7.1\end{array}$ & $\begin{array}{l}127.1^{* * *} \\
24.3\end{array}$ & $26.7^{* *}$ & 33.8 & 6 \\
\hline 30 & $\begin{array}{l}48.4^{\star \star \star \star} \\
5.5\end{array}$ & $\begin{array}{l}137.6^{\star \star *} \\
10.8\end{array}$ & $\begin{array}{l}23.8^{\star * * *} \\
6.6\end{array}$ & $\begin{array}{l}34.1^{\star} \\
4.1\end{array}$ & 9 \\
\hline 29 & $\begin{array}{l}46.4^{* * *} \\
5.7\end{array}$ & $\begin{array}{l}141.9^{* * *} \\
18.7\end{array}$ & $\begin{array}{l}24.8^{* * \pi} \\
4.2^{-1}\end{array}$ & $\begin{array}{l}34.5^{\star} \\
3.8^{\circ}\end{array}$ & 7 \\
\hline 28 & $44.4^{* * * *}$ & $151.9 * \star \star$ & $22.0 * * *$ & $33.1^{\star}$ & 8 \\
\hline 27 & $\begin{array}{l}6.8 \\
42.9 * * *\end{array}$ & $\begin{array}{l}20.2 \\
167.1\end{array}$ & $\begin{array}{l}4.0 \\
21.1 * * *\end{array}$ & $\begin{array}{l}6.2 \\
35.0 \star\end{array}$ & 6 \\
\hline & & 18.2 & 2.7 & 2.8 & \\
\hline 26 & $38.3^{* * *}$ & $186.9 * * *$ & $18.4^{\star \star \star *}$ & $33.9 *$ & 7 \\
\hline 25 & $\begin{array}{l}3.3 \\
37.7 \\
9.3\end{array}$ & $\begin{array}{l}16.5 \\
195.0 \\
59.0\end{array}$ & $\begin{array}{l}17.3 \\
5.0\end{array}$ & $\begin{array}{l}3.0 \\
32.0 \\
0.9\end{array}$ & 3 \\
\hline 22 & 30.0 & 310.0 & 13.0 & 41.4 & 2 \\
\hline 21 & 1.4 & 14.1 & 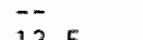 & 1.8 & \\
\hline$K 1$ & $\begin{array}{l}28.0 \\
1.4\end{array}$ & $\begin{array}{l}315.00 \\
17.7\end{array}$ & $\begin{array}{l}13.5 \\
2.1^{2}\end{array}$ & $\begin{array}{l}41.9 \\
5.8\end{array}$ & 2 \\
\hline
\end{tabular}

$*=p<0.05$

$* *=p<0.01$

$\star \star * *=p<0.001$ 


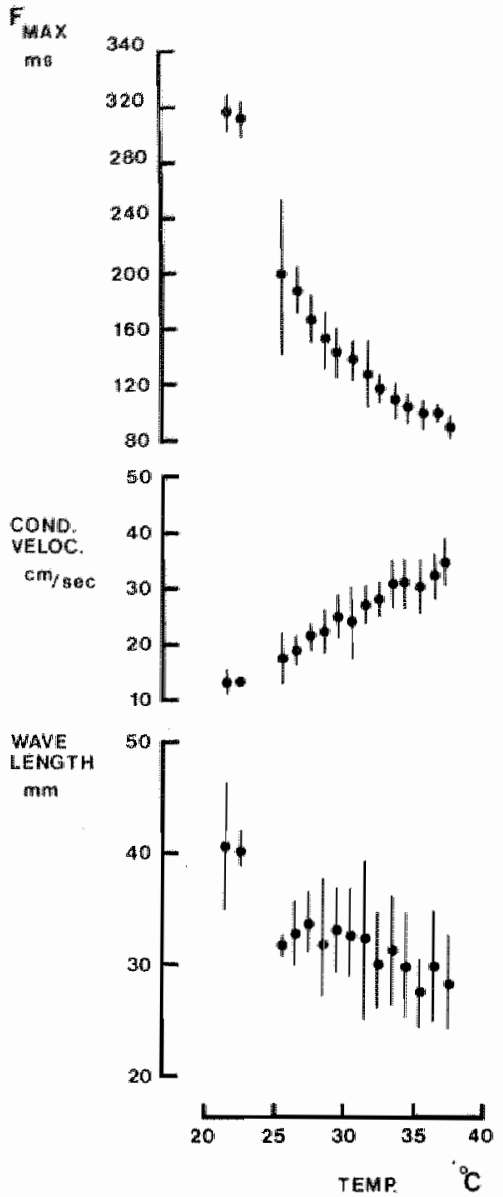

FIGURE 4.1 The effects of temperature on the shortest poseible pacing intervat (top panel), the conduction velocity at this rate (middie panel) and the wave length (bottom panel). Lowering of the temperature from 37 to 27 caubed a marked protongation of the shortest possible pacing interval from 85 to 170 msec. Concomitantly the conduction velocity was slowed from 34 to $21 \mathrm{~cm} / \mathrm{sec}$. The length of the excitation wave prolonged from 30 to 35 mon. If the temperature was Zowered from 27 to $21{ }^{\circ} \mathrm{C}$ the prolongation of the minimum pacing intervat was larger than the depresstion in conduction. As a consequence the wave length was markedly protanged.

the heart from 37 to $27^{\circ} \mathrm{C}$ caused a prolongation of the length of the excitation wave from 30 to $35 \mathrm{~mm}$. If the temperature was further decreased below $27{ }^{\circ} \mathrm{C}$ the minimum pacing interval increased steeply. Since this prolangation was more pronounced than the concomitant depression in conduction velocity, below $27{ }^{\circ} \mathrm{C}$ the wave length prolonged markedly. Cooling from 27 to $22{ }^{\circ} \mathrm{C}$ prolonged the wave length from 35 to $41 \mathrm{~mm}$.

In figure 4.2 the wave length at the highest pacing rate is plotted as a function of the highest pacing rate at different temperatures. It is clear that lowering the temperature from 37 to $32,28,26$, and $22{ }^{\circ} \mathrm{C}$ causes a marked and progressive prolongation of the shortest possible pacing interval. 


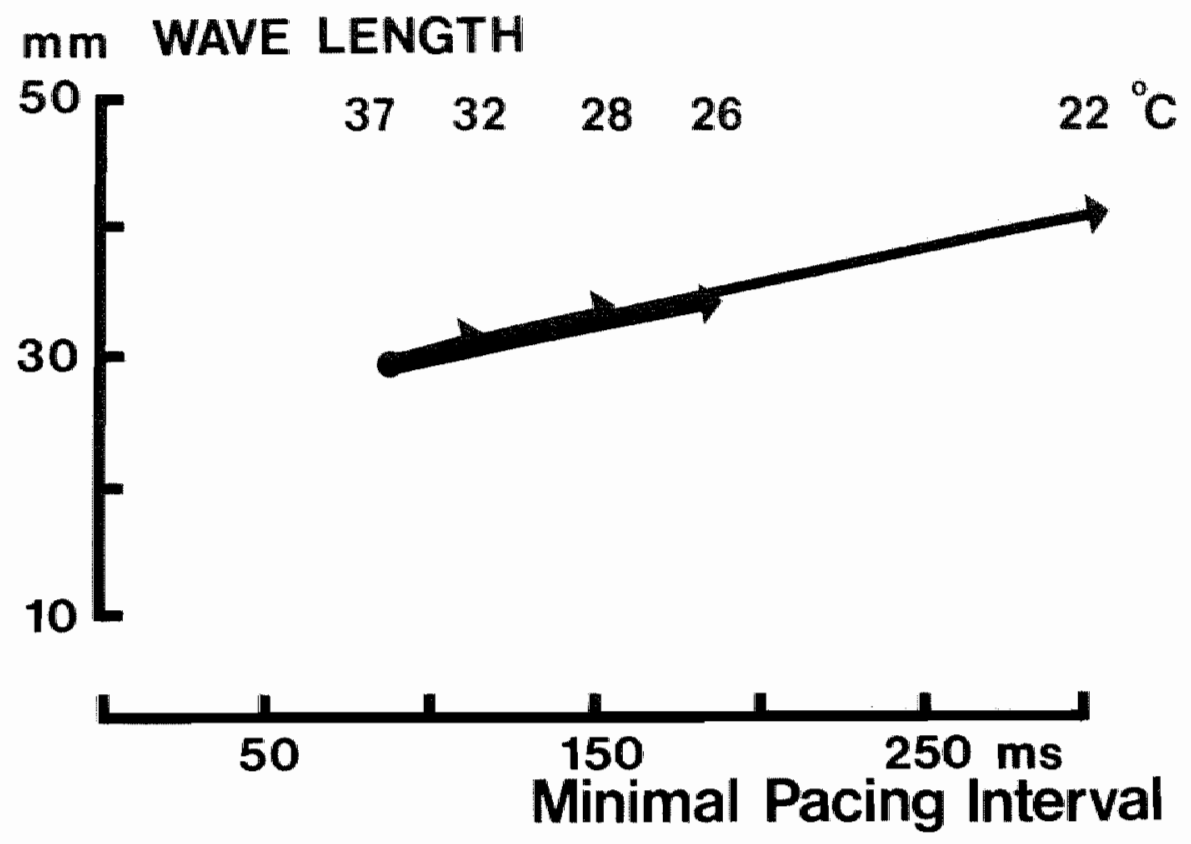

EIGURE 4.2. The changes in wave tength in relation to changes in Emax. The wave length at various temperatures is plotted as a function of the shortest poseible pacing interval. If the temperature is lowered to 32,28 , 26 and 22 $\mathrm{B}_{C}$ the shomtest pacing intervat protongs progressively, reaching $a$ thmeefold inerease at $22^{\circ} \mathrm{C}$. However the wave tergth is only protonged with about $30 \%$.

Simultaneously the wave length at the highest pacing rate is moderately prolonged, as indicatied by the slope of the arrows.

The effects of temperature on a reentrant circuit.

In 3 experiments we initiated long lasting reemtrant arrhythmias in isolated pieces of rabbit atrium under the influence of carbachol. After the fast reentrant rhythm has stabilized for 500 to 600 beats the tenperature of the perfusion solution was quickly lowered, while the cycle length of the arrhythmia was monitored. An example of such an experiment is shown in figure 4.3. Temperature changes are given by the dashed line (left ordinate), whereas the solid line shows the changes in cycle length of the tachycardia (right ordinate). In this example at $37^{\circ} \mathrm{C}$ the cycle length was about 100 msec. A lowering in temperature from 37 to $29^{\circ} \mathrm{C}$ was accomplished in about 4 minutes. During this gradual decrease in temperature the cycle length of the 


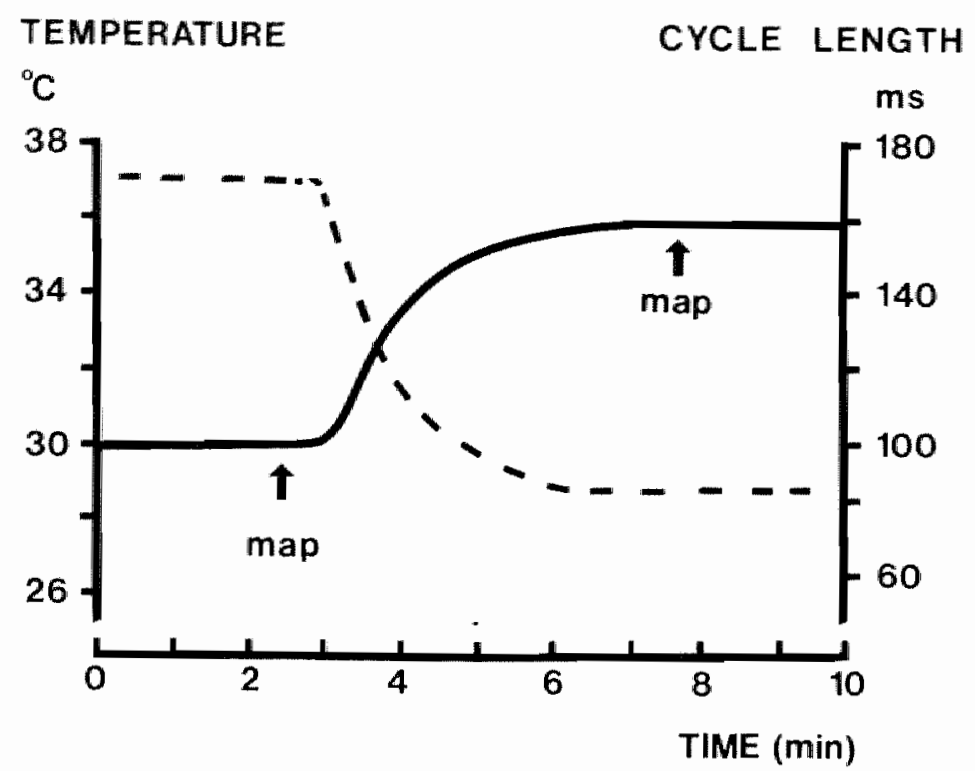

FIGURE 4.3. The effects of cooling on the cycle length of a reentrant arphythmia. The changes in cycle length of an atrial flutter are shoun during a lowering of the temperature from 37 to $29^{\circ} \mathrm{C}$. The cycle iength (right ordinatel gradualty prolongs from 100 msec to 160 msec if the temperature is lowered from 37 to $29{ }^{\circ} \mathrm{C}$ (Left ordinate). Although the flutter rate slowed considerabiy, the arphythmia continued. Activation maps shown in figure 4.4 were made at the moments indicated by the arrows.

atrial flutter increased gradually. At $29{ }^{\circ} \mathrm{C}$ the cycle length had increased from 100 to $160 \mathrm{msec}$. Although the rate of the reentrant rhythm slowed markedly, it was regular all the time and did not terminate spontaneously. During this period of cooling simultaneously recording of 192 electrograms was performed continuously. The activation sequence at 37 and $29{ }^{\circ} \mathrm{C}$ were reconstructed from these recordings and are shown in figure 4.4. At the left the activation map and a schematic representation of the reentrant circuit are shown at $37^{\circ} \mathrm{C}$, whereas at the right the map recorded at $29^{\circ} \mathrm{C}$ is given. A11 activation times are grouped in isochrones of $10 \mathrm{msec}$. It could be shown that at $37^{\circ} \mathrm{C}$ the impulse circulated around in a clockwise direction in about $100 \mathrm{msec}$. This revolution time was exactly equal to the cycle length of the arrhythmia. The hatched part in the map indicates the area of functional 


\section{EFFECT OF TEMPERATURE}

$37{ }^{\circ} \mathrm{C}$

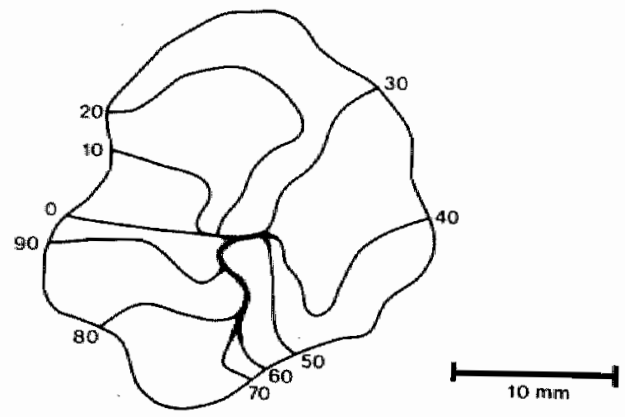

$98 \mathrm{~ms}$

cycle length

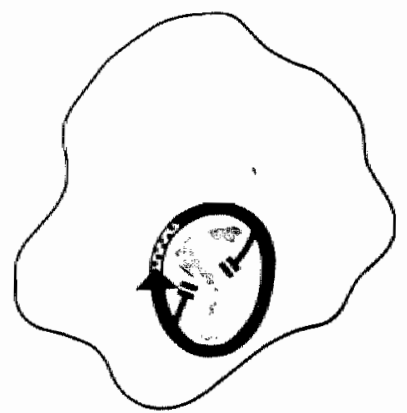

$29^{\circ} \mathrm{C}$

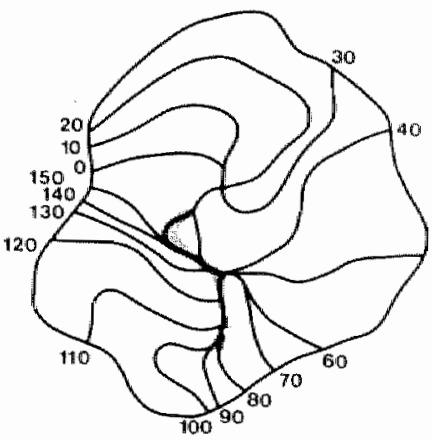

$159 \mathrm{~ms}$

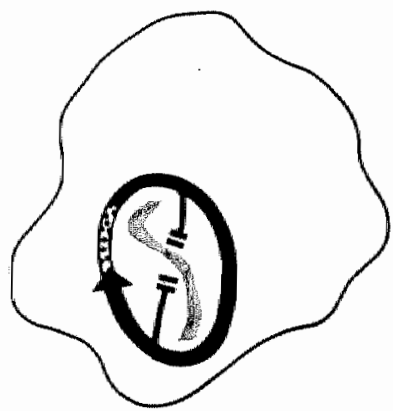

FIGURE 4.4 The effects of temperature on intra-atrial reentry. Actuation mape are show at 37 and $2 \mathrm{~g}^{\circ} \mathrm{C}$. The bottom panels give a schematic mepresentation of the cireutit. All activation times are grouped in isochmones of 10 msec. At $37^{\circ} \mathrm{C}$ the revolution time of the cincut was 98 meec. Cooling to $29^{\circ}{ }_{C}$ aused a change in the the functionalty determined aireuit in two aspects: the cycle length olowed to 159 msec and the wial of the reentrant cireuit increased sightly (bottom panell. 
conduction block around which the activation wave revolved. The bottom panel gives a schematic representation of the dimensions of this functionally determined circuit. Lawering the temperature to $29{ }^{\circ} \mathrm{C}$ caused a prolongation of the revolution time to $160 \mathrm{msec}$. The impulse was still circulating in a clockwlse direction, although much slower than it did at $37{ }^{\circ} \mathrm{C}$. It can be clearly seen that the number of isochrones has increased and that the isochrones are closer together, indicating that the speed of propagation of the activation wave was slowed uniformally along the circuitous pathway. Furthermore it must be noted that as a result of cooling the central area of functional block has been somewhat enlarged. As a consequence the size of the reentrant circuit is increased (bottom panel). Despite this increase in the size of the reentrant circuit the impulse continued to revolve regulariy and did not stop. However when the temperature was further lowered the flutter was suddenly interrupted at a temperature of $27^{\circ} \mathrm{C}$.

\subsection{DISCUSSION}

The effects of temperature on the wave length.

Cooling of the heart causes a pronounced slowing in conduction velocity of the impulse (Covino and D'Amato 1962, Yamagishi and Sano 1967) and a marked prolongation of refractoriness (Angelakos et al. 1957, Covino and D'Anato 1962). In the isolated rabbit atrium we observed a slowing in conduction of $31 \%$ during slow pacing and of $39 \%$ during maximal pacing when the heart was cooled from 37 to $27^{\circ} \mathrm{C}$. Simultaneously the shortest possible pacing interval was prolanged in excess of $90 \%$. Because the effect on the minimal pacing interval was greater than the slowing in conduction, the wave length prolonged in this temperature range although this was not a very marked change, namely $19 \%$. Progressive cooling below $27{ }^{\circ} \mathrm{C}$ caused a strong prolongation of the wave length because at these low temperatures the shortest possible pacing interval is influenced strongly.

Temperature and reentrant arrhythmias.

The observation that the refractory period prolongs markediy if the temperature of the heart is decreased was confirmed in these experiments. Lowering the temperature from 37 to $27{ }^{\circ} \mathrm{C}$ resulted in a prolongation of the shortest possible pacing interval with almost $100 \%$. Whether this protongation in refractoriness affects an intra-atrial reentrant arrhythmia 
was investigated by mapping a fast flutter in an isolated rabbit atrium while the temperature was lawered. It was observed that the cycle length of this fast intra-atrial reentry prolonged markedly. Allessie et al. (1977) suggested that the cycle length of such a reentrant arrhythmia was proportionai to the refractory period. The analogy between the observed decrease. in flutter rate and the slowing in the maximal pacing rate support this concept.

cooling the atrium during a reentrant rhythm not only resulted in a marked slowing of the rate of the tachycardia but also in a slight increase in the size of the reentrant circuit. At very low temperatures (below $25{ }^{\circ} \mathrm{C}$ ) the reentrant rhythm suddenly stopped. Measurement of the wave length in isolated strips of atrial myocardium showed identical results. Moderate lowering of the temperature resulted in a moderate increase in the length of the excitation wave, whereas a marked prolongation was observed at temperatures below $27{ }^{\circ} \mathrm{C}$. Thus the effects of changes in temperature on the shortest possible pacing interwal and the wave length are quite similar to the changes in rate and size of a functionally detemined intra-atrial circuit.

The observed prolongation in wave length and the resulting increase in size of a reentrant circuit do not fit with the increased incidence of ventricular fibrillation during hypothermia. On the contrary, these results indicate that induction of fibrillation should be more difficult. A possible explanation might be that the ventricular response to hypothermia is different from the atrial response. However the existence of such a difference is unlikely. So if we assume that the wave length in ventricular muscle is prolonged during hypothermia, we must expect that hypothermita impedes the induction of reentrant arrhythmias. The obserwation during intra-operative mapping studies that the induction of ventricular arrhythmias is more difficult when the thorax is opened and the heart is cooled, fits with this assumption. The increased incidence of ventricular fibrillation therefore cannot be explained by the changes in the wave length; other factors must play a role in the induction of fibrillation during hypothermia. Most probably increased spatial dispersion of refractoriness (Han and Moe 1964) and increased inhomogeneity in conduction are involved. It may also be that increased adrenergic activity induced by hypothermia (Nielsen and owman 1968 ) is of importance. 


\section{REFERENCES}

Allessie MA, Bonke FIM, Schopman FJG: Circus movement in rabbit atrial muscle as a mechanism of tachycardia. IIL. The "leading circle" concept: A new model of circus movement in cardiac tissue without the involvement of an anatomic obstacle.

Circ Res, 41: 9-18, 1977.

Allessie MA, Lammers WJEP, Smeets JLRM, Bonke FIM, Hollen SJ: Total mapping of atrial excitation during acetylcholine-induced atrial flutter and fibrillation in the isolated canine heart.

In: Atrial Fibrillation. Edited by Kulbertus HE, 01sson SB, Schlepper M, Publ Hassle, Molndal Sweden, 44-61, 1982.

Angelakos ET, Laforet EG, Hegnauer AH: Ventricular excitability and refractoriness in the hypothermic dog.

Am J Physiol, 189: 591-595, 1957.

Covino BG, D'Amato HE: Mechanism of ventricular fibrillation in hypothermia. Circ Res, 10: 148-155, 1962.

Han J, Moe GK: Nonuniform recovery of excitability in ventricular muscle. Circ Res, 14: 44-60, 1964.

Moe GK, Abildskov JA: Atrial fibrillation as a self-sustaining arrhythmia independent of facal discharge.

Am Heart J, 58: 59-70, 1959.

Nielsen $K C$, Owman $c$ : Control of ventricular fibriliation during induced hypothermia in cats after blocking the adrenergic neurons with bretylium. Life Sci, 7: 159-168, 1968.

Wit AL, Allessie MA, Bonke FIM, Lammers W, Smeets J, Fenoglio Ju: Electrophysiologic mapping to determine the mechanism of experimental ventricular tachycardia initiated by premature impulses. Experimental approach and initial results demonstrating reentrant excitation. Am J Cardial, 49: 166-185, 1982.

Yamagishi S, Sano T: Effect of temperature on pacemaker activity of the rabbit sinus node.

Am J Physiol, 212(4): 829-834, 1967. 
5. THE EFFECTS OF NEUROTRANSMITTORS ON THE LENGTH OF THE EXCITATION WAVE.

The autonomic nervous system plays an important role in the genesis of cardiac arrhythmias. Both increase in parasympathetic as well as sympathetic activity are associated with a higher incidence of rhythm disturbances. An increased sympathetic activity is reported to favor the occurrence of ventricular arrhythmias (Lown and Verrier 1976), whereas a high parasympathetic tone increases the risk of atrial flutter and fibrillation (Coumel et al. 1978).

It is already an old observation (Rothberger and Winterberg 1910) that atrial fibrillation can easily be provoked during vagal stimulation. In 1921 Lewis et al. showed that atrial flutter can degenerate into fibrillation if the vagal nerwe is stimulated. If we consider fibrillation to be a state in which multiple reentrant circuits are simultaneousy present in the myocardium (Moe and Abildskov 1959, Allessie et al. 1982), the chance for initiation and continuation of fibrillation will depend on the number of wavelets which can exist. Many circuits can be present simultaneously if either the heart is large or the circuits are smal1. A possible explanation for the occurrence of fibrillation during vagal stimulation is that the size of the reentrant circuits is diminished due to the action of acetylcholime. An experimental proof of this hypothesis was given by Allessie and coworkers (1977), who showed that the size of a reentrant circuit, in an isolated left atrium of the rabbit, gets smaller if exposed to acetyllcholline. This means that stimulation of the vagus may increase the number of wavelets which can be present in the heart.

In this chapter we will describe the effects of neurotransmittors on the length of the excitation wave both during regular pacing and the application of premature stimuli. We found that carbamylcholine strongly shortens the length of the depolarization wave in the atrium. In our opinion this gives a satisfactory explanation for the arrhythmogenic action of acetylcholine on the atrium. The effects of epinephrine on the wave length turned out to be strongly dependent on the pacing rate.

\subsection{MATERIALS AND EXPERIMENTAL PROTOCOL}

The effects of neurotransmittors were investigated in 13 left atrial preparations. We used carbamylcholine (Carbacholum, ACF Chemiefarmal as 
parasympathicomimetic agent. This derivative of acetylcholine exerts identical electrophysiological effects as acetylcholine, but is not inactivated by cholinesterase. This guarantees that the carbamylcholine concentration is constant at the myocardial receptor throughout the experiment. Epinephrine was used as a sympathicomimetic agent.

The drugs were administered to the superfusing solution either by means of a continuous infusion to the tissue bath or simply by adding the desired dosage directly to the 10 liter reservoir.

The protocol of administration of neurotransmittors was as follows: control period ( 1 hour), epinephrine $\left(6 \times 10^{-7} \mathrm{M}, 1\right.$ hour), washout (1 hour), carbamylcholline $\left(4 \times 10^{-7} \mathrm{~g} / \mathrm{ml}, 1\right.$ hour), washout (1 hour).

At these concentration of the drugs clear electrophysiological changes can be expected. Epinephrime in this dosage shortens the intrinsic sinus node cycle length with about $100 \mathrm{msec}$ (Bonke et al. 1982), whereas at this concentration of carbamylcholine generally the sinus node activity ceases.

During each of these protocol steps the wave length of the regularly driven impulse and the earliest premature impulse were measured at various pacing rates.

\subsection{RESULTS}

\subsubsection{The effects of carbamylcholine}

An example of the effects of carbamylcholine on the wave length during maximal pacing is shown in figure 5.1. The shortest possible pacing interval, the conduction velocity and the wave length during the highest pacing rate are plotted before, during and after administration of carbamylcholine $\left(4 \times 10^{-7} \mathrm{~g} / \mathrm{ml}\right)$. After a control period of 1 hour during which the measured parameters were constant, carbamylcholine was added to the Tyrode solution in a final concentration of $4 \times 10^{-7} \mathrm{~g} / \mathrm{ml}$. The shortest possible pacing interval, at which every impulse was still conducted, shortened markedly due to carbamylcholine (from 80 to $55 \mathrm{msec}$ ). Despite this increase in maximum pacing rate, the conduction velocity at this high rate during carbamylcholine administration was equal to the control value. As a consequence the length of the excitation wave during maximal pacing shortened from $27 \mathrm{~mm}$ to $17 \mathrm{~mm}$. After termination of infusion of carbamylcholine, all parameters returned to their control values. 
In figure 5.2 the effects of carbamylcholine on the wave length of a regular rhythm (top panel) are compared with the wave length of the earliest premature impulse (bottom panel). The effects of pacing rate on the wave length are similar as described in chapter 3 . At relatively slow pacing rates the wave length is almost constant, but a marked shortening occurs at pacing rates faster than $5 \mathrm{~Hz}$. Administration of carbamylcholine to the solution

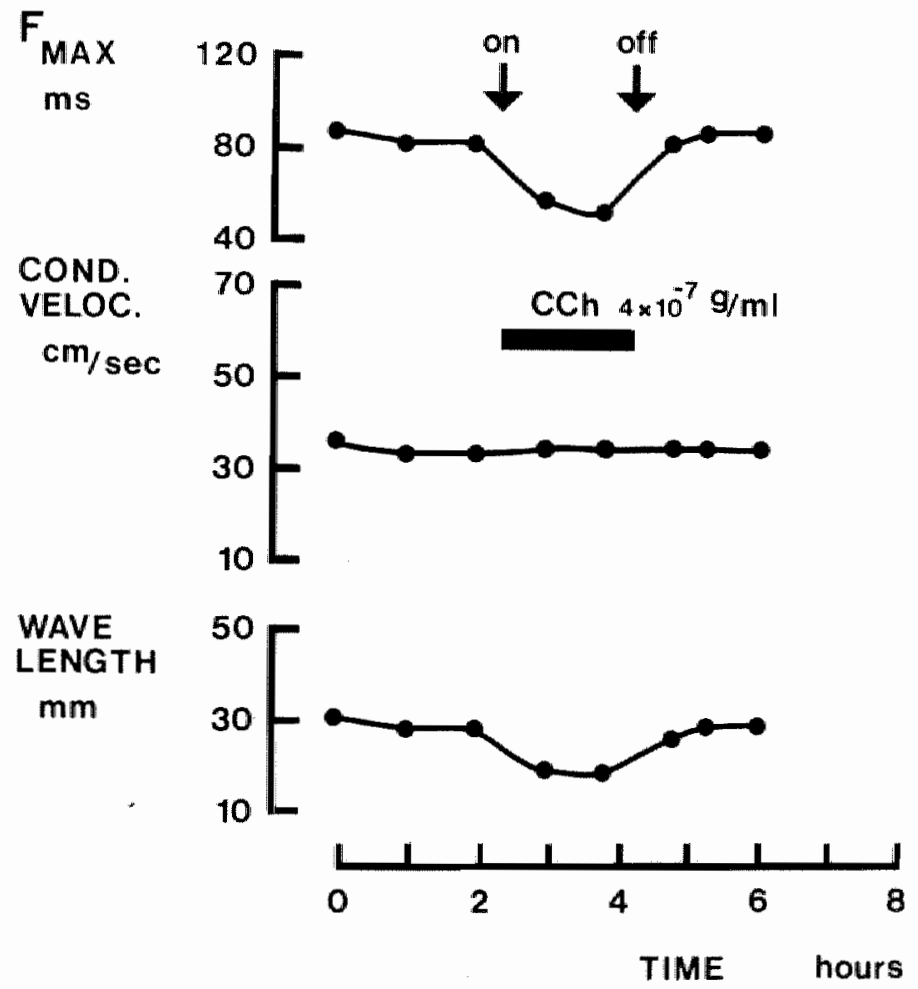

FIGURE 5.1 The effects of carbamylcholine on the wave length during maximat pacing. The shortest possible pacing interval (top panel), the conduction velocity (middle panel) and the wave length (bottom panel) at the highest pacing rate are shown. After a control period of 1 hour, during which alt variables were constant, carbamylcholine was added to the perfusion solution in a final concentration of $4 \times 10^{-7} \mathrm{~g} / \mathrm{ml}$. The administration period is indicated by the arrows. Carbamylcholine shortened the minimal pacing interval from $80 \mathrm{msec}$ to $55 \mathrm{meec}$, whereas the conduction velocity at this rate was not affected. As a consequence the wave length shortened from 27 to $17 \mathrm{~mm}$. All the variablee returned to their control value after termination of the administration indicating a complete wash out of the drug. 
(filled squares) shifted this curve downwards and to the 1eft. At all pacing intervals the wave length was shorter than during control. At a pacing interval of $500 \mathrm{msec}$ administration of carbachol shortened the wave length from about $50 \mathrm{~mm}$ to about $20 \mathrm{~mm}$. However this effect was less outspoken at higher rates. At a pacing interval of 80 msec the wave length was shartened
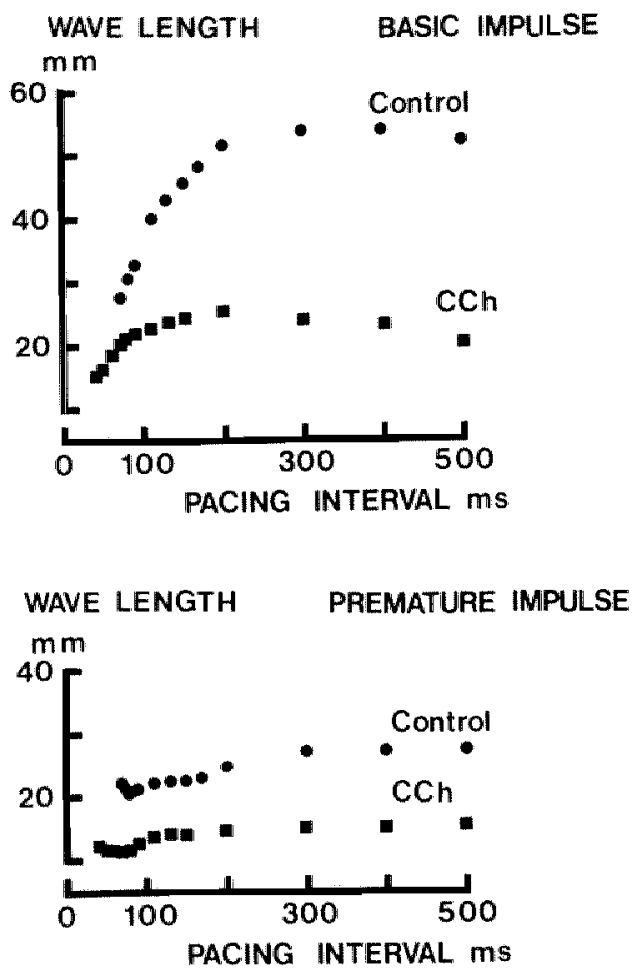

FIGURE 5.2 The effect of carbarnylcholine on the wave length of a basic and a premature impulse during incrementat pacing. The wave length of a regularity driven imputae as a function of the pacing interval during controt and arbamylcholine administration are plottel in the top panel, whereas the bottom panet gives the effects on the wave length of the earliest premature beat. During administration of carbamylcholine (filled squares) the wave length of a regularly driven impulse is shortened at all pacing intervals. However this effect is less at higher pacing rates. Furthermore the minimum pacing interval is shortened under the influence of carbamylcholine 145 vereus $70 \mathrm{meec}$. The wave length of the earliest premature impulse during carbamylcholine infusion is shortened at all pacing intervals to almost an equal extent (bottom panet). 
from 28 to $20 \mathrm{~mm}$. The second major change is a shift of the curve to the left and this indicates that the minimum pacing interval under carbamylchol ine is shorter than during control. The bottom panel gives the wave length of the earliest premature impulse at different pacing intervals during control and carbamylcholine administration. In contrast with the impulse during regular rhythm the wave length of the earliest premature beat is shortened to an equal extent at all pacing rates. This is indicated by the almost parallel shift of the curve downwards.

A summary of the effects of carbamylcholine on the wave length during slow pacing $(2 \mathrm{~Hz})$, the earliest premature impulse and at the highest pacing rate is given in table 5.1. For each parameter, the left column gives the mean and standard deviation during control whereas the right column indicates these values during administration of carbamylcholine $(n=12)$. The major effect of carbamylcholine is a shortening of the refractory period, as can be seen in the first two vertical columns. The refractory period at a pacing rate of $2 \mathrm{~Hz}$ shortens from 70 to $38 \mathrm{msec}$, a decrease of almost $50 \%$. In an

TABLE 5.I

\section{THE EFFECTS OF CARBAMYL CHOL INE}

$\underset{\mathrm{mEFRACTORY}}{\mathrm{mS}}$
$\begin{gathered}\text { CONDUCTION VELOCITY } \\ \mathrm{cm} / \mathrm{sec}\end{gathered}$
WAVE LENGTH
$\mathrm{mm}$

control carbamyl- control carbamyl- control carbamyl-
choline

\begin{tabular}{|c|c|c|c|c|c|c|}
\hline $\begin{array}{l}\text { REGULAR } \\
\text { RHYTHM } \\
(2 \mathrm{~Hz})\end{array}$ & $\begin{array}{l}70.2 \\
\pm 11.0\end{array}$ & $\begin{array}{l}37.6 \\
+6.7 \\
\star \star \star\end{array}$ & $\begin{array}{l}59.5 \\
\pm 11.6\end{array}$ & $\begin{array}{l}57.4 \\
\pm 11.0 \\
\mp *\end{array}$ & $\begin{array}{r}41.5 \\
+8.4\end{array}$ & $\begin{array}{l}21.4 \\
+4.4 \\
\star \star \star *\end{array}$ \\
\hline $\begin{array}{l}\text { EARL IEST } \\
\text { PREMATURE } \\
\text { BEAT }\end{array}$ & $\begin{array}{r}65.7 \\
+9.8\end{array}$ & $\begin{array}{l}37.5 \\
+6.4 \\
\bar{\pi} \star\end{array}$ & $\begin{array}{r}34.6 \\
+8.6\end{array}$ & $\begin{array}{l}42.3 \\
+7.8 \\
* * *\end{array}$ & $\begin{array}{r}22.7 \\
+5.8\end{array}$ & $\begin{array}{l}16.1 \\
+5.0 \\
\hbar * \pi\end{array}$ \\
\hline $\begin{array}{l}\text { SHORTEST } \\
\text { PAC ING } \\
\text { INTERVAL }\end{array}$ & $\begin{array}{r}79.6 \\
+8.1\end{array}$ & $\begin{array}{l}54.2 \\
+6.0 \\
\star \star \star \star\end{array}$ & $\begin{array}{r}33.3 \\
+6.1 \\
\end{array}$ & $\begin{array}{l}34.0 \\
+6.1 \\
n s\end{array}$ & $\begin{array}{r}26.6 \\
+5.1\end{array}$ & $\begin{array}{l}18.0 \\
+3.0 \\
\star \star \star\end{array}$ \\
\hline
\end{tabular}


analogous way the time needed to restore the excitability after the earliest premature impulse is also shortened; the shortest $A_{2}-A_{3}$ interval is $66 \mathrm{msec}$ during control and $38 \mathrm{msec}$ under the influence of carbamylcholine. The faster recovery of excitability during carbamylcholine infusion is also expressed in a higher maximum pacing rate. The average minimum pacing interval was shortened from $80 \mathrm{msec}$ to $54 \mathrm{msec}$. The conduction velocity was not altered by carbamylcholine, with the exception of the earliest premature impulse, which was conducted somewhat faster during carbamylcholine infusion (42 vs 35 $\mathrm{cm} / \mathrm{sec}$ ). These changes in electrophysiological properties by carbamylcholine resulted in a shortening of the length of the excitation wave of $48 \%$ during slow pacing, of $32 \%$ during rapid pacing and of $29 \%$ during a very early premature beat.

The relation of the changes in wave length with the shortening of the minimum pacing interval is shown in figure 5.3. It is clear that together with a shortening of the minimum pacing interval, also the length of the excitation wave is shortened markedly.

\subsubsection{The effects of epinephrine.}

Figure 5.4 gives an example of the effects of epinephrine on the shortest possible pacing interval, the conduction velocity and the length of the excitation wave during rapid pacing. After a control period of 1 hour, during which these parameters were constant, administration of epinephrine $\left(6 \times 10^{-7}\right.$ M) was started. This did not result in any significant change in the measured electrophysiological parameters. The shortest possible pacing interval remained $80 \mathrm{msec}$ and also the conduction velocity was unchanged. As a consequence the wave length at the shortest pacing interval was unchanged too. This lack of electrophysiologic effect was not caused by an insufficient dosage of epinephrine. When applied to the sinus nade the same dosage has a strong chronotropic effect (Bonke et al. 1982). The atrial myocardium is also affected by this concentration of epinephrine, as illustrated in figure 5.5 . In the top panel the wave length of a regularly driven impulse is plotted as a function of the pacing interval both during control and during epinephrine administration. It is clear that the effect of epinephrine strongly depends on the pacing rate. After addition of epinephrine to the perfusion fluid the wave length of the basic impulse at $500 \mathrm{msec}$ interval clearly prolonged from 


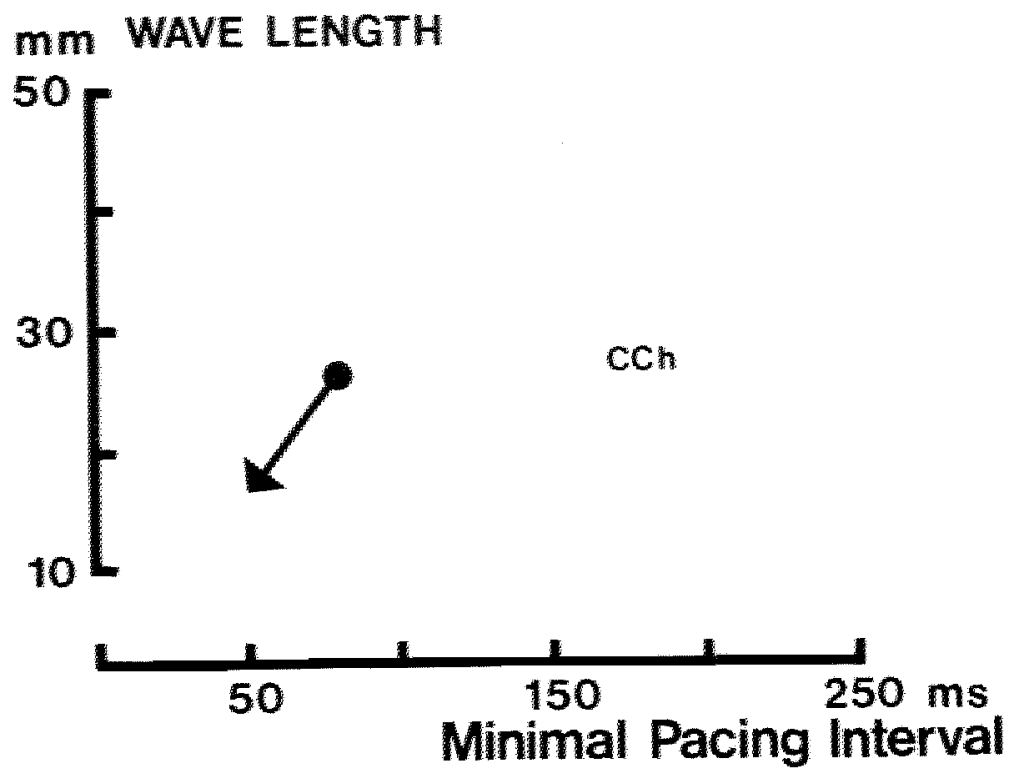

EIGURE 5.3 Retation between wave tength and highest pacing rate under the infuence of carbarylaholine. A cleat whortening of the wove length is

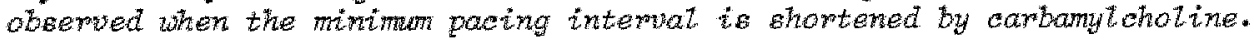

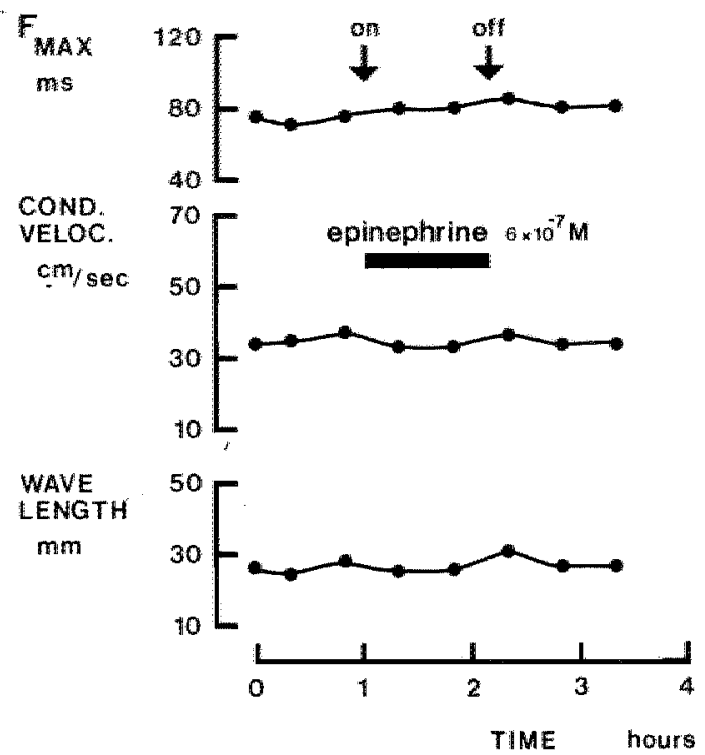

FICURE 5.4 The shontest possible pacing interval, the conduction velocity at this rate and the wave length during the highest pacing rate are ohown during adminstration of epinephine. After a control period of 1 hour epinephrine was added to the perfubion solution in a concentration of $6 \approx 10^{-7} \mathrm{M}$. It is clear that nether of the meabured parconetera was affected by epinephrine. 

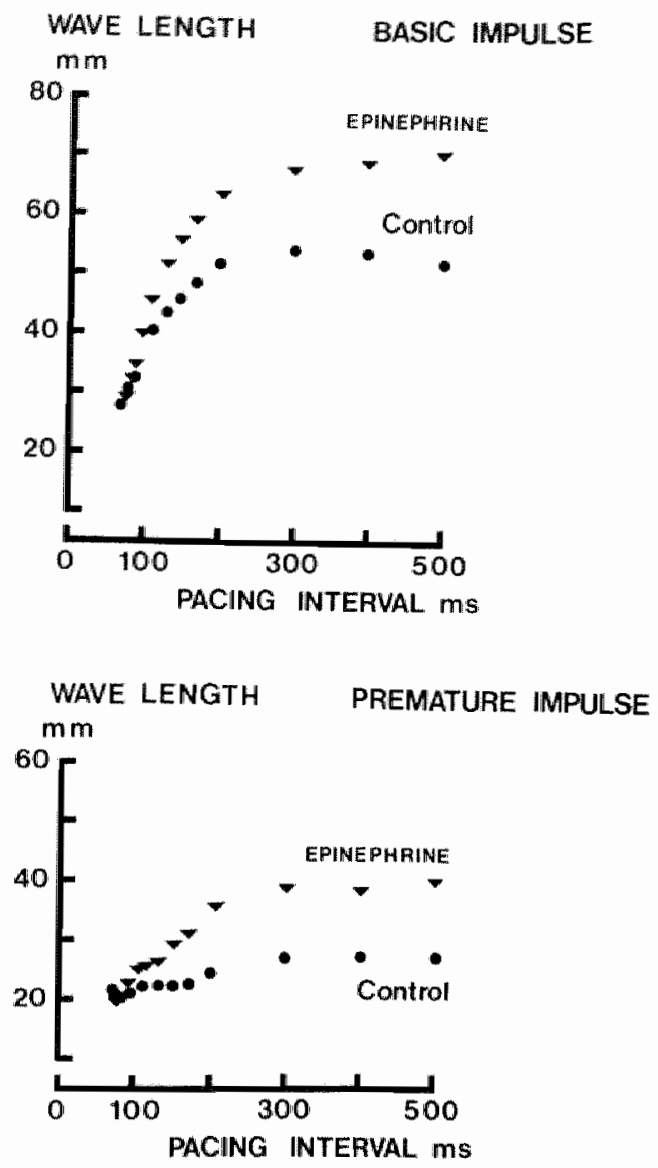

FIGURE 5.5 The effect of epinephrine on the wave zength during incrementat pacing. The length of the excitation wave of a regularty driven impulse is shown in the top panet, whereas the bottom pamel gives the wave tength of the eartiest posible premature beat. Epinephrine causes a protongation of the wave length of both a megularly dmiven impulse and the earliest premature impulse. However the effect is alearity rate dependant. If the pacing interval is ahortened, the effect of epinephrine is diminished. 
50 to about $70 \mathrm{~mm}$. At an interwal range from 500 to $200 \mathrm{msec}$ this prolongation was constant. However if the pacing interval was shortened beyond $200 \mathrm{msec}$ the effect of epinephrine on the wave length gradually diminished. Finally at the highest pacing rate the wave length became. almost equal to the control value. This explains why in figure 5.4 no effect was seen. In the bottom panel of figure 5.5 the wave length of the earliest premature impulse is shown as a function of the pacing interval. Here the effects of epinephrine are quite similar as during a regular rhythm. In this example during control the wave length of the earliest premature impulse at a pacing interval of $500 \mathrm{msec}$ was $27 \mathrm{~mm}$. Under the influence of epinephrine this prolonged to $40 \mathrm{~mm}$. However at faster pacing rates this epinephrine effect gradually diminished.

The effects of epinephrine are summarized in table 5.II. The left vertical columns of the three pairs give the control values, the right columns give the measurements during epinephrine infusion. The refractory

TABLE 5. II

THE EFFECTS OF EP INEPHR INE

REFRACTORY PERIOD mS
CONDUCTION VELOCITY $\mathrm{cm} / \mathrm{sec}$

control

56.5

$\pm 10.4$

33.2

$+9.7$

93.5
+13.3
$* * *$

87.3

$+12.4$
33.9

$\pm 5.9$ epine-

nephrine

58.3

$+10.9$

31.2

$+9.1$

32.2

$+5.2$
WAVE LENGTH

$\min$

control epine-

phrine

$37.6 \quad 58.3$

$\pm 8.3+15.8$

$20.5 \quad 28.8$

$\pm 6.6 \quad+8.4$

$27.3 \quad 28.0$

$\pm 6.1+5.4$

\footnotetext{
ns =not significant

$\star \quad=p<0.05$

$\star \star \quad=p<0.01$

$\star * * \quad=p<0.001$
} 
perfod during regular pacing at $2 \mathrm{~Hz}$ prolonged from 67 to $98 \mathrm{msec}$, whereas the refractory period of the earliest premature impulse prolonged from 62 to 94 msec. Epinephrine only caused a slight increase in the shortest possible pacing interval from 80 to $87 \mathrm{msec}$. It is interesting to see that under the influence of epinephrine the refractory period at a slow pacing rate is longer than the shortest possible pacing interval (98 msec vs $87 \mathrm{msec}$ ). During control the refractory period at $2 \mathrm{~Hz}$ is always shorter than the minimal pacing interval. The conduction velocity of the earliest premature impulse, during slow pacing and during the highest possible pacing rate were almost identical to contral. As a consequence the wave length during slow pacing ( $2 \mathrm{~Hz}$ ) prolonged from 38 to $58 \mathrm{~mm}$, whereas the wave length of the earliest premature impulse prolonged from 20 to $29 \mathrm{~mm}$. Since the shortest possible pacing interval and the conduction velocity at this rate were hardly affected by epinephrine, also the wave length at the highest pacing rate was unchanged (27 compared to $28 \mathrm{~mm}$ ). Thus the changes in refractoriness and

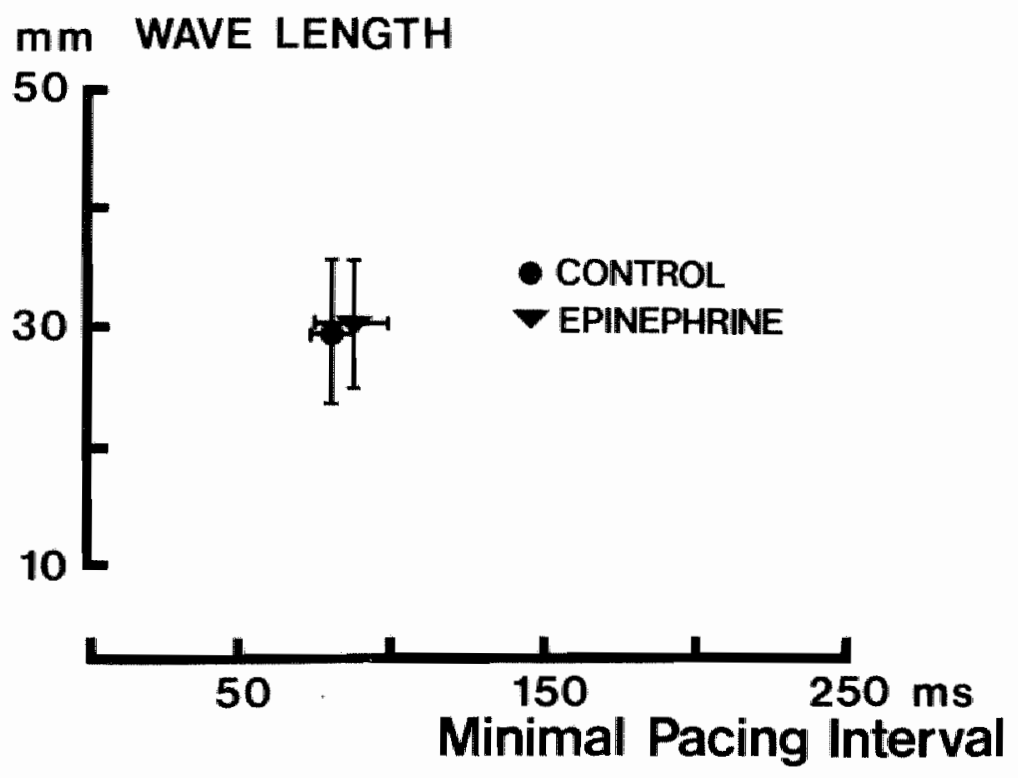

FIGUFE 5.6 Retation between wave length and higheat pacing rate under the infuence of eptinephmine. The fitzed airole give the mean of the controt meabuments, the filted triangte gives the average of the measurements duming epinephrine infusion. Both the shomtest pacing intemal and the wave tength during rapid pacing are hardly affected. 
conduction by epinephrine resulted in a prolongation of the wave length of 55 \& during slow pacing, a lengthening of $40 \%$ during an early premature beat whereas at the highest pacing rate the wave length hardly was affected ( $3 \%$ ).

In figure 5.6 the mean value of the wave length during maximal pacing is plotted as a function of the shortest pacing interval during control (filled circles) and during epinephrine (filled squares). It is obvious that both wave length and minimal pacing interval only show minor changes.

\subsection{DISCUSSION}

Acetylcholine, either released fram nerve terminals after vagal stimulation or directly administered, causes a dramatic shortening of the refractory period of the atrium (Hoffman and Cranefield 1960). This is true both for a regullarly driven impulse (shortest $A_{1}-A_{2}$ interval), as well as for the refractory periad of a premature impulse (shortest $A_{2}-A_{3}$ interva1). The shortest possible pacing interval is also markedly decreased. The conduction velocity was not affected, with exception of the speed of propagation of the earliest premature impulse, which was somewhat faster. It was shown in this study that the length of the excitation wave is markedly shortened by the action of carbamylcholine. This shortening of the wave length was obserwed at all heart rates and at all degrees of prematurities. It is primarily caused by a shortening in the refractory period, while the conduction velocity is unaltered. In case of premature beats the shortening of the wave length is attenuated by a relative increase in conduction velocity.

Epinephrine and norepinephrine have variable effects on the electrophysiological properties of atrial muscle. A shortening of the action potential duration has been reported in canine and cat atria (Brooks et al. 1955), whereas in rats (Webb and Hollander 1956) and rabbits (Hoffman and Cramefield 1960) a prolongation was found. In the isolated rabbit atrium we observed a prolonglation of the refractory pertod with almost $50 \%$ at slow pacing rates. However at higher pacing rates this prolongation disappeared.

The effects of acetylcholine and epinephrine in relation to reentrant arrhythmías.

Fibrillation induced by rapid pacing in the in situ atrium usually terminates spontaneously within seconds. However during stimulation of the vagal nerve fibrillation becomes self-sustained and no spontaneous 
termination occurs. Also in the isolated canine atrium fibrillation is long lasting during acetylcholine administration and stops as soon as acetylcholline administration is interrupted. Our results show that acetylcholine may exert its ffbrillatory action by shortening of the wave length. This shortening of the length of the impulse will lead to a smaller dimension of circuitous pathways within the atrium and consequently to a larger number of wavelets being present simultaneously during fibrillation. This hypothesis is supported by the observation of Allessie et a1. (1977) that the size of the functionally determined reentrant circuit in an isolated rabbit atrium gets smaller when acetylcholine is added during the tachycardia. Thus, a decrease in the size of the reentrant circuits will make that more wavelets can be simultaneously present in the atrium making the chance of spontaneous termination sma11. In this study we found that the length of the excitation wave, being identical to the size of a functionally determined circuit, is markedly shortened by the action of carbarylcholine. The wave length during the highest pacing rate is shortened with $32 \%$, whereas the wave length of the earliest premature impulse is diminished with about $30 \%$. Cbviously such a shortening of the wave length with about $30 \%$ is sufficient to maintain atrial fibritlation.

The action of epinephrine on the atrial myocardium is less prominent. Allessie et al. (1977) showed that the cycle length of a reentry within an isolated piece of rabbit atrium was slightly prolonged by epinephrine. Although the rate of this fast reentrant rhythm slowed slightly, it remained regular and did not stop. The results in isolated strips of atrial nuocardium reported in this chapter, support these findings. Epinephrine did not affect the wave length during maximal pacing, whereas the shortest possible pacing interval increased about 7 msec. Although epinephrine did not influence the continuation of intra-atrial reentry, we might expect that induction of these reentrant circuits is more difficult during exposure to epinephrine. The wave length of the earliest premature beat was significantly prolonged over a wide range of pacing rates. This means that the premature impulse only can be trapped in a circuitous route, if a large arc of conduction block is present. Thus epinephrine would protect the atrial myocardium for the initiation of reentrant arrhythmias. However it must be realized that the effects of epinephrine on the ventricular myocardium are not only stronger but also qualitatively different. In general the refractory period of the ventricular 
myocardium is shortened under the influence of epinephrine (Hoffman and cranefield 1960). Whether epinephrine also changes the wave length in ventricular myocardium needs to be further investigated.

\section{REFERENCES}

Allessie MA, Bonke FIM, Lammers WJEP: The effects of Carbamylcholine, Adrenaline, Cuabain, Quinidine and Verapamil on Circus Movement Tachycardia in isolated segments of rabbit atrial mocardium.

In: Re-entrant Arrhythmias. Mechanisms and treatment. Edited by: H.E. Ku 1 bertus, MTP Press Limited Lancaster, 63-71, 1977.

Allessie MA, Lammers WJEP, Smeets ILRM, Bonke FIM, Hollen Su: Total mapping of atrial excitation during acetylcholine-induced atrial flutter and fibrillation in the isolated canine heart.

In: Atrial Fibrillation. Edited by Kulbertus HE, Olsson SB, Schlepper M, Publ Hassle, Molndal Sweden, 44-61, 1982.

Bonke FIM, Steinbeck G, Allessie MA, Mackaay AJC, Slenter VAJ: The electrophysiological effects of cardiac glycosides on the isolated sinus noce of the rabbit.

In: Narmal and abnormal conduction in the heart. Eds.: Paes de Carvalho A, Hoffman BF, Lieberman M. Futura Publishing Company, Mount Kisko, New York, 347-361; 1982.

Brooks ChMcC, Hoffman BF, Suckling EE, Orias O: Excitability of the heart. Grune and Stratton, New York, London, 1955.

Coume1 P, Attuel P, Lavaldee J, Flammang D, Leclerq J, S1ama R: Syndrome d'arythmie auriculaire d'origine vagale. Arch Mal Coeur, 71: 645-656, 1978. 
Hoffman BF, Cranefield PF: Electrophysiology of the heart.

McGraw-Hi11, New York, 1960, (Futura Publishing Company, Mount Kisco, New York 1976 (reprint edition)).

Lewis T, Drury AN, Bulger HA: Observations upon flutter and fibrillation. Part VII The effects of vagal stimulation.

Heart, 8: $141-169,1921$.

Lown B, Verrier RL: Meural activity and ventricular fibrillation. N Eng J Med, 294: 1165, 1971.

Moe GK, Abildskov JA: Atrial fibrillation as a self-sustaining arrhythmia independent of focal discharge. Am Heart J, 58: 59-70, 1959.

Rothberger $\mathrm{CJ}$, Winterberg $H$ : Uber das Elektrokardiogramm bei Flimmern der Vorhofe. Pfluegers Arch, 132: 233, 1910.

Webb $\mathfrak{u}$, Hollander PB: The action of acetylcholine and epinephrine on the cellular membrane potentials and contractility of rat atrium. Circ Res, 4: 332-336, 1956. 


\section{THE EFFECTS OF CHANGES IN EXTRACELLULAR POTASSIUM CONCENTRATION.}

It is well known that the risk of rhythm disturbances in the heart is increased if the extracellular potassium concentration is either too low or too high. Hyperkalemia results in a progressive slowing of conduction and a decrease in excitability. Hypokalemia precipitates ectopic beats and rhythms due to enhanced automatic activity in quiescent Purkinje fibers (Vassalle 1965, Gettes and Surawicz 1968). It was reported by Saito et al. (1978) that triggered activity could be elicited in isolated rabbit. atrium in a low-potassium environment. Besides such arrhythmias based on abnormal impulse formation. hypokalemia may also facilitate reentry. Using detailed electrophysiological mapping, Lammers et al. (1981) showed that intra-atrial reentry was the underlying mechanism of tachy-arrhythmias during exposure to low potassium. Perfusion of isolated hearts with potassium-deficient solutions produces ventricular fibrillation (Grumbach et al. 1954, Surawicz et al. 1959). In patients with severe hypokalemia, serious ventricular tachy-arrhythmias, including wentricular tachycardia and fibrillation have been reported (Curry et al. 1976).

In the present study we investigated whether the increased incidence of reentrant arrhythmias during hypokalemia is related to changes in the wave length. We measured the length of the excitation wave in the atrium at different extracellular potassium concentrations both during slow and rapid pacing. It could be shown that the wave length is significantly shortened when the heart is exposed to low potassium. On the other hand moderate hyperkalemia did not affect the length of the excitation wave, whereas a significant prolongation was observed in severe hyperkalemia. These abservations are in agreement with the hypothesis that shortening of the wave length of the cardiac impuise favors the occurrence of intra-myocardial reentry.

\subsection{EXPERIMENTAL PROTOCOL.}

The potassium concentration in the surperfusing solution was varied stepwise between 2.0 and $9.0 \mathrm{mM}$ in 13 experiments. The heart was allowed to equilibrate at each potassium concentration for at least one hour. A typical sequence of changes in potas;ium concentrations is as follows: $4.5 \mathrm{~mm}, 2.0$ 
$\mathrm{mM}, 4.5 \mathrm{mM}, 7.0 \mathrm{~mm}, 4.5 \mathrm{mM}, 9.0 \mathrm{mM}$. At each potassium concentration the wave length at a rate of $2 \mathrm{~Hz}$ and at the highest pacing rate were measured in all preparations. In addftion the wave length was measured in another 13 experiments at a potassium concentration of $5.6 \mathrm{mM}$, but in these experiments potassium concentration was not changed during the experiment.

statistical analysis was done using the student-t test. The results at the different potassium concentrations were compared with the values at 4.5 min.

\subsection{RESULTS.}

The effects of potassium during slow pacing.

In table 6.1 and figure 6.1 the mean values and standard deviation of refractory period, conduction velocity and wave length during slow pacing (2 $\mathrm{Hz}$ ) are plotted at different potassium concentrations.

The refractory period at this slow rate is clearly affected by changes in the potassium concentration of the superfusing solution. Lowering the potassium concentration fram 4.5 to $2.0 \mathrm{mM}$ caused a significant shortening of

\section{TABLE 6. I}

\section{THE EFFECTS OF POTASSIUM DURING A SLOW RATE. $(2 \mathrm{~Hz})$}

\begin{tabular}{|c|c|c|c|c|}
\hline $\begin{array}{l}\text { Potassium } \\
\text { concen- } \\
\text { tration }\end{array}$ & N & $\begin{array}{l}\text { Refractory } \\
\text { period }\end{array}$ & $\begin{array}{l}\text { conduction } \\
\text { velocity }\end{array}$ & $\begin{array}{l}\text { wave length } \\
\text { of a basic } \\
\text { impulse }\end{array}$ \\
\hline $\mathrm{mM}$ & & ms & $\mathrm{cm} / \mathrm{sec}$ & mim \\
\hline 2.0 & 13 & $49.6 \pm 7.0$ & ${ }_{* \star *} 1.7 \pm 9.2$ & ${ }_{\star \star \star}^{24.8} \pm 6.6$ \\
\hline 4.5 & 13 & $69.8 \pm 10.0$ & $60.2 \pm 10.1$ & $41.8 \pm 9.1$ \\
\hline 5.6 & 13 & - & $\begin{array}{l}62.1 \pm 7.0 \\
\mathrm{~ns}\end{array}$ & - \\
\hline 7.0 & 9 & $76.0 \pm 10.3$ & $\underset{* \star \star}{50.9} \pm 8.3$ & $\begin{array}{l}38.9 \pm 7.7 \\
\text { ns }\end{array}$ \\
\hline 9.0 & 8 & - & $\underset{* \star *}{33.0} \pm 10.2$ & - \\
\hline
\end{tabular}


the refractory period from 70 to $50 \mathrm{msec}$. On the other hand an elevation of the potassium concentration to $7.0 \mathrm{~mm}$ resulted in a significant prolongation from 70 to $76 \mathrm{msec}$.

The shortening of the refractory period at low potassium was accompanied by a depression in conduction velocity from 60 to $52 \mathrm{~cm} / \mathrm{sec}$. At a potassium concentration of $5.6 \mathrm{mM}$ the speed of propagation was identical to the value at $4.5 \mathrm{~mm}$, but a significant slowing of the conduction from $60 \mathrm{ta} 51 \mathrm{~cm} / \mathrm{sec}$ was found at $7.0 \mathrm{mM}$. Further elevation of the potassium concentration to 9.0 $\mathrm{mM}$ resulted in a marked depression of the conduction velocity to $33 \mathrm{~cm} / \mathrm{sec}$.

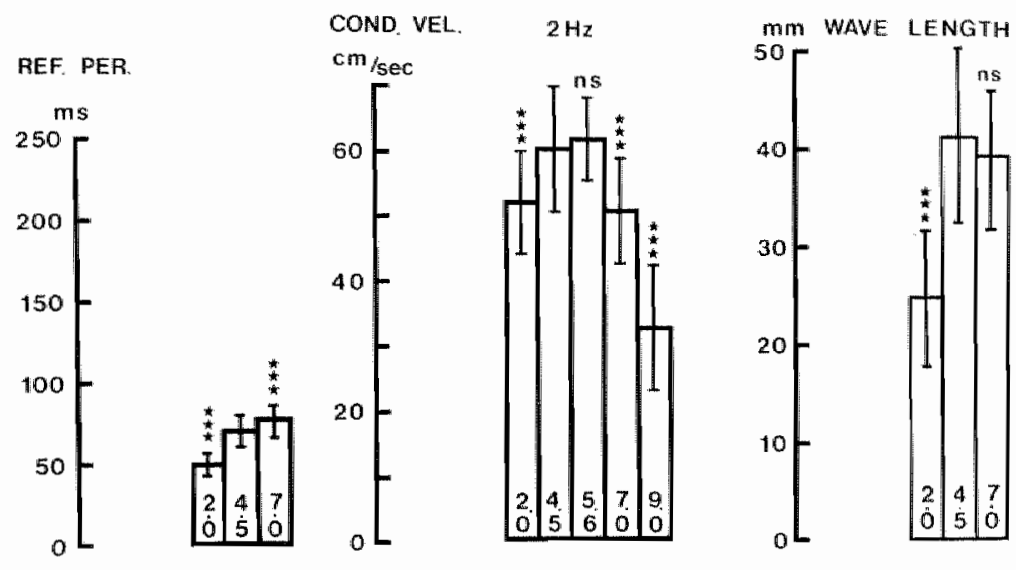

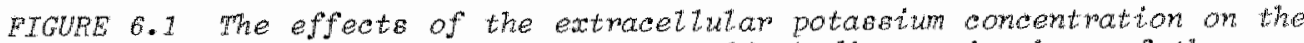
wave length during stow pacing (2 $\mathrm{Hz}$. A biock diagram ie show of the meam values of refractomy period, conduction velocity and wave length at different potasium concentrations, as indicated at the bottom of the bars. whe refractory period is shortest at the touest potassium concentration $(2.0 \mathrm{~m} / \mathrm{l})$. At increasing extracellutar potassim concentrations the refractomess protonged progressively. However the conduction velooity showed a biphasia pattem. The speed of propagation was highest at a potaseium range of 4.5 to 5. 6 m, whereas a depression was noted both at Low potassium coneantrations (2.0 mill and at high potassium tevels 17.0 and 9.0 mil. Due to both the slowing in conduction and the shomening of mefmatory period, the wave tength was significantly ahomened if the potaseium concentration wa lowered from 4.5 to 2.0 $\mathrm{m}$. An inerease of the potassium concentration from 4.5 to $7.0 \mathrm{~m}$ did not cause a significant change of the wave zength. Statistical anatyeis was done using the student-t test ins = not signifieant, $* *=0(0.001)$. 
Obviously the propagation of the electrical impulse in isolated rabbit atrium is optimal at potassium concentrations between 4.0 and $6.0 \mathrm{mM}$. Both at lower and higher concentrations conduction is depressed.

The changes in electrophysiological properties at low extracellular potassium resulted in a shortening of the wave length from 42 to $25 \mathrm{~mm}$. This decrease in wave length during slow pacing $(2 \mathrm{~Hz})$ with $40 \%$ was caused both by a shortening of the refractory period and by a decrease of conduction velocity. No change in the length of the excitation wave was found when the potassium concentration was increased from 4.5 to $7.0 \mathrm{mM}$. At this concentration the effect of depressed conduction on the wave length was completely neutralized by a concomitant prolongation in refractory period.

The effects of potassium during rapid pacing.

The effects of different extracellular potassium concentrations on conduction velocity and wave length during maximal pacing are illustrated in figure 6.2. After a control period of about 1 hour, during which the electrophysiological properties were constant we switched to a superfusing solution containing $2.0 \mathrm{mM}$ potassium. Analogous to the shortening of the refractory period during slow pacing, also the shortest possible pacing interval decreased considerably in hypokalemia. Because the conduction velocity at the highest pacing rate was not different from control, the wave length was shortened proportional to the decrease in minimum pacing interval. After switching back to the superfusing solution containing $4.5 \mathrm{mM}$ potassium all values returned to their control values. Increasing the potassium concentration to $7.0 \mathrm{mM}$ caused a s7ight prolongation of the shortest possible pacing interval, whereas the conduction was depressed. Because these changes exerted an opposite effect on the wave length, the length of the excitation wave was unchanged. After return to control the potassium concentration was further elevated to $9.0 \mathrm{mM}$. At this concentration we observed strong changes in the electrophysiological properties of the myocardium. The shortest possible pacing interval rapidly prolonged from about 70 to $125,160 \mathrm{msec}$ and even longer intervals. Also the conduction was depressed markedly, reaching a minimum value after about 20 minutes. As a result at this high potassium level the wave length prolonged markedly, because the effect of the prolongation of the shortest possible pacing interval overruled the depression of conduction velocity. No complete washout 


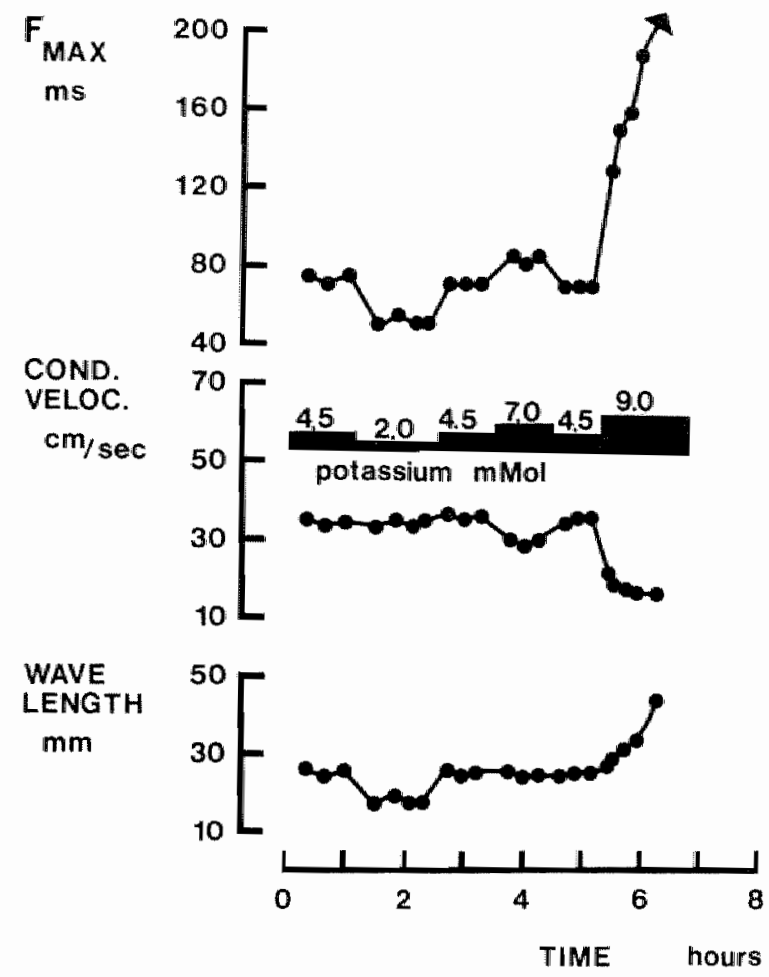

FIGURE 6.2 The effects of the extnaceltular potaswiwn concentration on the shortest poseible pacing interval, the conduction velocity and the wave lengtin. Lowering of the potassium concentration from 4.5 to 2.0 mu caued a marked shortening of the minimal pacing intemat, whereas the conduction velocity at this rate was not affected. As a consequence the wave terigth ehortened proportional to the shortest pacting intemal. When the potaseivm concentration was raised to $7.0 \mathrm{~m}$, the shortest postibie pacing interval protonged and simultaneously propagation was stowed. However the 2 ength of the excitation wave was unchanged. At a potaseitum zevel of 9.0 m the shortest poseible pacing intemat protonged markedly. Since this prolongation was larger than the concomitant depression in conduction, the tength of the excitation wave prolonged. 
of the effects of this potassium concentration could be achieved within 30-60 minutes.

In table 6.11 and figure 6.3 the mean values and standard deviation of the conduction velocity and wave length during the highest pacing rate are given for all experiments.

The preparation can be paced fastest at a potassium concentration of 2.0 $\mathrm{mM}$. An increase in potassium concentration caused a progressive prolongation of the shortest possible pacing interval from 66 to 78,86 , and $97 \mathrm{msec}$ at $2.0,4.5,5.6$, and $7.0 \mathrm{mM}$ respectively. At $9.0 \mathrm{mM}$ the shortest possible pacing interval was even prolonged to $235 \mathrm{msec}$.

In contrast with our findings during slow pacing, during rapid pacing propagation was not depressed at a low potassium concentration. However a significant lowering of conduction velocity from $37 \mathrm{~cm} / \mathrm{sec}$ to 30 and 21 $\mathrm{cm} / \mathrm{sec}$ was found at 7.0 and $9.0 \mathrm{mM}$ respectively.

During rapid pacing lowering the potassium concentration caused a shortening of the wave length from 29 to $24 \mathrm{~mm}(17 \%)$ and this was solely based on the fact that the preparation could be paced at a higher rate compared to control. No change in the length of the excitation wave was

\section{TABLE 6. II}

THE EFFECTS OF POTASSIUM DUR ING RAPID PACING

\begin{tabular}{|c|c|c|c|c|}
\hline $\begin{array}{l}\text { Potassium } \\
\text { concen- } \\
\text { tration }\end{array}$ & $\mathbb{N}$ & $\begin{array}{l}\text { Interval } \\
\text { Fimax }\end{array}$ & $\begin{array}{l}\text { Conduction } \\
\text { velocity } \\
\text { Fmax }\end{array}$ & $\begin{array}{l}\text { Wave length } \\
F_{\max }\end{array}$ \\
\hline $\mathrm{mM}$ & & ms & $\mathrm{cm} / \mathrm{sec}$ & $\mathrm{mm}$ \\
\hline 2.0 & 13 & $\underset{* *}{65.8} \pm 13.4$ & $\begin{array}{l}36.6 \pm 6.3 \\
\text { ns }\end{array}$ & $23.7 \pm 4.3$ \\
\hline 4.5 & 13 & $77.9 \pm 7.6$ & $37.0 \pm 6.1$ & $28.7 \pm 4.4$ \\
\hline 5.6 & 13 & ${ }_{*}^{85.9} \pm 9.5$ & $\begin{array}{l}34.5 \pm 4.5 \\
\text { ms }\end{array}$ & $\begin{array}{l}29.5+4.4 \\
n s\end{array}$ \\
\hline 7.0 & 9 & $\underset{\star * *}{96.7} \pm 10.3$ & ${ }_{\star \pi \star}^{30.0} \pm 3.9$ & $\begin{array}{l}28.8 \pm 4.8 \\
\text { ns }\end{array}$ \\
\hline 9.0 & 8 & $235.6 \pm 131.9$ & $\underset{\star \star \star *}{20.9} \pm 5.0$ & $45.5 \pm 19.9$ \\
\hline $\begin{array}{ll}* & =p<0.05 \\
* * & =p<0.01 \\
* * * & =p<0.001\end{array}$ & & & & \\
\hline
\end{tabular}


observed when the potassium concentration was increased to 5.6 and $7.0 \mathrm{mM}$. At these concentrations the effect of the prolongation of the shortest possible pacing interval is counteracted by an equal depression of conduction. However at a potassium concentration of $9.0 \mathrm{mM}$, the prolongation of the shortest possible pacing interval becomes larger than the depression in conduction velocity. Now the wave length is prolonged from 29 to $46 \mathrm{~mm}$.

In figure 6.4 the relation between the wave length and the shortest possible pacing interval is given at different potassium concentrations. It is clear that at $2.0 \mathrm{mM}$ both the minimum cycle length and the wave length are shortened, as indicated by the arrow pointing to the left and dowmards. At 7.0 $\mathrm{mm}$ the arrow is horizontal, indicating that the prolongation of the shortest possible pacing interval did not affect the wave length. However at
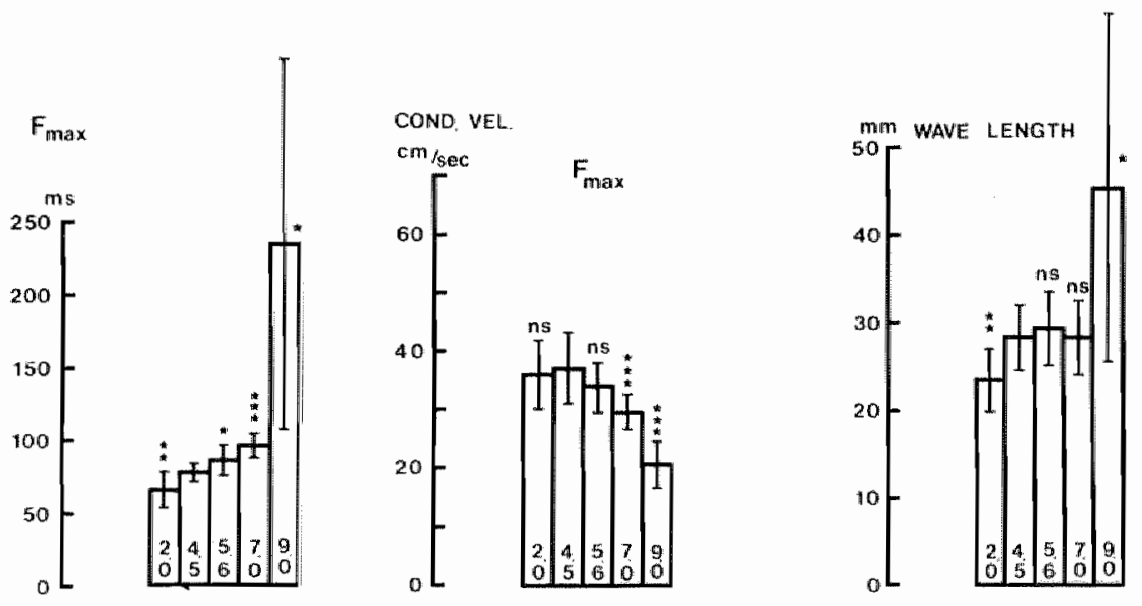

EIGURE 6.3 The wave length auming rapid pacing at different extracellutar potasetum concentrations. The mean values of the shortest possible pacing interval, conduction velocity and wave tength are plotted as a block diagram. Lowering the extracelluzar potassium level from 4.5 to $2.0 \mathrm{mM}$ caused a bignificant shortening of the minimat pacing intervat, whereas a elevation of the potassium concentration to $5.6,7.0,9.0 \mathrm{ml}$ caused a significant prolongation of the shortest pacing intemal. The conduction velocity at the highest rate was not changed at potaseium concentratione between 2.0 and 5.6 m. A significant slowing wa obsemed at 7.0 and $9.0 \mathrm{~m}$. The length of the excitation wave was constant at potassium qevels between 4.5 and 7.0 mM, whereas at $2.0 \mathrm{mH}$ a sigmificant shomtening and at $9.0 \mathrm{~m}$ a aignificant prolongation was abserved. 


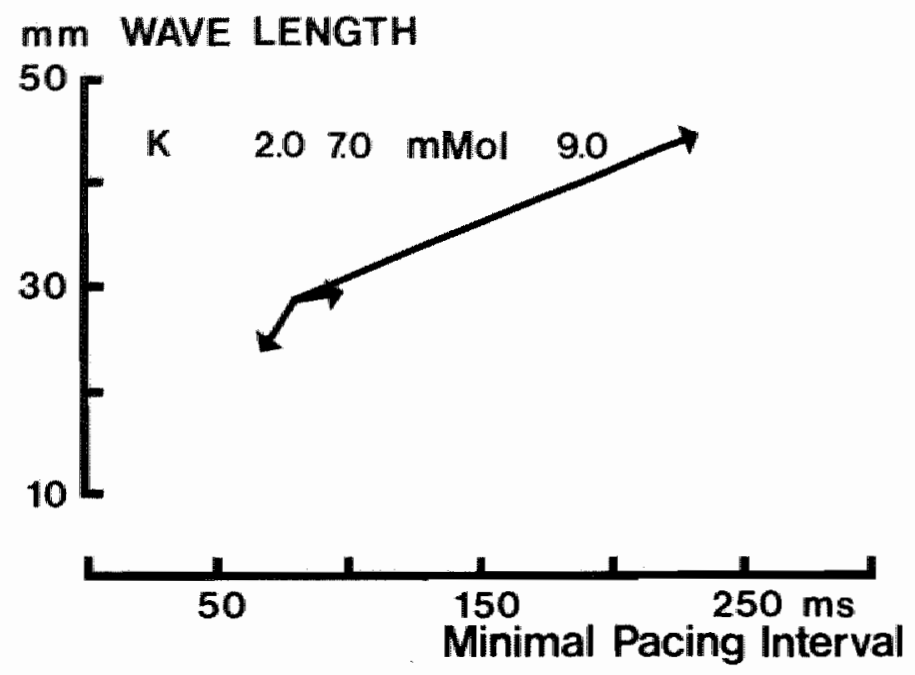

FIGURE 6.4 The relation between wave length and minimat pacing interval $(=$ cycle length during fastest ratel at different potasaizom concentrations. The wave length at the shortest posible pacing interval is ptotted as a function of the shomtest pacing interval at potaseium concentration of 2.0 , 7.0 and $9.0 \mathrm{~m}$. At $2.0 \mathrm{mM}$ the shortening of the pacing interval was accompanied by a shortering of the wave tength, as indicated by the arrow pointing to the teft and downurase. At $7.0 \mathrm{~m}$ the arrow points almost horizontally to the might, indicating that the wave zength was hardly changed atthough the preparation could not be paced as fast as at a concentration of $4.5 \mathrm{mM}$. Increasing the potassium concetration to $9.0 \mathrm{~mW}$ caused a protongation of both the wave length and the shomtest possible pacing interval.

$9.0 \mathrm{mM}$ the wave length is also prolonged, although still to a lesser extent than the shortest possible pacing interval.

\subsection{DISCUSSION}

The effects of low potassium on refractarimess and conduction velocity. Both Teiger et al. (1969) and Lammers et al. (1981) showed that in the rabbit atrium the refractory period was shortened in low potassium. The shortening of the functional refractory period with $29 \%$ during slow pacing (2 $\mathrm{Hz}$ ) and during fast pacing with $17 \%$ in our experiments is in agreement with these references. At low extracellular potassium concentration the conduction velocity is lowered (Antoni and Zerweck 1967). In our experiments the 
conduction velocity decreased significantly during slow drive but was not altered during fast pacing; in the latter case conduction velocity even did not change although the maximum driving rate was higher, namely 66 msec versus $78 \mathrm{msec}$ as shortest possible driving interval (a change of about $15 \%)$.

The effects of high potassium on refractoriness and conduction velocity. If the potassium concentration is increased from 4.5 to $7.0 \mathrm{mM}$ the conduction is slowed with about $15 \%$ both during slow and rapid pacing. This is in agreement with the literature as presented by Hoffmann and Cranefield (1960), Dominiguez and Fozzard (1970) and Sperelakis et al. (1970). We found in our experiments an increase of the functional refractory period during slow pacing (about $10 \%$ ) and more outspoken during fast pacing (more than $20 \%$ ) if the potassium concentration was increased from 4.5 to $7.0 \mathrm{~mm}$. If the potassium concentration was increased to $9.0 \mathrm{mM}$ the effects on conduction and refractoriness are more pronounced.

Changes in potassium concentration and wave length of the impulse.

Since in our experiments the reduced conduction velocity is counteracted by the increased refractoriness, there is almost no change in wave length in case of changes of the extracellular potassium concentration between 4.5 and $7.0 \mathrm{mM}$. However at higher potassium concentrations refractoriness increased considerably and this caused an outspoken increase of the length of the excitation wave. On the other hand a reduction of the extracellular potassium concentration to $2.0 \mathrm{~mm}$ induces a clear reduction of the wave length of the impulse.

Potassium and reentrant arrhythmias.

According to the concept of Allessie et al. (1977a) the size of a functionally determined circuit should be equal to the length of the excitation wave. We may expect that inttiation of intra-atrial and intra-ventricular reentry will be facilitated by lowering the extracellular potassium concentration, since under these conditions the wave length of the impulse is considerabiy shortened. Recently Lammers and coworkers (1981) have shown that initiation of reentry within the atrium was indeed highly favored 
by lowering the potassium concentration of the superfusing fluid to $2.0 \mathrm{~m}$. It has been postulated that low extracellular potassium concentrations increases the inhomogeneity in refractoriness. Gettes and Surawicz (1968) have shown that hypokalemia increases the difference in action potential duration of the Purkinje and ventricular fibers. The increased sensitivity of patients with severe hypokalemia to serious ventricular tachy-arrhythmias like ventricular tachycardia and fibrillation may be due to a combination of increased inhomogeneity in excitability and a marked shortening of the length of the excitation wave.

If the potassium concentration was raised moderately $(7.0 \mathrm{mM})$, we did not find a difference in the length of the excitation wave compared to contral. This indicates that initiation or termination of a reentrant circuit in the atrium is not influenced by moderate hyperkalemia. However a slowing in rate of an existing reentrant rhythm can be expected because the refractory period and the shortest possible pacing interval were both prolonged at $7.0 \mathrm{mM}$. This is in agreement with the observation that atrial flutter and fibrillation do not revert to sinus rhythm after potassium administration, probably because the dosage used in the therapy of the arrhythmia does not reach the apropriate concentration. Clinical and labaratory observations suggest that defibrillation of the atria can be expected when the potassium concentration exceeds $7.0 \mathrm{mM}$ (Brooks et al. 1955, Bettinger et a1. 1956, Burn et a1. 1956). Also in patients with chronic atrial fibrillation, defibrillation has been reported by inducing severe hyperkalemia (Brown et al. 1951). The observation that during severe hyperkalemia the length of the excitation wave is markediy prolonged gives again a good explanation for this clinical experience. Our studies on the electrophysiological effects of changes in the extracellular potassium concentrations support the concept that changes in the wave length of the impulse can be used as a marker for the risk of intra-myocardial reentry. 


\section{REFERENCES}

Allessie MA, Bonke FIM, Schopman FJG: Circus movement in rabbit atrial muscle as a mechanism of tachycardia. III. The "leading circle" concept: A new model of circus movement in cardiac tissue without the involvement of an anatomic obstacle.

Circ Res, 41: 9-18, 1977.

Antoni $H$, Zerweck $T$ : Besitzen die sympathischen Ubertragersstoffe einen directe Einfluss auf die Leitungsgeschwindigkeit des Sauegetiermyokards. Elektrophysiologische Untersuchungen an isolierten Papillarmuskeln und Purkinjefaden des Rhesus Affen. Pfluegers Arch, 293: 310-330, 1967.

Bettinger JC, Surawicz B, Eryfogle JW, Anderson BN, Bellet 5 : The effect of intravenous administration of potassium chloride on ectopic rhythms, ectopic beats and disturbances in A-V conduction.

An J Med, 21: 521-533, 1956.

Brooks ChMCC, Hoffman BF, Suckling EE, Orias 0: Excitability of the heart. Grune and Stratton, New York, London, 1955.

Brown H, Tanner GL, Hecht HH: Effect of potassium salts in subjects with heart disease.

J Lab C1 in Med, 37: 506-514, 1951.

Burn JW, Gunning AJ, Walker JM: The effects of $\mathrm{KCl}$ on atrial fibrillation caused by acetylcholine.

Circ Res, 4: 288-293, 1956.

Curry P, Fitchett D, Stubbs W, Krikler D: Ventricular arrhythmias and hypokalemia.

Lancet, 2: 231-233, 1976.

Dominguez G, Fozzard HA: Influence of extracellular $\mathrm{K}^{4-}$-concentration on cable properties and excitability of sheep cardiac Purkinje fibers.

Circ Res, 26: 565-574, 1970.

Gettes $R$, Surawicz B: Effects of low and high concentrations of potassium on the simultaneousiy recorded Purkinje and ventricular action potentials of the perfused pig moderator band.

Circ Res, 23: 717-729, 1968. 
Grumbach L, Howard J, Merrill J: Factors related to the initiation of ventricular fibrillation in the isolated heart: Effect of calcium and potassium.

Circ Res, 2: 452-459, 1954.

Hoffman BF, Cranefield PF: Electrophysiology of the heart.

McGraw-Hil1, New York, 1960, (Futura Publishing Company, Mount Kisco, New York 1976 (reprint edition)).

Lammers WJEP, Bonke FIM, Allessie MA: Arrhythmien wahrend Hypoxie und Hypokalaemie am fsolierten Herzen.

In: Ventriculaere Herzrhythmusstorungen. Ed.: Luederitz,B. Springer Verlag, New York, Heidelberg, Berlin, 59-69, 1981.

Saito T, Otoguro M, Matsubara T: Electrophysiologicall studies on the mechanism of electrically induced sustained rhythmic activity in the rabbit right atrium.

Circ Res, 42: 199-206, 1978.

Sperelakis N, Mayer G, MacDonald R: Velocity of propagation in vertebrate cardiac muscies as functions of tonicity and $\mathrm{K}^{+}{ }_{0}$.

Am d Physiol, 219: 952-963, 1970.

Surawicz B, Lepeschkin HC, Henlich HC, Hoffman BF: Effects of potassium and calcium deficiency on the monophasic action potential, electrocardiogram and contractility of isolated rabbit hearts.

Am J Physiol, 196 (6): 1302-1307, 1959.

Teiger D, Scheider F, Farah A: The effects of sodium ion and rate of stimulation on the refractory period of isolated rabbit atrial muscle.

$J$ Pharmacol Exp Ther, 155 (1): 58-68, 1967.

Vassalle M: Cardiac pacemaker potentials at different extra-and intracellular potassium concentrations. Anl J Physiol, 208: 770-775, 1965. 
7. THE EFFECTS OF LIDOCAINE.

The local anesthetic lidocaine is an antiarrhythmic drug which is especially useful in the treatment of acute life threatening arrhythmias. It is used to treat ventricular arrhythmias in the setting of acute myocardial infarction to prevent ventricular fibrillation and sudden death (Lie et al. 1974). Lidocaine is also used in the treatment of arrhythmias caused by digitalis intoxication, and arrhythmias occurring after open heart surgery (Bigger and hoffmann 1980). However lidocaine is less effective in the treatment of supraventricular rhythm disturbances. Although Danahy and Aronow (1978) reported a slight slowing of the rate of atrial flutter by lidocaine, it seldomly reverts atrial flutter and fibrillation to sinus rhythm.

In this chapter the effects of different dosages of lidocaine are studied on conduction velocity and refractoriness of the electrical impulse in the atrium. From these electrophysiologial properties the wave length was calculated. Special attention was paid to changes in the electrophysiological properties at high heart rate. It was speculated that in the light of the poor antifibrillatory properties of iddocaine in the atrium, it should not alter the length of the excitation wave.

\subsection{EXPERIMENTAL PROTOCOL}

To study the effect of lidocaine we selected three different dosages: 2, 5 and $10 \times 10^{-6} \mathrm{~g} / \mathrm{ml}$. The concentrations of 2 and $5 \times 10^{-6} \mathrm{~g} / \mathrm{ml}$ are within the range of normal therapeutic plasma levels $\left(1\right.$ to $5 \times 10^{-6} \mathrm{~g} / \mathrm{m} 1$, Hoffman and Bigger 1971, Koch-Weser 1975). The highest concentration of $10 \times 10^{-6} \mathrm{~g} / \mathrm{ml}$ has to be considered as a toxic dosage. After administration of lidocaline to the perfusion solution the electrophysiological effects are attained within 10 minutes. After three reproducable measurements were made the concentration of lidocaine in the superfusing fluid was increased, without an intermittent return to control. After the highest concentration has been reached, lidocaine was washed out. The effects of lidocaine were completely reversible. All electrophysiologic parameters returned to control within 30 minutes of washout with normal Tyrode solution. The effects of lidocaine were studied in 18 experiments. 


\title{
7.2 RESULTS.
}

The effects of lidocaine during slow pacing.

In table 7.1 the effects of different lidocaine concentrations on refractoriness, conduction velocity and wave length are given during slow pacing.

At a concentration of $2 \times 10^{-6} \mathrm{~g} / \mathrm{ml}$ the refractory period is hardly affected ( 78 versus $75 \mathrm{msec}$ ). However at higher concentrations of lidocaine recovery of excitability is clearly delayed. A prolongation to 99 and 158 msec is observed at concentrations of $5 \times$ and $10 \times 10^{-6} \mathrm{~g} / \mathrm{m} 1$.

Simultameously with this prolangation of the refractory period, the

\author{
TABLE 7.I
}

THE EFFECTS OF LIDOCAINE DURING SLOW PACING (2HZ)

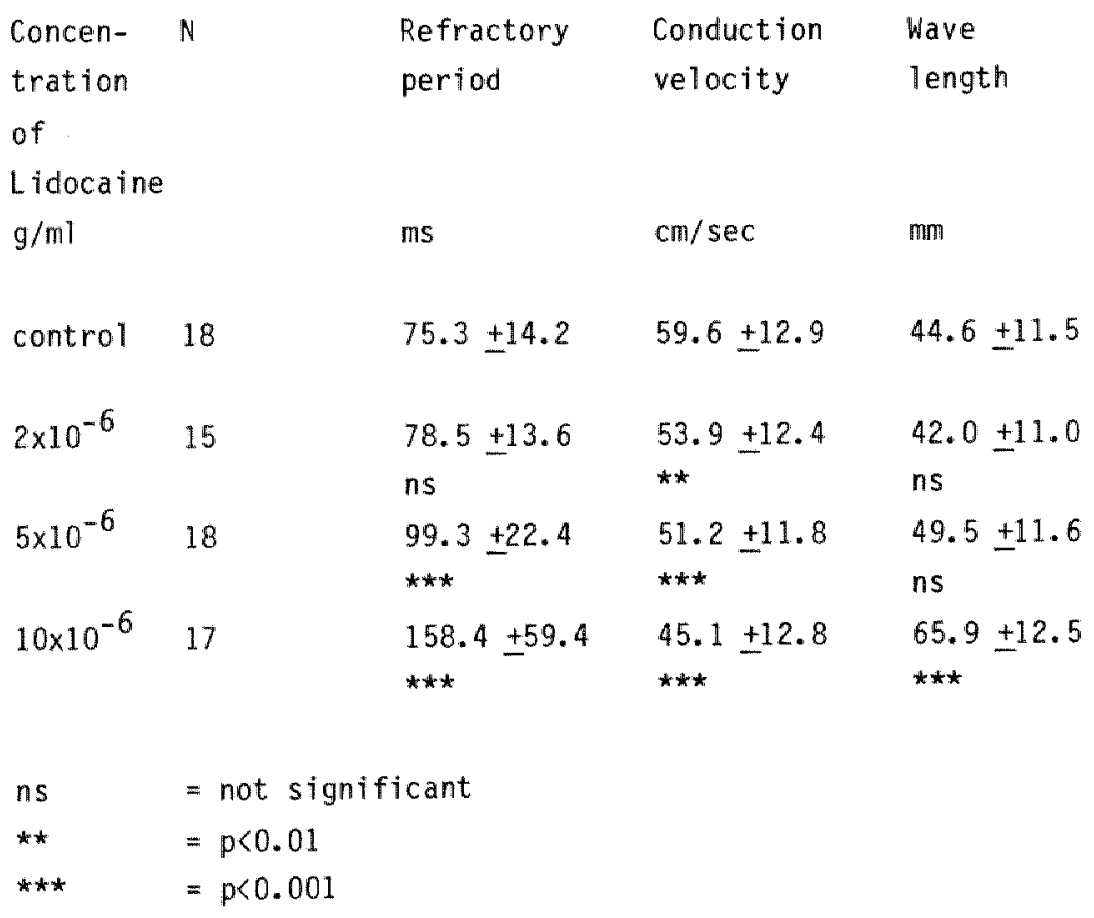


conduction velocity is depressed, being lawered from $60 \mathrm{~cm} / \mathrm{sec}$ to 54 , 51 and $45 \mathrm{~cm} / \mathrm{sec}$ at $2 x, 5 \times$ and $10 \times 10^{-6} \mathrm{~g} / \mathrm{ml}$ lidocaime.

The length of the excitation wave at a pacing rate of $2 \mathrm{~Hz}$ was not significantly changed at "therapeutic" lidocaine concentrations. However a significant prolongation of the wave length was found at a concentration of $10 \times 10^{-6} \mathrm{~g} / \mathrm{m} 7$. This was caused by the fact that at this high level of lidocaine the prolongation of the refractory period clearly exceeded the slowing in conduction. As a result the length of the depolarization wave at a regular rhythm of $2 \mathrm{~Hz}$ prolonged from 45 to $66 \mathrm{~mm}$.

\section{The effects of 7 idocaine during rapid pacing.}

In figure 7.1 an example of the effects of lidocaine on conduction and wave length during maximum pacing is given. After a control period of one hour during which the measured parameters were constant, lidocaine in a concentration of $2 \times 10^{-6} \mathrm{~g} / \mathrm{ml}$ was administered to the superfusing solution. At this concentration the shortest possible pacing interval slight ly prolonged. Increasing the lidocaine concentration to $5 \times 10^{-6}$ or $10 \times 10^{-6} \mathrm{~g} / \mathrm{m} 1$ caused a progressive prolongation of the shortest possible pacing interval. Simultaneously the conduction velocity during the maximum pacing rate was depressed. The wave length remained unchanged or was only silightly prolonged. In table 7. I t the effects of lidocaine on the shortest possible pacing interval, the conduction velocity and the wave length during rapid pacing are summarized.

If we compare table 7.1 and $7 . \mathbb{I}$, it is clear that the effects of lidocaine as seen during slow rate are exaggerated if the atrium is paced rapidly. Already at a concentration of $2 \times 10^{-6} \mathrm{~g} / \mathrm{m} 1$ the shortest possible pacing interval was prolonged from 86 to $105 \mathrm{msec}$. A further prolongation to 130 and $175 \mathrm{msec}$ was observed at lidocaine concentrations of 5 and $10 \times 10^{-6}$ $\mathrm{g} / \mathrm{m}$. The speed of propagation at the highest pacing rate was slowed from 32 $\mathrm{cm} / \mathrm{sec}$ to 24,21 , and $19 \mathrm{~cm} / \mathrm{sec}$ at $2 x, 5 x, 10 \times 10^{-6} \mathrm{~g} / \mathrm{ml}$ of 1 idocaine.

The length of the excitation wave during maximal pacing was not significantly influenced by lidocaine. At "therapeutic" Tidocaline concentrations the wave length was 24 and 26 man, compared to 27 mm during control. At these concentrations the effect of slawing of conduction on the wave length was completely neutralized by the concomitant prolongation of the minimal pacing interval. Although not statistically significant at "toxic" 


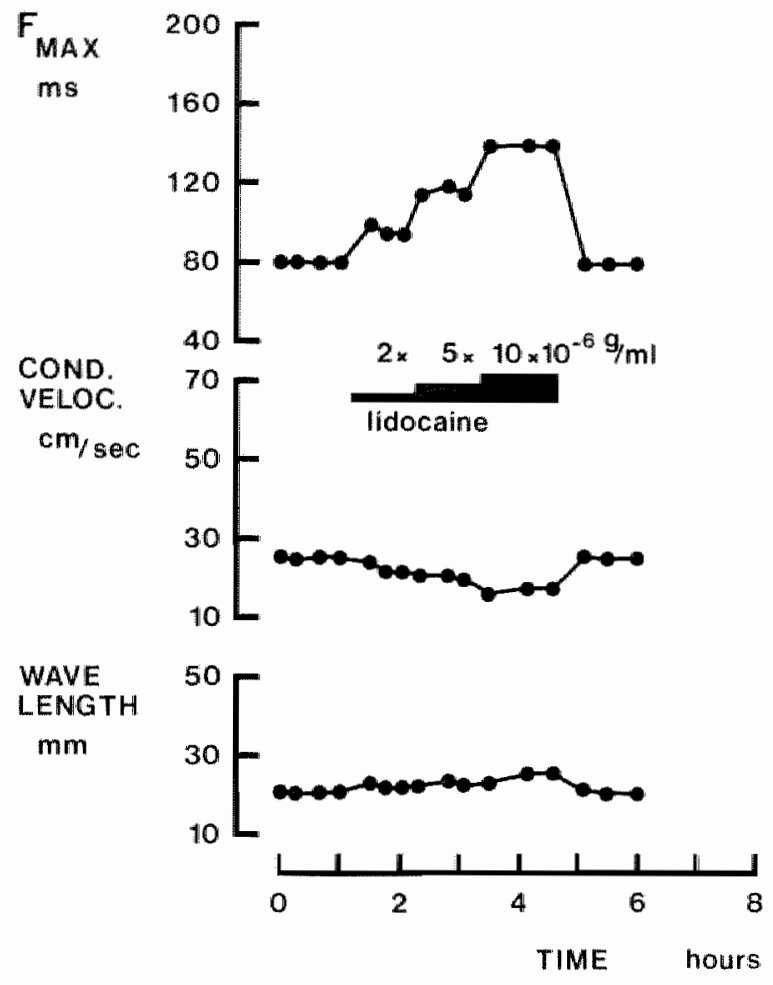

FICURE 7.1 The effects of lidocatne on the shortest possible pacing interval, conduction velocity and wave length. The shortest possible pacing interal (top panel) is protonged progressively at increasing lidocaine concentrations whemeas simultaneously the conduction velocity at this rate (middle panel) is depressed during increasing lidocaine concentrations. As a consequence the length of the excitatiop wave at the highest pacing rate remained almost unchonged at 2 and $5 \times 10^{-5} \mathrm{~g} / \mathrm{mt}$. At the highest concentration $\left(10 \times 10^{-6} \mathrm{~g} / \mathrm{mi}\right)$ a olight prolongation of the wate length was observed. Wash out of alt effects of tidocaime was achieved within $30 \mathrm{~min}$. 
TABLE 7. II

\section{THE EFFECTS OF LIDOCAINE DURING RAPID PACING}

\begin{tabular}{|c|c|c|c|c|}
\hline $\begin{array}{l}\text { concen- } \\
\text { tration }\end{array}$ & N & $\begin{array}{l}\text { Interval } \\
\text { of }\end{array}$ & $\begin{array}{l}\text { Conduction } \\
\text { velocity }\end{array}$ & $\begin{array}{l}\text { Wave } \\
\text { length }\end{array}$ \\
\hline of & & Fmax & at $F \max$ & at Fmax \\
\hline \multicolumn{5}{|c|}{ Lidocaine } \\
\hline $\mathrm{g} / \mathrm{ml}$ & & ms & $\mathrm{cm} / \mathrm{sec}$ & $\mathrm{mm}$ \\
\hline control & 18 & $86.4 \pm 15.7$ & $31.8 \pm 7.3$ & $26.7 \pm 5.4$ \\
\hline $2 \times 10^{-6}$ & 15 & $\begin{array}{l}105.2 \pm 15.2 \\
\star \star \star\end{array}$ & $23.8 \pm 5.6$ & $\begin{array}{l}24.5 \pm 4.5 \\
\mathrm{~ns}\end{array}$ \\
\hline $5 \times 10^{-6}$ & 18 & $\begin{array}{l}130.3 \pm 24.3 \\
\star \star \star\end{array}$ & $\begin{array}{l}20.8 \pm 5.7 \\
\star \star \star\end{array}$ & $\begin{array}{l}26.5 \pm 6.5 \\
\mathrm{~ns}\end{array}$ \\
\hline $10 \times 10^{-6}$ & 17 & $\begin{array}{l}175.7 \pm 52.9 \\
\star \star \star\end{array}$ & $18.8 \pm 4.3$ & $\begin{array}{l}32.1 \pm 10.0 \\
\mathrm{~ns}\end{array}$ \\
\hline 015 & $=$ not & cant & & \\
\hline ** & $=p<0$ & & & \\
\hline
\end{tabular}

lidocaine concentration $\left(10 \times 10^{-6} \mathrm{~g} / \mathrm{ml}\right)$ the prolongation of the shortest possible pacing interval exceeded the slowing in conduction, resulting in a slight prolongation of the wave 7 ength to $32 \mathrm{~mm}$.

In figure 7.2 the wave length at the highest pacing rate (ordinate) is plotted as a function of the shortest possible pacing interval (abscissa) at different lidocaine concentrations. At low concentrations of lidocaine the arrow points slightly downwards, indicating that the prolongation of the shortest possible pacing interval is accompanied by a slight shortening of the wave length. At high therapeutic lidocaine concentrations the arrow is pointing almost horizontally. This means that although the shortest possible pacing interval is markediy prolonged, the length of the excitation wave remains constant. Toxic concentration of 1 idocaine $\left(10 \times 10^{-6} \mathrm{~g} / \mathrm{m} 1\right)$ caused more than a doubling of the shortest possible pacing interval and only a slight prolongation of the wave length. 


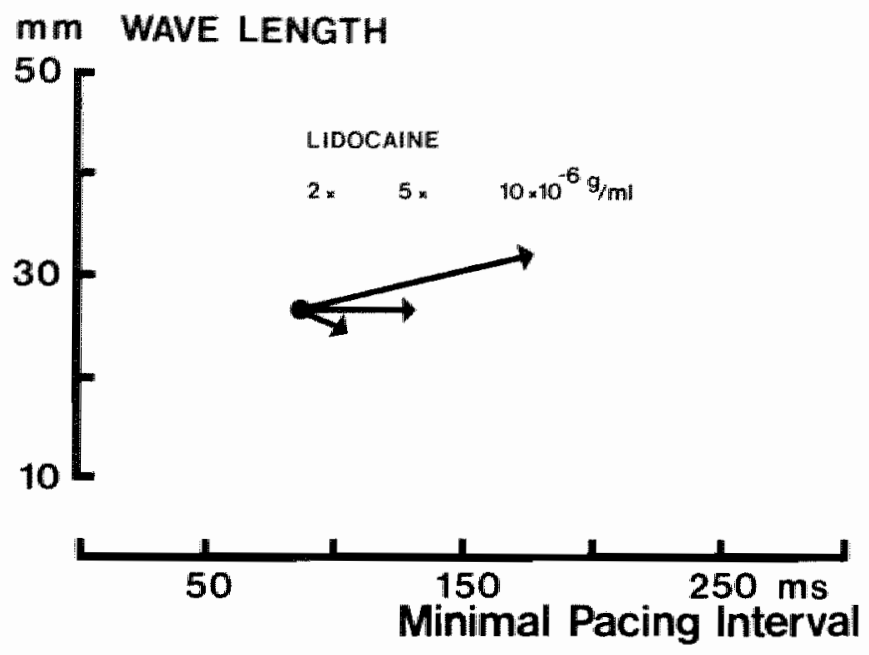

FIGURE 7.2 The relation of the minimat pacing interval and wave length at different lidocaine concentratione. The shortest possible pacing intemal and the wave length at this rate are plotted at $2 x, 5 x$, and $10 \times 10^{-6} \mathrm{~g}^{\prime} \mathrm{ml}$ lidocaine. At the loweat concentration lidocaine the short arrow points to the right and downwards, indicating that the shortest, possible pacing intervat prolonged whereas the wave length was elightly reduced. The middle arrow $\left(5 \times 10^{-6} \mathrm{~g} / \mathrm{ml}\right)$ is almost homizontal which means that the prolongation of the minimal cycle length is not gecompanied by a change in wave length. At the highest concentration $\left(10 \times 10^{-6} \mathrm{~g} / \mathrm{ml}\right)$ both the shortest possible pacing interval and wave length are prolonged, as indicated by the large upward pointing arrots.

\subsection{DISCUSSION}

The action of lidocaine, being a class 1 antiarrhythmic drug (Vaughan Williams 1970) consists mainly of a reduction of the maximal rate of depolarization in cardiac muscle. Changes in the rate of depolarization are associated with an increase in threshold of excitability and depression of conduction velocity. The effect of lidocaine is different in ischemic and normal tissue. Depression of the maximum rate of depolarization occurs in ischemic tissue at a much lower concentration of lidocaine than in normal tissue (Allen et al. 1978, Lazarra et a1. 1978).

In this study, on healthy atrial tissue under nomokalemic conditions, we observed during slow pacing $(2 \mathrm{~Hz})$ a depression of the conduction velocity with 10-14\% at therapeutic lidocaine concentrations. At the highest possible 
pacing rate the propagation was depressed with 25-35\%. These findings support the observation that the effect of lidocaine is enhanced at higher heart rates (Tritthart et al. 1978).

Although the conduction is slowed under influence of lidocaine the wave length is not significantly changed at therapeutic concentrations. Simultaneously with the slawing in conduction, the refractory period and the shortest possibie pacing interval prolonged to an equal extent, completely neutralizing the effect of the slowing in conduction on the wave length. Onjy at toxic concentrations of lidocaine the prolongation in refractoriness and shortest pacing interval become larger than the slowing in conduction, resulting in a prolongation of the wave length.

The clinical observation that lidocaine seldomly restores the sinus rhythm in patients with atrial fibrillation is in good accordance with this finding. It supports the possibility that direct measurement of the length of the cardiac impulse may be used as a marker for the fibrillatory and antifibrillatory action of a drug.

In contrast to its action on the atria, lidocaine is very effective in protecting the ventricles against fibrillation (Lie et al. 1974, Cardinal et a). 1981). Cardinal et al. (1981) showed that lidocaine did not prevent the occurrence of large reentrant circuits in an acute ischemic porcine heart, but protected it from degenerating into ventricular fibrillation. It has been shown by Kabella (1973) that the effects of lidocaine on atrial and ventricular myocardium are very different. Direct measurement of the wave length in ventricular muscle has not been done. To further evaluate the validity of our hypothesis measurement of the effect of lidocaine on the length of the cardiac impulse in both healthy and ischemic ventricular myocardium seems worthwhile. 


\section{REFERENCES}

Allen JD, Brennan FJ, Wit AL: Actions of lidocaine on transmembrane potentials of subendocardial Purkinje fibers surviving in infarcted canine hearts.

Circ Res, 43: 470-481, 1978.

Bigger Jr JT, Hoffman BF: Antiarrhythmic drugs.

In: The pharmacological basis of therapeutics. Eds. Goodman Gilman A, Goodman LS, Gilman A, sixth edition, Macmillan, New York, Toronto, London, 761-792, 1980.

Cardinal $R$, Janse $M d$, wan Eden $I$, Werner $G$, Naumann d'Alnoncourt $C$, Durrer $D$ : The effects of lidocaine on intracellular and extracellular potentials, activation and ventricular arrhythmias during acute regional ischemia in the isolated porcine heart. Circ Res, 49: 792-807, 1981.

Danahy DT, Aronow WS: Lidocaine-induced rate changes in atrial fibrillation and flutter.

Am Heart J, 95: 474-482, 1978.

Hoffman BF, Bigger ur JT: Antiarrhythmic drugs.

In: Drill's pharmacology in medicine, fourth edition, ed. Di Palma J, McGraw-Hi11 New York, 824-852, 1971.

Kabella $E$ : The effects of lidocaine on potassium efflux from various tissues of dog heart.

J Pharmacal Exp Ther, 184: 611-618, 1973.

Koch-Weser: Pharmacokinetics of amtiamrhythmic drugs.

Cardiovasc Clin, 7(2): 191-202, 1975.

Lazzarra R, Hope RR, El-Sherif N, Scherlag EJ: Effects of lidocaine on hypoxic and ischemic cardiac cells.

Am J Cardiol, 41: 872-879, 1978. 
Lie KI, Wellens HJ, van Capelle FJ, Durrer D: Lidocaine in the prevention of primary ventricular fibrillation. A double-blind, randomized study of 212 consecutive patients.

N Engl J Med, 291: 1324-1326, 1974.

Tritthart $H$, Fleckenstein $B$, Fleckenstein $A$ : Some fundamental actions of antiarrhythmic drugs on the excitability and contractility of single myocardial fibers. Arch Pharmacol, 269: 212-219, 1971.

Vaughan Williams EM: Classification of antiarrhythmic drugs.

In: Cardiac arrhythmias, Eds Sandoe E, Flensted-Jensen E, Olesen KH, Publ Astra, Sondertalje, Sweden, 449-472, 1970. 

8. THE EFFECTS OF QUINID INE

In 1914 Wenckebach discovered that quinine, used in the treatment of malaria, was also effective against atrial fibrillation. In 1918 Frey reported that in this respect quinidine was even more effective than quimine. This observation was followed by a number of papers (Frey 1921, Viko et al. 1923) reporting conversion of atrial fibrillation to sinus rhythm in 50 to $70 \%$ of the cases after administration of quinidine. According to Lewis and Drury (1921) this beneficial effect of quinidine on atrial fibrillation should be attributed to a prolongation of the effective refractory period of atrial myocardium. On the other hand it has been reported that quinidine also depresses the conduction velocity of the impulse. Wallace et al. (1966) even suggested that a possible mechanism of action of quinidine could be a lowering of the stimulating efficacy of the wave front, resulting in conduction block.

It has been proposed that fibrillation is based on multiple reentrant circuits and that continuation of fibrillation is related to the number of simultaneously present wavelets (Moe and Abildskov 1959, Allessie et al. 1982). Any intervention which increases the size of intra-atrial reentrant pathways will result in a decrease of the number of impulses circulating around during fibrillation. Because of this decrease in number of wavelets the fibrillatory process may terminate spontaneously.

In this chapter we investigated whether the antifibrillatory action of quinidine can be attributed to such an increase in the dimensions of intraatrial reentry. The effect of quinidine on the length of the excitation wave was measured at different pacing rates.

\subsection{EXPER IMENTAL PROTOCOL.}

The effects of quinidine on the electrophysiological properties of the atrium were studied in 14 experiments. The dosages of quinidine used (between 1 and $7 \mathrm{mg} / 1$ ) are within the therapeutic range (3 to $6 \mathrm{mg} / 1$, Sokolow and Edgar 1949, Hoffman et al. 1975). After addition of quinidine to the superfusing solution it took a rather long time before the first effects could be noticed. During the first hour the major changes occurred, but in the second 
hour the effects of quinidine still progressed. Even after 3 hours of administration of quinidine no steady state was reached. This slow uptake of quinidine in the in vitro heart prevented us from making a full quantitative analysis of the effects of quinidine on the length of the excitation wave. In designing the experimental protocol a compromise had to be found between the limited total duration of in vitro experiments and the condition that the measurement of the electrophysiologic properties should be done in a steady state. The following protocol turned out to be the most appropriate. Since in the experimental protocol no steady state measurement could be made, the results could not be plotted in dose-response curves. Instead we used the effect of quinidine on the shortest possible pacing interwal as parameter to compare the different experiments. The measurements during quinidine administration were divided in two groups. In group I the electrophysiological properties are given at the moment that quinidine prolonged the shortest possible pacing interval to 150 msec. Group II represents all results when the shortest possible pacing interwal was increased to $200 \mathrm{msec}$ due to quinidine. If the electrophysiolagical properties of the preparation were constant, quinidine administration was started with a concentration of $3 \times 10^{-6} \mathrm{~g} / \mathrm{ml}$ (in one preparation the starting dosage was $1 \times 10^{-6} \mathrm{~g} / \mathrm{ml}$, see figure 8.1). After a period of at least 90 minutes the concentration of quinidine was stepwise increased to $5 \times 10^{-6} \mathrm{~g} / \mathrm{ml}$ and 1 hour later to $7 \times 10^{-6}$ $\mathrm{g} / \mathrm{ml}$. In some experiments, however this latter change was not performed and the quinidine concentration was kept during the rest of the experiment at $5 \times 10^{-6} \mathrm{~g} / \mathrm{ml}$ or was lowered to the original concentration of $3 \times 10^{-6} \mathrm{~g} / \mathrm{ml}$. The length of the excitation wave was measured in all preparations during slow and rapid pacing (Fmax).

\subsection{RESULTS.}

Figure 8.1 and figure 8.2 illustrate the great differences in sensitivity to quinidine from preparation to preparation. Figure 8.1 gives an example of a preparation which was very sensitive to quinidine. Administration of $1 \times 10^{-6}$ $\mathrm{g} / \mathrm{ml}$ quinidine started to prolong the shortest possible pacing interval already after half an hour. Simultaneously the conduction velocity at this pacing rate was depressed. Because the effect of quinidine on the conduction velocity was less than the change in the maximum pacing rate, the length of the excitation wave was clearly prolonged. After about 90 minutes of exposure 
to this concentration of quinidine, electrophysiological changes progressed rapidly, finally leading to conduction block during regular driving $(2 \mathrm{~Hz})$.

In figure 8.2 the effects of quinidine in another experiment are shown. The arrangements of the panels is identical as in figure 8.1. After a control period of 1 hour, quinidine was administered to the Tyrode solution at a concentration of $3 \times 10^{-6} \mathrm{~g} / \mathrm{ml}$. Here again the shortest possible pacing interval prolonged whereas the conduction velocity at this rate was

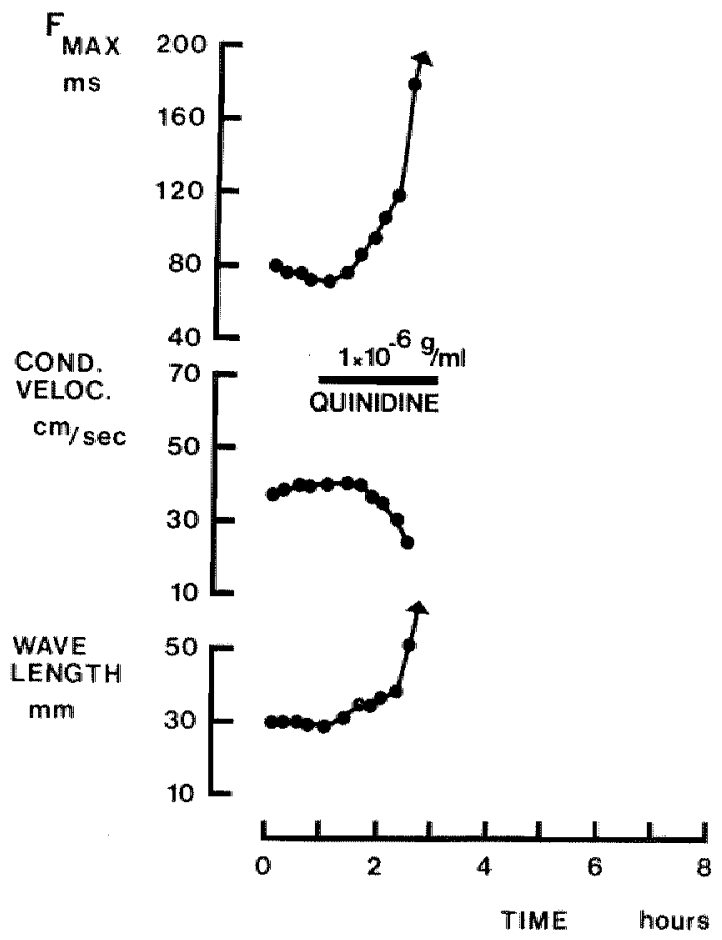

FIGURE 8.1 The effecte of a low concentration of quinidine on the shortest possible pacing intemal, conduction velocity and the wave length. After a control period of about 1 hour quinidine $\left(10^{-6} \mathrm{~g} / \mathrm{ml}\right.$ ) was administered to the Tyrode solution. After an exposure of 30 minutes the first effecto were noticed. The shortest poseible pacing interval prolonged, whereas the conduction velocity was depressed. The length of the excitation wave prolonged markedly because the inerease in the minimal pacing intervat was Zarger that the concomitant depression in conduction velocity. After about 90 minutes the electrophysiological changes progressed rapidty, resulting in conduction block during slow pacing. 
depressed. The wave length at the highest pacing rate prolonged gradually during superfusion with $3 \times 10^{-6} \mathrm{~g} / \mathrm{mi}$. This prolangation was caused by the fact that the prolongation of the shortest possible pacing interval was larger than the concomitant depression in conduction velocity. After 150 minutes the concentration of quinidine was increased to $5 \times 10^{-6} \mathrm{~g} / \mathrm{ml}$. At this concentration of quinidine the shortest possible pacing interval prolonged further and the slowing in conduction increased. Since the prolongation of the minimum pacing interval exceeded the depression in conduction velocity

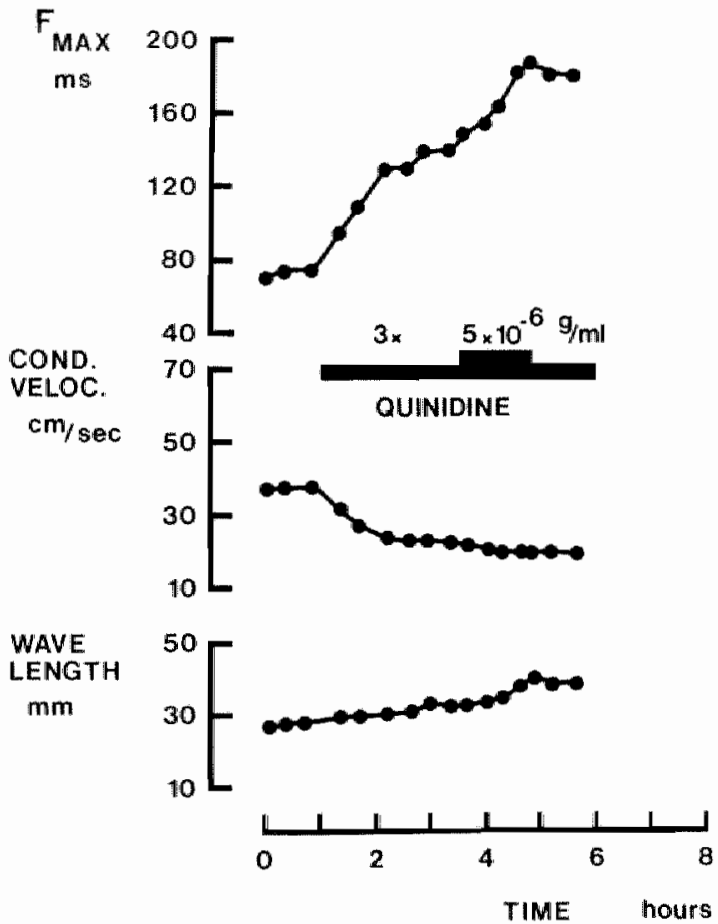

EIGURE 8.2 The effect of quinidine on the shortest possible pacing interval, conduction velocity and wave length. After a control perriod of 60 minutes, quinidine $6^{2 u a s}$ adminiatered in a concentration of $3 \times 10^{-6} \mathrm{~g} / \mathrm{ml}$ (150 minutes) and $5 \times 10^{-6} \mathrm{~g} / \mathrm{ml}(80$ minutes). Quinidine caused a marked protongation of the shortest possible pacing intervat and simultaneousty the speed of propagation was slowed. Since the increase in shortest possible pacing interval exceeded the depression in conduction, the wave length prolonged. After loweming the quinidine concentration to $3 \times 10^{-6} \mathrm{~g} / \mathrm{ml}$ the interval. at Fmax, the conduction velocity were more or less constant. 
the length of the excitation wave prolonged further. After 80 minutes the concentration was again lowered to $3 \times 10^{-6} \mathrm{~g} / \mathrm{ml}$, and the electrophysiological properties remained more or less constant.

In tabel 8. I and 8.II the effects of quinidine are given in two groups. In group I all data are gathered at the moment quinidine had prolonged the shortest possible pacing interval to $150 \mathrm{msec}$. Group II represents the values at the moment the shortest possible pacing cycle was prolonged to 200 msec. The effects of quimidine on refractoriness, conduction velocity and wave length during slow $(2 \mathrm{~Hz})$ and rapid pacing are given. Quinidine exerted clear changes in the electrophysiological properties of the atrial myocardium during slow pacing $(2 \mathrm{~Hz})$. The refractory period prolonged significantly from $73 \mathrm{msec}$ to 104 and $123 \mathrm{msec}$ in group $\mathbb{I}$ and group II respectively. Also the conduction velocity is markedly lowered during administration of quinidine. The speed of propagation was slowed from $61 \mathrm{~cm} / \mathrm{sec}$ during control to 43 and $38 \mathrm{~cm} / \mathrm{sec}$ in group $\mathbb{I}$ and $I \mathbb{I}$. The length of the excitation wave during this slow rate $(2 \mathrm{~Hz})$ was not significantly changed, since the prolongation of the refractory period was equal but opposite to the slowing in the conduction velocity.

TABLE 8.I

\section{THE EFFECTS OF QUINIDINE DURING SLOW PACING (2HZ)}

Quini- $N$

dine

\begin{tabular}{|c|c|c|c|c|}
\hline & & ms & $\mathrm{cm} / \mathrm{sec}$ & $\mathrm{mm}$ \\
\hline control" & 14 & $72.6 \pm 11.6$ & $60.8 \pm 9.4$ & $43.5 \pm 5.7$ \\
\hline group 1 & 13 & $\underset{* * *}{104.5 \pm 15.6}$ & ${ }_{\star \star \star \star}^{43.2} \pm 8.7$ & $\begin{array}{l}45.0 \pm 9.9 \\
\mathrm{~ns}\end{array}$ \\
\hline group II & 12 & $\underset{\star * \star}{123.1 \pm 11.7}$ & ${ }_{\star \star *}^{38.2} \pm 7.4$ & $\begin{array}{l}46.7 \pm 8.1 \\
\mathrm{~ns}\end{array}$ \\
\hline $\begin{array}{l}\text { ns } \\
\star \star \star \\
\text { group II } \\
\text { group II }\end{array}$ & \multicolumn{4}{|c|}{$\begin{aligned}= & \text { not significant } \\
= & p 0.001 \\
= & \text { results at the moment the interval of Fmax increased to } \\
& 150 \text { msec during quinidine administration. } \\
= & \text { results at the moment the interval af Fmax prolonged to } \\
& 200 \text { msec during quinidine administration. }\end{aligned}$} \\
\hline
\end{tabular}

$\begin{array}{lll}\text { Refractory } & \text { Conduction } & \text { Wave } \\ \text { period } & \text { velocity } & \text { length }\end{array}$

velocity

length 
TABLE 8. II

\section{THE EFFECTS OF QUINIDINE DURING RAPID PACING (Fmax)}

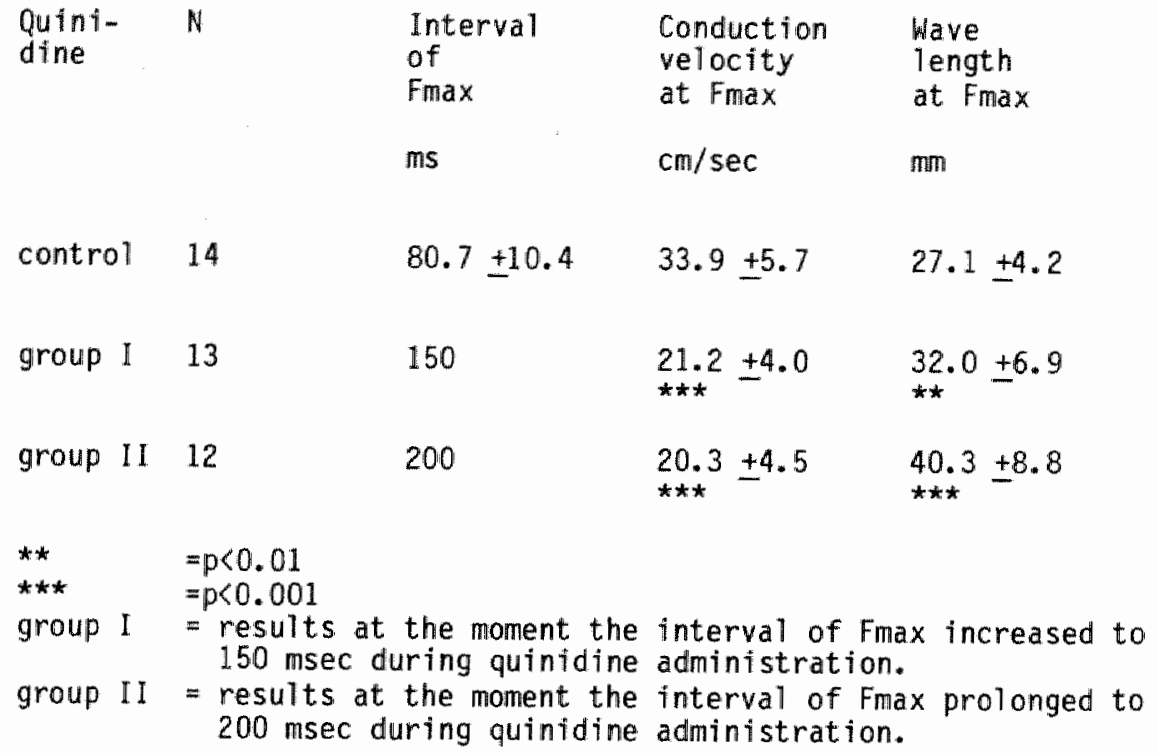

The changes during rapid pacing are shown in table 8.II. It must be noted that the changes in the shortest possible pacing interval 1150 , and $200 \mathrm{msec}$, being the selection criterfum) were almost twice as large as the prolongation of the refractory period. The conduction velocity during maximum pacing was depressed from 34 to 21 and $20 \mathrm{~cm} / \mathrm{sec}$ in group I and group II respectively. This slowing in conduction velocity with 37 and $40 \%$ was almost equal to the depression in conduction during slow pacing (29 and $37 \%$ ). Obviously quinidime did not enhance the slowing in conduction at higher pacing rates.

The wave length during maximum pacing was significantly prolonged from 27 $\mathrm{mm}$ to $32 \mathrm{~mm}$ in group I and to $40 \mathrm{~mm}$ in group II. This prolongation of the wave length is caused by the fact that the increase in the shortest possible pacing interval was larger than the concomitant slowing in conduction.

In figure 8.3 the relation between the prolongation of the shortest possible pacing interval and the associated wave length is given for quinidine group I and II. The shorter arrow indicates that a prolongation of the shortest possible pacing interval to $150 \mathrm{msec}$ was already accompanied by 


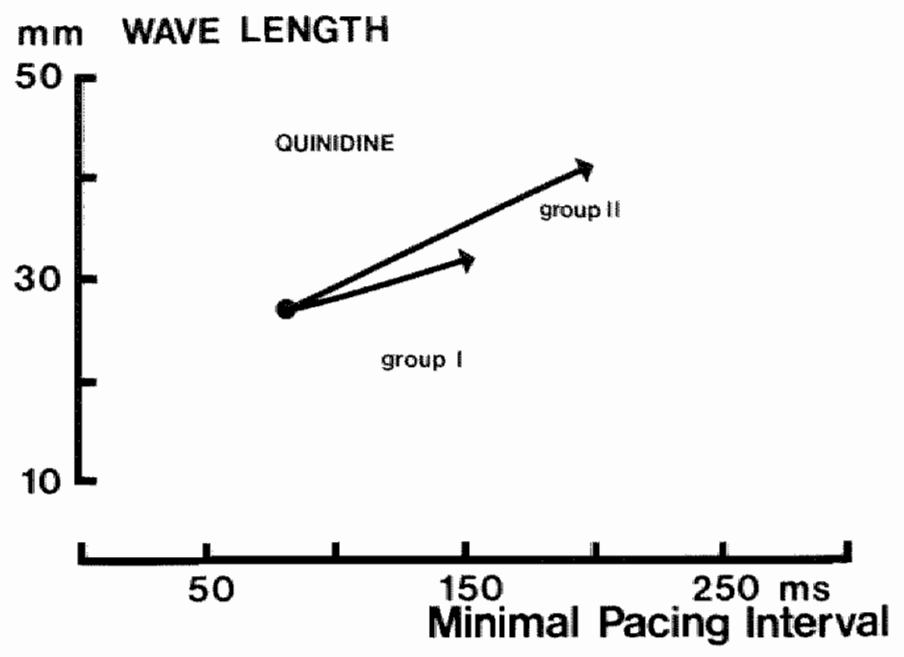

FIGURE 8.3 The effects of quinidine on the relation of shortest posaibie pacing interval and wave length. If due to the effect of quinidine the shortest possibte pacing intervat prolonged to 150 msec, the iength of the excitation wave was also prolonged, as indicated by the short armon. This prolongation of the wave length was even more pronounced if the minimum pacing interval was prolonged to 200 msec under the influence of quinidine (the arrow is langer and points more upwards).

an increase in the length of the excitation wave. This prolongation of the wave length was even more pronounced when the pacing interval was increased to $200 \mathrm{msec}$ (group II, large arrow).

\subsection{DISCUSSION}

Quinidine and quinidine like drugs cause marked changes in the electrophysiological properties of cardiac tissue. The maximum upstroke velocity of the transmembrane potential is progressively decreased at increasing quinidine concentrations. The action potential duration is hardly affected by quinidine (Vaughan williams 1958). In spite of this the refractory period is markedly prolonged (Lewis and Drury 1926). Also the highest possible pacing rate is considerably decreased under the influence of quinidine (Dawes 1946). We found a prolongation of the refractory period with 40 to $70 \%$ during slow pacing. At higher pacing rates the refractory period prolonged even more, as is also reflected in the pronounced prolongation of the shortest possible pacing interval. A marked slowing in the conduction velocity of the impulse 
with about $40 \%$ both during slow and rapid pacing was found. In contrast with lidocaine (see chapter 7) the depression in conduction was not rate dependent. Although the effects of quinidine on the conduction velocity and refractoriness exerted opposite effects on the length of the excitation wave, the lengthening in refractory period was far more outspoken than the slowing in conduction of the impulse. As a result quinidine caused a marked prolongation of the length of the excitation wawe in the atrium.

Although these changes in electrophysiological properties are pronounced, the experimental conditions were not strictly constant, because the effect of quinidine progressed slowly in time. These measurements of refractoriness, conduction velocity and wave length should actually be repeated in a steady state condition. This probably could be achieved by chronic administration of quinidine to the animal, before the heart is isolated.

Quinidine, wave length and reentrant arrhythmias.

Although quinidine is a relatively old drug, it is still of great clinical value in terminating atrial flutter and fibrillation. Furthermore it is used to reduce the incidence of relapse of atrial fibrillation after electrical cardioversion (Sodermark et al. 1975). Administration of quinidine during intra-atrial reentry in rabbits resulted in a gradual slowing of the rate and eventually in termination of the arrhythmia (Allessie et al 1977b). Such slowing in the rate of a reentrant arrhythmia can be understood by the prolongation of the refractory period by quinidine, which is also reflected in the decrease of the maximum pacing rate.

However this does not yet explain why quinidine may terminate atrial fibrillation and prevent its recurrence. We consider the prolongation of the length of the excitation wave by quinidine, as reported in this chapter, to be responsible for the antifibrillatory action of quinidine. There is evidence that the susceptibility for initiation and maintenance of fibrillation is associated with a large atrial mass (Garrey 1914, Moore and Spear 1982). Moe an Abildskov (1959) demonstrated that atrial fibrillation can persist in a stable state if a sufficient number of wavelets are randomly wandering around. According to the multiple wavelet hypothes is the number of wavelets should be directly rellated to the mass of tissue involved and inversely related to the size of the intra-atrial reentrant circuits. If the number of circulating wavelets within the myocardium gets lower than a 
critical level, the fibrillatory proces gets unstable and may terminate spontaneously. The marked prolongation of the wave length by quinidine must decrease the number of wave fronts which can be present simultaneously in atria of a certain size. The clinical observation that quinidine can change "fine" fibrillation into "coarse" and more regular fibrillation (Hart 1922) is consistent with a decrease in the number of wavelets.

Although the present in vitro studies did not allow quantitative analysis of the effects of quinidine, we conclude that the observed lengthening of the activation wave offers a good explanation for the antifibrillatory action of the drug.

\section{REFERENCES}

Al lessie MA, Bonke FIM, Lammers WJEP: The effects of Carbamylcholine, Adrenaline, Ouabain, Quinidine and Verapamil on Circus Mavement Tachycardia in isolated segments of rabbit atrial myocardium.

In: Re-entrant Arrhythmias. Mechanisms and treatment. Edited by: H.E. Kulbertus, MTP Press Limited Lancaster, 63-71, $1977 \mathrm{~b}$.

Allessie MA, Lammers WJEP, Smeets JLRM, Bonke FIM, Hollen Su: Total mapping of atrial excitation during acetylcholine-induced atrial flutter and fibrillation in the isolated canine heart.

In: Atrial Fibrillation. Edited by Kulbertus ME, 01sson SB, Schlepper M, Publ Hassie, Molndal Sweden, 44-61, 1982.

Dawes GS: Synthetic substitutes for quinidine.

Br J Pharmacol, 1: 90-112, 1946.

Frey W: Ueber Vorhofflimmerm beim Menschen und seine Beseitigung durch Chinidin.

Berl K1 in Wchenschr, 55: 450-452, 1918. 
Frey W: Weitere Erfahrungen mit Chinidin bei absoluter Herzunregelmaessigkeit.

Ber1 K1 in Wchenschr, 55: 849-853, 1918.

Hart TS: Quinidin in auricular fibrillation, with some observations on its use in combination with digitalis. Arch Intern Med, 30: 593-605, 1922.

Hoffman BF, Rosen MR, Wit AL: Electrophysiology and pharmacology of cardiac arrhythmias. VII. Cardiac effects of quinidine and procainamide. Am Heart J, 89: 804-808, 1975.

Lewis T, Drury AN: Revised views of the refractory period, in relation to drugs reputed to prolong it, and in relation to circus movement. Heart, 13: $95-100,1926$.

Moe GK, Abildskov JA: Atrial fibrillation as a self-sustaining arrhythmia independent of focal discharge.

Am Heart J, 58: 59-70, 1959.

Moore EN, Spear JF: Natural occurrence and experimental initiation of atrial fibrillation in different animal species.

In: Atrial fibrillation. Edited by Kulbertus HE, 01 sson SE, Schlepper M. Publ Hassle, Molndal Sweden, 33-44, 1982.

Sodermark $T$, Jonsson $B$, 07 sson $A$, Oro L, Wallin H, Edhag 0 , Sjogren A, Danielsson $M$, Rosenhamer $G$ : Effect of quinidine on maintaining sinus rhythm after conversion of atrial fibrillation or flutter. A multicentre study from Stockholm.

Brit Heart J, 37: 486-492, 1975.

Sokolow M, Edgar AL: Blood quinidine concentrations as a guide in the treatment of cardiac arrhythmias.

Circulation, 1: 576-592, 1950. 
Viko LE, Marvin HM, White PD: A clinical report on the use of quinidin sulphate.

Arch Intern Med, 31: 345-363, 1923.

Wallace AG, Cline RE, Sealy WC, Young Jr WG, Troyer Jr WG: Electrophysiologic effects of quinidine. Studies using chronically implanted electrodes in awake dogs with and without cardiac denervation.

Circ Res, 19: 960-969, 1966.

Wenckebach KF: Die unregelmassige Herztatigkeit und ihre klinische Bedeutung. Engelman, Leipzíg, 1914. 

Digitalis is frequently used in the treatment of two groups of cardiac patients. First of all it is used in patients with congestive heart failure to increase the contractility of the heart. Secondly digitalis is used in atrial flutter and fibrillation to slow the venticular response by direct and indirect effects on the atrio-ventricular node. The direct action is an increase in effective refractory period of the A-W node (Hoffman and Bigger 1980) and indirectly the conduction through the $A-V$ node is impaired because of the increased parasympathetic effect on the node. In patients with atrial flutter cardiac glycosides not only influence the $A-V$ conduction but also induce a change in the rate of the flutter; the flutter rate increases and can finally degenerate into fibrillation. This action of cardiac glycosides on the behaviour of atrial flutter might be attributed to an increase in parasympathetic influence on the atrial myocardium, as demonstrated in the dog by Farah and Loomis (1950). In the same study it was shown that cardiac glycosides cause an increase of refractoriness and was accompanied by a reversion of atrial flutter into sinus rhythm. Therefore we decided to include a study on the direct effects of a cardiac glycoside, namely ouabain, on the isolated left atrium of the rabbit during regular and fast driving.

\subsection{EXPERIMENTAL PRCTOCOL}

As a representative of cardiac glycosides we have chosen ouabain, because this drug has a rapid onset of action (Strophantin G. British Drug House). The starting dosage was $2 \times 10^{-7} \mathrm{M}$ in 6 preparations and $3 \times 10^{-7} \mathrm{M}$ in 2 preparations. After this concentration had been given for 2 to 3 hours, the ouabain concentration was increased stepwise to 3 and $4 \times 10^{-7} \mathrm{M}(4$ experiments) and $5 \times 10^{-7} \mathrm{M}$ (in 2 experiments). We measured the effects of different concentrations of digital is in $\&$ experiments.

In 4 of these experiments we isolated also the right atrium of the rabbit heart to monitor direct chronotropic effects of ouabain on the sinus node.

In figure 9.1 an example of the experimental protocol is given. The effects of different concentrations of oubain on the shortest possible pacing interval, the conduction velocity and the wave length are plotted against time. After a control period of 45 minutes, a concentration of $2 \times 10^{-7}$ M ouabain was administered during 2 hours. The concentration of ouabain was 
fncreased to $3 x, 4 x$ and $5 \times 10^{-7}$ M. Under the influence of ouabain the shortest possible pacing interwal prolonged gradually, whereas the conduction velocity was hardly affected. As a result the length of the excitation wave prolonged. At $5 \times 10^{-7} \mathrm{M}$ the conduction rapidly deteriorated and the preparation became inexcitable. Washout did not reverse these effects. Statistical analysis was done using the student-t test (paired samples).

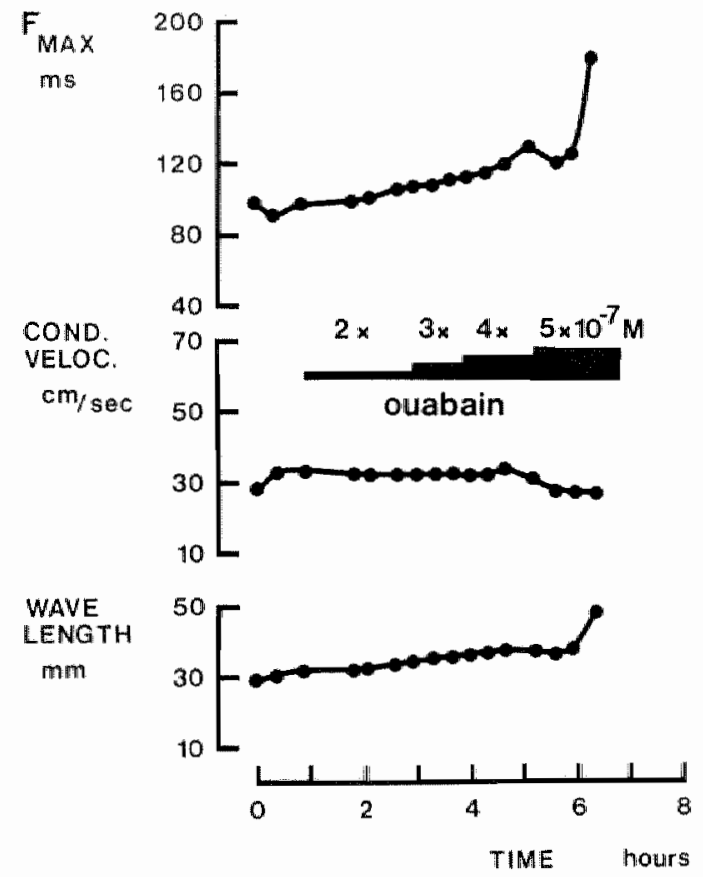

PIGURE 0.1 The effects of different concentrations of ouabain on the shortest posuble pacing intervat, conduction velocity and wave length. Ouabain wa administered in stgpwise increasing dosages from $2 \times 10^{-7} \mathrm{M}(120$ minutes) to $3 x, 4 x$, and $5 \times 10^{-7} M(60$ minutes each). The shortest possible pecing interval protonged gradualzy, whereas the conduction velocity at this rate was slightly depressed. Since the protongation in the minimum pacing interval was somewhat larger than the depression in conduction velocity, the wave length prolonged moderately. 


\subsection{RESULTS}

The effect of ouabain at a slow pacing rate.

In each experiment the refractory period and the conduction velocity were measured during regular driving with $2 \mathrm{Kz}$ at the end of 2 hour administration of ouabain in a concentration of $2 \times 10^{-7} \mathrm{M}$ and at the end of a subsequent perjod of one hour in which the concentration of the drug was ralised to $3 \times 10^{-7} \mathrm{M}$. Refractory period did not change in case of the lower concentration but increased significantly from $73 \mathrm{msec}$ to $87 \mathrm{msec}$ when the higher concentration of ouabain was present (table 9.I). Conduction velocity did not change in either of the two concentrations. Therefore the length of the excitation wave could be calculated to be not affected at an ouabain concentration of $2 \times 10^{7} \mathrm{M}$, whereas it was slightly prolonged if ouabain was administered in a concentration of $3 \times 10^{-7} \mathrm{M}$.

The effect of ouabain on the wave length of the earliest premature impulse.

In table 9.II the effects of ouabain on refractoriness, conduction velocity and wave length of the earliest premature impulse are plotted. The

\section{TABLE 9.1}

\section{THE EFFECTS OF OUABAIN DURING LOW PACING (2HZ)}

REFRACTORY

PERIOD

ms

CONTROL

73.0

OUABAIN

$2 \times 10^{-7} M$

$(120 \mathrm{~min})$

OUABAIN

$(60 \min )$

$+16.7$

86.7

$+22.9$ $\pm 13.5$
CONDUCT ION

VELOCITY

$\mathrm{cm} / \mathrm{sec}$

61.5

$+12.1$

61.2

$+12.3$

$\overline{\mathrm{n} s}$

59.3

$\pm 10.2$

ns
WAVE LENGTH N

min

46.4

$+7.7$

44.5

$+8.8$

$\overline{\mathrm{n} s}$

50.2

$+10.5$
$\mathbb{N}$
8

ns $=$ not significant

$\star \quad=p<0.05$ 
TABLE 9.11

THE EFFECTS OF OUABAIN DURING AN EARL Y PREMATURE BEAT.

REFRACTORY
PERIOD

ms

66.5

$\pm 12.9$

OUABA IN N

$2 \times 10^{-7} \mathrm{M}$

(120 min)

DUABA IN

(60 min)

$+16.3$

$\bar{n} \mathrm{~s}$
CONDUCTION

VEL OC ITY

$\mathrm{cm} / \mathrm{sec}$
WAVE LENGTH N

$\pi m$

26.6

$\pm 5.0$

$+6.7$

21.7

$+4.8$

36.2

$\pm 8.1$

34.7

$+6.2$

23.7

$\pm 5.5$
8

5

6 N

$n_{\star}^{n s}=$ not significant

$\bar{n} s$

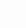

8

6

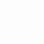$$
\star \quad=p<0.05
$$

refractory period of the earliest premature impulse, being the shortest possible $A_{2}-A_{3}$ interval, is slightly shortened from $67 \mathrm{msec}$ to 61 and $64 \mathrm{msec}$ at $2 x$ and $3 \times 10^{-7} M$ respectively. However these changes were not statistically significant. The conduction velocity of the earliest premature impulse was slightly depressed by ouabain. At $2 \times 10^{-7} \mathrm{M}$ it was slowed from $41 \mathrm{~cm} / \mathrm{sec}$ to 36 $\mathrm{cm} / \mathrm{sec}$, whereas at $3 \times 10^{-7} \mathrm{M}$ it was further depressed to $35 \mathrm{~cm} / \mathrm{sec}$. The length of the excitation wave was 51 ightly shortened from $27 \mathrm{~mm}$ to 22 and $24 \mathrm{~mm}$ at $2 x$ and $3 \times 10^{-7} M$ (not statistically significant). This slight shortening was caused by both a slight shortening of the refractory period and a minor reduction in the conduction velocity.

The length of the excitation wave at the highest pacing rate.

In table 9. II the effects of ouabain during maximal pacing are given. As during slow pacing and early premature beats, also during rapid pacing the direct effects of ouabain were not very evident. The shortest possible pacing interval increased from $82 \mathrm{msec}$ to 95 and $102 \mathrm{msec}$ at $2 \times$ and $3 \times 10^{-7} \mathrm{M}$ ouabain. Simultaneously the conduction velocity at this rate was depressed from $38 \mathrm{~cm} / \mathrm{sec}$ to 35 and $33 \mathrm{~cm} / \mathrm{sec}$ during the different ouabain concentrations. Calculation of the length of the excitation wave during fast 
TABLE 9. III

THE EFFECTS OF OUABAIN DURING RAP ID PACING (FMAX)

$\begin{array}{lll}\text { INTERVAL } & \begin{array}{l}\text { CONDUCTION } \\ \text { VELOCITY }\end{array} & \text { WAVE LENGTH } \\ \text { Fmax } & \text { at Fmax } & \text { at Fmax } \\ \text { ms } & \mathrm{cm} / \mathrm{sec} & \mathrm{mm}\end{array}$

\begin{tabular}{|c|c|c|c|}
\hline CONTROL & $\begin{array}{l}81.9 \\
+12.2\end{array}$ & $\begin{array}{r}38.0 \\
+6.7\end{array}$ & $\begin{array}{r}30.7 \\
+4.9\end{array}$ \\
\hline $\begin{array}{l}\text { OUABA IN } \\
2 \times 10^{-} \mathrm{M} \\
(120 \mathrm{~min})\end{array}$ & $\begin{array}{l}95.0 \\
+10.0 \\
\star *\end{array}$ & $\begin{array}{l}35.4 \\
+4.9\end{array}$ & $\begin{array}{r}33.5 \\
+5.0 \\
\frac{\pi}{\pi}\end{array}$ \\
\hline $\begin{array}{l}\text { OUABBA LN } \\
3 \times 10^{-7} \mathrm{M} \\
(60 \mathrm{~min})\end{array}$ & $\begin{array}{l}102.5 \\
+10.8 \\
\star \star\end{array}$ & $\begin{array}{l}32.8 \\
+4.6 \\
\bar{\pi} \star\end{array}$ & $\begin{array}{l}33.7 \\
+4.7\end{array}$ \\
\hline
\end{tabular}

$\begin{aligned} n s & =\text { not significant } \\ * & =p<0.05 \\ \star \star & =p<0.01\end{aligned}$

pacing rate revealed a slight but significant prolongation from $31 \mathrm{~mm}$ to 34 man at both concentrations of ouabain. This prolongation of the length of the excitation wave was caused by the fact that the prolongation of the shortest possible pacing interval was somewhat larger than the depression in conduction velocity.

In figure 9.2 the effects of owabain $\left(3 \times 10^{-7} M\right)$ on the shortest passible cycle length and the concomitant wave length are given. The prolongation of the shortest possible pacing interval is accompanied by a prolongation of the wave length, as is indicated by the arrow, pointing upwards and to the right.

The effect of ouabain on pacemaker activity.

The relation between concentration of ouabain and its effect can be indicated by monitoring the effect on the intrinsic sinus rate. In general the intrinsic rate of the sinus node is not influenced by "therapeutic" plasma concentrations of ouabaim. However, at toxic concentration of ouabain a shortening of the spontaneous cycle length can be noted, followed by 


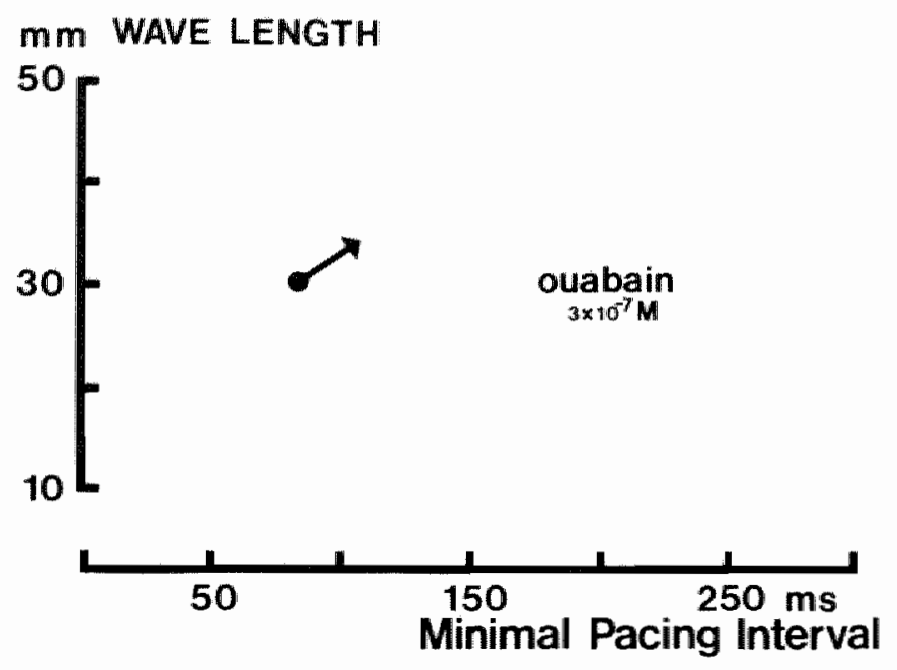

FIGURE 9.2 Retation of wave length and shortest possible pacing intervat under the influence of oubair. Ouabain in a concentration $3 \times 10^{-7}$ M caused a prolongation of the shortest possible pacing interval rarrow points to the right) and together with this increase in minimum pacing intervat, the length of the excitation wave prozonged (arrow points upwards).

irregularities and sinus node exit-biock (Steinbeck et al. 1980). Irregularities in sinus rhythm were observed in all four preparations, in 2 at a concentration of $2 \times 10^{-7} \mathrm{M}$, and in the other 2 preparations at $5 \times 10^{-7} \mathrm{M}$ oubain. In three sinus node preparations these irregularities were preceded by a shortening of the spontaneous cycle length of the simus node. These results indicate that the ouabain at the concentrations used in the present study exert toxic effects after long lasting administration.

In four strips of left atrial mocardium, devoid of any nodal tissue, spontaneous activity was observed during the administration of ouabain. The concentration of ouabain at which this spontaneous activity occurred was $2 \times 10^{-7} \mathrm{M}$ in 1 preparation, $3 \times 10^{-7} \mathrm{M}$ in 2 preparations and $4 \times 10^{-7} \mathrm{M}$ in 1 preparation. In general this activity was observed after pacing the preparations at high rates for a few minutes. The duration of this spontaneous activity ranged from 1-2 seconds to 8-10 minutes on one occasion; the cycle length of this spontaneous ectopic pacemaker activity ranged from 220 to $280 \mathrm{msec}$. 


\subsection{DISCUSSION}

Effect of cardiac glycosides on refractoriness and conduction velocity.

In animal studies as well as in man, cardiac glycosides will cause a slowing of heart rate and this effect is considered to be vagal in origin because it is partly abolished by atropine. To explain this vagal effect several hypotheses have been advanced: 1) sensitization of the heart to vagal activity, 2) central vagal stimulation and 3) sensitization of the carotid sinus (thus an effect via the baroreflex). The first hypothesis is correct as was demonstrated by Gaffney et al. (1958) in the open-chest dog (vagotomized so that no central vagal influences on the heart could be present): they found that stimulation of the peripheral trunk of the vagal nerve led to a more pronounced slowing of the heart rate than under control conditions. Recently it was demonstrated by Bonke et al. (1982) that ouabain in a mon toxic concentration $\left(10^{-7} \mathrm{M}\right.$ : causing no effect on impulse formation, but exercising a positive inotropic effect) enhances the sensitivity of the isollated sinus node to cholinergic substances.

Thus in a heart with intact innervation cardiac glycosides can enhance the shortening of the refractoriness of atrial myocardium during parasympathetic stimulation. However it was reported that the direct action of cardiac glycosides on atrial myocardium was a prolongation of the refractory periad (Mendez and Mendez 1953). These studies were done in anesthetized dogs with denerwated hearts and intraveous injection of cardiac glycosides and this procedure makes it difficult to compare their results with ours. We found no change of refractoriness during regular driving of atrial mocardium during administration of ouabain $\left(2 \times 10^{-7} \mathrm{M}\right)$, but if the concentration was increased to $3 \times 10^{-7} \mathrm{M}$ the prolongation of refractoriness was obvious. The shortest possible pacing rate decreased $(15-25 \%)$ under the influence of cardiac glycosides. This is in agreement with the results of Farah and Loomis (1950) in canine atrium. The conduction velocity was not affected by ouabain during slow drive, but at the highest pacing rate a sligth lowering of the conduction was observed.

Effect of cardiac glycosides on wave length of the impulse in atrial myocardium.

Since cardiac glycosides caused a prolongation of refractoriness in 
atrial myocardium with a concomitant decrease of the conduction velocity, the wave length of the impulse did not change in an explicit way. There was an increase of the length of the excitation wave of about $10 \%$ during fast pacing.

Cardiac glycosides and reentrant arrhythmias in the atrium.

Farah and Loomis (1950) studied the effects of cardiac glycosides on atrial flutter in the dog heart. They induced a flutter according to the method of Rosenblueth and Garcia Ramos (1947) by making an obstacle in the atrium around which the impulse has to travel. In such a case of circus movement around an anatomical obstacle the flutter rate decreased during the administration of cardiac glycosides and finally reversion to sinus rhtyhm occurred. In their opinion this was caused by the increase in the refractory period. However if the heart was not denervated auricular flutter changed into fibrillation and because atropine or cutting the vagal nerves promptly reverted the fibrillation to a sinus rhythm, they concluded that this change from flutter into fibrillation was mediated through the vagus. In case there is no anatomical obstacle, for instance in the experiments of Allessie and coworkers (1982) inducing fibrillation in the canine atrium, we might expect that cardiac glycosides will have hardly any effect on the fibrillation since the wave length of the circulating impulse is only slightly increased and this will not be enough to really enhance the chance of termination of fibrillation. Further experiments are needed to prove this hypothesis.

REFERENCES

Allessie MA, Lammers WJEP, Smeets JLR, Bonke FIM, Hollen SJ: Total mapping of atrial excitation during acetylcholine-induced atrial flutter and fibrillation in the isolated canine heart.

In: Atrial Fibrillation. Edited by Kulbertus HE, 01sson SB, Schlepper M, Publ Hassle, Molndal Sweden, 44-61, 1982. 
Bonke FIM, Steinbeck G, Allessie MA, Mackaay AJC, Slenter VAJ: The electrophysiological effects of cardiac glycosides on the isolated-sinus node of the rabbit.

In: Normal and abnormal conduction in the heart. Eds.: Paes de Carwalho A, Hoffman BF, Lieberman M. Futura Publishing Company, Mount Kisko, New York., $347-361,1982$.

Farah A, Loomis TA: The action of cardiac glycosides on experimental auricular flutter.

Circulation, 2: 742-748, 1950.

Gaffney TE, Kahn JE, Van Maanen EF, Acheson GH: A mechanism of the vagal effect of cardiac glycosides. J Pharmacol Exp Ther, 122: 423-429, 1958.

Hoffman BF, Bigger JT: Digitalis and allied cardiac glycosides.

In: The pharmacological basis of therapeutics. Eds.: Goodman Gilman A, Goodman LS, Gilman A, sixth edition, Macmillan Publishing Company, New York, 729-760, 1980.

Mendez R, Mendez $C$ : The action of cardiac glycosides in the refractory period of heart tissues.

J Pharmacol Exp Ther, 1.07: 24-36, 1953.

Rosenbilueth A, Garcia Ramos $\mathrm{J}$ : Studies on flutter and fibrillation. II. The influence of artificial abstacles on experimental auricular flutter. Am Heart J, 33: 677-684, 1947.

Steinbeck G, Bonke FIM, Allessie MA, Lammers WJEP: The effect of ouabain on the isolated sinus node preparaton of the rabbit studied with microelectrodes.

Circ Res, 46: 406-414, 1980. 


\section{THE EFFECTS OF VERAPAMIL.}

Verapamil was initially introduced by Haas and Hartfelder in 1962 as a coronary vasodilator in the treatment of ischemic heart disease. It soon became apparent that verapami 1 aiso possessed antiarrhythmic properties (Melville at al. 1964, Bender et a1. 1966, Schmid and hanna 1967, Kauman and Armendia. 1968). Given intravenously verapamil caused a slowing of the ventricular rate in case of atrial fibrillation (Schamroth 1971, Schamroth et a1. 1972). In patients with paroxysmal supraventricular tahycardias intravenous administration of verapamil caused a prompt termination of the arrhythmia and restoration of sinus rhythm (Krikler and Spurrel 1974). In the same study it was shown that in patients with supraventricular tachycardias associated with the Wolff-Parkinson-White syndrome, the arrhythmia could also be stopped by verapamil. These and others studies have demonstrated that verapamil is very effective against tachycardias based on a circus movement either completely within a nodal structure (for instance the A-V-node) or a circuit in which nodal tissue is a part. This is in agreement with the fact that verapamil can be considered as a calcium antagonist or a calcium-entry blocker and therefore will reduce the slow inward current during the action potential (Fleckenstein et al. 1969, Kohlhardt et al. 1975). Since the slow inward current is especially important as depolarizing current in nodal tissue and only of 1 imyted value for the depolarization of normal atrial myocardial cells, one might expect that verapamil will act predominanty on nodal tissue. Assuming that atrial fibrillation is based on multiple intra-atrial circuits - as was already stated in the previous chapter - one might expect that verapamil will not influence atrial fibrillation. This hypothesis seems to be supported by the fact that only in $16 \%$ of the patients with atrial fibrillation the arrhythmia could be reverted into sinus rhythm using verapamil (Zipes and Troup 1978). Therefore if our hypothesis about the importance of the wave length as determinant of circular excitation in atrial myocardium is correct we expect that verapamil will not effect the electrophysiological properties of atrial nyocardium in such a way that a change in wave length will occur. 
the isolated atrium we selected 3 dosages of the drug: $0.1 \mathrm{mg} / 1,0.5 \mathrm{mg} / 1$ and $1 \mathrm{mg} / 1$ (Isoptin, knoll). It has been previously described that verapamil in this concentration range influences the electrophysiological properties of the isolated rabbit sinus node (Wit and Cranefield 1974). After a control period of 1 hour the administration of verapamil was started in a concentration of $0.1 \mathrm{mg} / 1$. After about 1 hour the concentration of verapamil was stepwise increased to $0.5 \mathrm{mg} / 1$. After this dosage had been given for another hour, the concentration of verapamil was further increased to $1.0 \mathrm{mg} / \mathrm{l}$. No

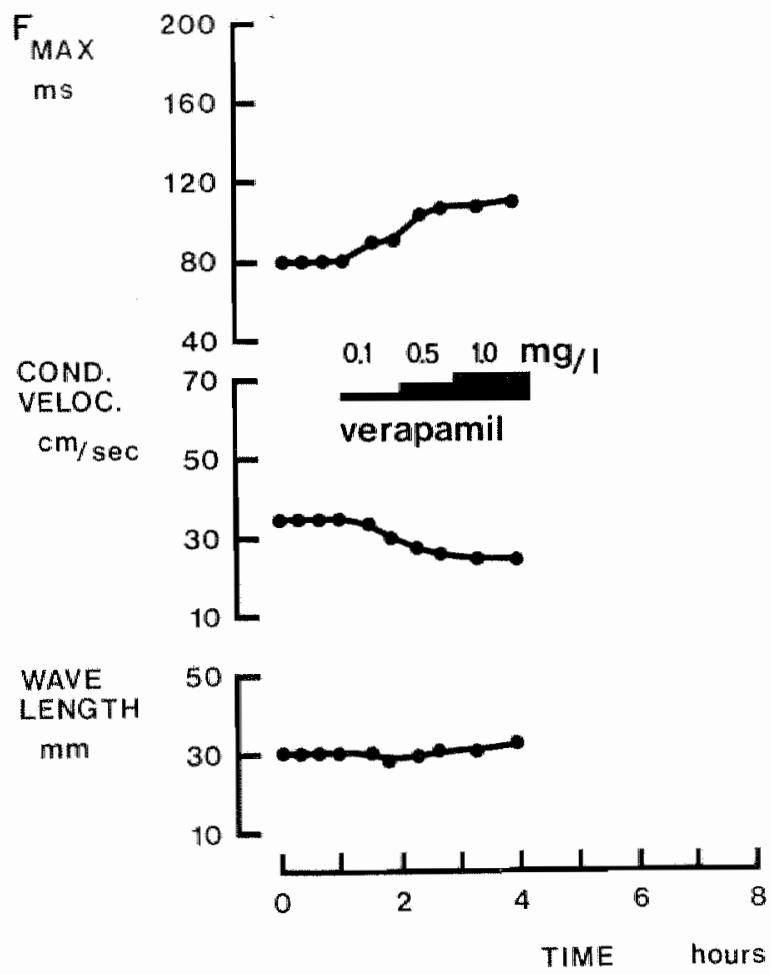

FIGURE 10.1 The effects of different concentration of verapamit on the shortest poseible pacing interval, conduction velocity and wave length. After a controt period of 1 hour verapamit was given at a concentration of 0.1 , $0.5,1.0 \mathrm{mg} / \mathrm{l}$, without an intermittent return to control. The shortest possible pacing interval prolonged, and simultaneously the condwction velocity was depressed. Since the protongation of the minimum pacing intervat was equal but opposite to the depression in conduction velocity, the wave tength was not changed. 
attempts were made to washout the drug effects. In a few preliminary experiments we had superfused the preparation after verapamil administration, during a period of more than 1 hour with nomal verapamil-free solution, but we were not able to washout the effects of verapamil completely. At each concentration at least two complete sets of measurements were made. An example of the experimental protocal is given in figure 10.1 .

\subsection{RESULTS}

In figure 10.1 the results of a representative experiment are given. Under the influence of verapamil the shortest possible pacing interval prolonged, whereas the conduction velocity at the highest pacing rate was depressed. However the length of the excitation wave was not changed because the changes in conduction velocity and shortest pacing interval were opposite and about equal to each other.

In table 10 . I the effects of different concentrations of verapamil on the refractory period, the conduction velocity and the wave length are given during pacing at $2 \mathrm{~Hz}$. The restoration of the excitabilty was prolonged by verapami1. At a concentration of $0.1 \mathrm{mg} / \mathrm{l}$ the refractary period prolonged from $66 \mathrm{msec}$ to $69 \mathrm{msec}$, and was further increased to 78 and $77 \mathrm{msec}$ at 0.5 and $1.0 \mathrm{mg} / 1$. The speed of propagation was slightly depressed from $56 \mathrm{~cm} / \mathrm{sec}$

TABLE 10. I

\section{THE EFFECTS OF VERAPAMIL DURING SLOW PACING $(2 \mathrm{~Hz})$}

\begin{tabular}{|c|c|c|c|c|}
\hline $\begin{array}{l}\text { Concen- } \\
\text { tration } \\
\text { of } \\
\text { Verapamil } \\
\text { mig/ } 1\end{array}$ & $N$ & $\begin{array}{l}\text { Refractory } \\
\text { period }\end{array}$ & $\begin{array}{l}\text { Conduction } \\
\text { velocity }\end{array}$ & $\begin{array}{l}\text { Wave } \\
\text { length }\end{array}$ \\
\hline control" & 7 & $66.4 \pm 12.3$ & $56.4+8.2$ & $37.0 \pm 5.1$ \\
\hline 0.1 & 5 & $\begin{array}{l}69.0 \pm 14.1 \\
n s\end{array}$ & $\begin{array}{l}52.6 \pm 9.9 \\
\text { ns }\end{array}$ & $\begin{array}{l}35.5 \pm 5.4 \\
n s\end{array}$ \\
\hline 0.5 & 6 & $\begin{array}{l}77.8 \pm 19.2 \\
\mathrm{~ns}\end{array}$ & $\mathrm{~ns}_{\mathrm{n}}^{51.2 \pm 11.1}$ & $\begin{array}{l}38.4 \pm 5.0 \\
\mathrm{~ns}\end{array}$ \\
\hline 1.0 & 7 & $\begin{array}{l}76.8 \pm 28.0 \\
\text { ns }\end{array}$ & $\begin{array}{l}53.0 \pm 13.9 \\
n s\end{array}$ & $\begin{array}{l}37.7 \pm 2.1 \\
n s\end{array}$ \\
\hline
\end{tabular}


to 53,51 and $53 \mathrm{~cm} / \mathrm{sec}$ at different concentrations of verapamil. None of the changes in refractory period and conduction velocity were significant. Consequently there was no significant alteration in the calculated wave length at different verapamil concentrations, being 36,38 and $38 \mathrm{~mm}$ versus $37 \mathrm{~mm}$ during control.

In table 10.11 the effects of verapamil on the refractory period, conduction velocity and wave length of the earliest possible premature beat during slow pacing are given. The refractory period of the earliest premature beat was somewhat prolonged by verapamil. It increased from $61 \mathrm{msec}$ during control to 63,64 and $69 \mathrm{msec}$ at $0.1,0.5$ and $1 \mathrm{mg} / 1$ verapamil. The speed of propagation of the earliest premature impulse was hardly influenced since conduction velocity changed from $34 \mathrm{~cm} / \mathrm{sec}$ during controll to 32,30 and 33 $\mathrm{cm} / \mathrm{sec}$ at $0.1,0.5$ and $1.0 \mathrm{mg} / 1$ verapamil. Neither the changes in refractory period nor the changes of the conduction velocity were significant, and therefore the wave length of the premature impulse remained unchanged by verapami1.

The measurements during maximal pacing are given in table 10.III. Also during rapid pacing the effects on refractoriness and conduction velocity are not prominent. The shortest possible pacing interval prolonged slightly from

TABLE 10.II

THE EFFECTS OF VERAPAMIL DURING PREMATURE STIMLATION

\begin{tabular}{|c|c|c|c|c|}
\hline $\begin{array}{l}\text { concen- } \\
\text { tration }\end{array}$ & N & $\begin{array}{l}\text { Refractory } \\
\text { period }\end{array}$ & $\begin{array}{l}\text { Conduction } \\
\text { velocity }\end{array}$ & $\begin{array}{l}\text { Wave } \\
\text { length }\end{array}$ \\
\hline $\begin{array}{l}\text { Verapamil } \\
\mathrm{mg} / 1\end{array}$ & & ms & $\mathrm{cm} / \mathrm{sec}$ & $\mathrm{mm}$ \\
\hline control & 7 & $60.9 \pm 11.8$ & $33.9 \pm 7.2$ & $20.3 \pm 3.2$ \\
\hline 0.1 & 5 & $\begin{array}{l}62.8 \pm 13.5 \\
\text { ns }\end{array}$ & $\begin{array}{l}32.4 \pm 7.7 \\
\mathrm{~ns}\end{array}$ & $\begin{array}{l}19.8 \pm 3.5 \\
\mathrm{~ns}\end{array}$ \\
\hline 0.5 & 6 & $\begin{array}{l}64.0 \pm 13.2 \\
\mathrm{~ns}\end{array}$ & $\begin{array}{l}30.3 \pm 10.7 \\
\mathrm{~ns}\end{array}$ & $20.5 \pm 5.6$ \\
\hline 1.0 & 6 & $\begin{array}{l}68.7 \pm 20.0 \\
n s\end{array}$ & $\begin{array}{l}33.2 \pm 8.1 \\
*\end{array}$ & $\begin{array}{l}22.2 \pm 3.8 \\
\mathrm{~ns}\end{array}$ \\
\hline $\begin{array}{l}\mathrm{ns} \\
*\end{array}$ & & nt & & \\
\hline
\end{tabular}


TABLE 10. III

THE EFFECTS OF VERAPAMIL DURING RAPID PACING (Fmax)

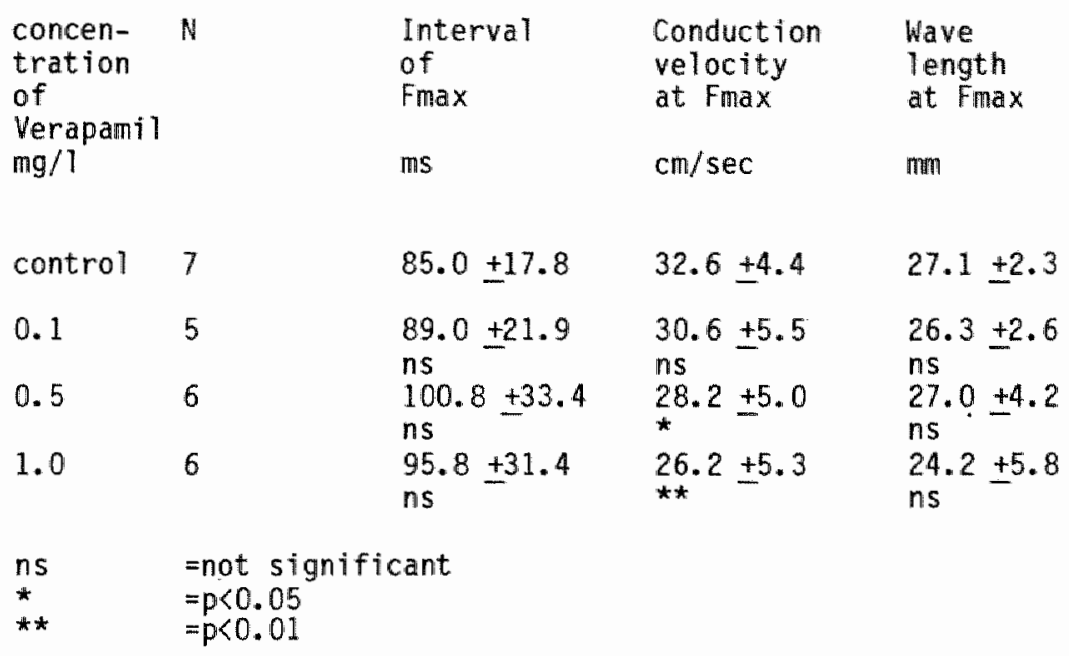

$85 \mathrm{msec}$ during control, to 89,101 and $96 \mathrm{msec}$ at $0.1,0.5$ and $1.0 \mathrm{mg} / 1$ verapamil. These differences did not reach a statistically significant level. Simultaneously the conduction velocity during maximal pacing was diminished from $33 \mathrm{~cm} / \mathrm{sec}$ to 31,28 and $26 \mathrm{~cm} / \mathrm{sec}$ at the different verapamil concentrations. Since again the slight prolangation of the shortest possible pacing interval was equal and opposite to the depression in conduction, the length of the excitation wave was not changed by verapamil. At $0.1,0.5$ and $1 \mathrm{mg} / 1$ the values were 26,27 and 24 min compared to 27 mm during control.

\section{$\underline{10.3 \text { DISCUSSION }}$}

The effects of verapamil on refractoriness and conduction velocity of normal atrial myocardium.

Wit and Cranefield (1974) showed that the maximal upstroke velocity of the action potential in atrial fibers of the rabbit was not changed by verapamil even at a concentration of $2 \mathrm{mg} / 1$. Verapamil also did not change the action patential amplitude and the action potential duration at $50 \%$ repolarization (at high concentrations of verapamil). From these results one might expect 
that impulse conduction in atrial fibers is not influenced by verapamil. Our study is in agreement with this statement as far as it concerns the conduction of the impulse during slow pacing or during a single premature beat; however during fast pacing conduction velocity in atrial tissue was slightly depressed by verapamil in a concentration of $1 \mathrm{mg} / 1$. Studies on the effect of verapamil on refractoriness are very limited. Rosen et al. (1974) reported that the effective refractory period of Purkinje fibers is only slightly altered by verapamil. Indirect support for this is given by the studies by singh and Vaughan Williams (1972) and Wit and Cranefield (1974) demonstrating that the duration of the action potential of rabbit atrial tissue is hardly affected by verapamil.

Verapami 1 and reentrant arrhythmias.

Both the Titerature on the effect of verapamil on the electrophysiology of atrial myocardium as discussed above and the results of our study, point out that verapamil has no major effect on the electrophysiological properties of healthy atrial myocardium. It is therefore not surprising that the wave length of the impulse is not influenced by the drug. However verapamil may suppres electrical activity from diseased atrial or ventricular muscle fibers having reduced resting membrane potentials; in such fibers activity largely depends on the calcium flux through the "slow" channel. Therefore we postulate that verapamil will not influence reentrant arrhytmias occurring in healthy myocardium, whereas in case nodal tissue or diseased myocardium is part of the circuit the arrhythmia will be influenced and probably terminated by verapamil. This is in agreement with the literature reviewed by zipes and Troup (1978) who found that conversion to sinus rhythm accurred after intravenous administration of verapamil in $80 \%$ of episodes of supraventricular tachycardia, $30 \%$ of episodes of atrial flutter and only $16 \%$ of episodes of atrial fibrillation. 


\section{REFERENCES}

Bender F, Kojima N, Replah HD, Delmann G: Behandlung tachykarde Rhythmustorungen des Herzens durch Beta-Rezeptorenblockade des Atrioventriculargewebes.

Med We1t, 17: 1120-1123, 1966.

Fleckenstein A, Tritthart $H$, Fleckenstein B, Herbst A, Gruen G: Eine neue Gruppe kompetitiver $\mathrm{Ca}^{++}$-Antagonisten (Iprowetatril, D600 Prenylamin) mit starken Hemmeffekten auf die elektro-mechanische Koppelung im Warmblueter Myokard.

Pluegers Arch, 307: R25, 1969.

Haas H, Hartfelder G: A-isopropyl-a-( (n methyl-n-homoveratryl)-d-aminopopyl) -3,4-dimethoxyphenyl-acetonitril.

Arzneim Forsch, 12: 549-558, 1962.

Kauman AJ, Aramendia P: Prevention of ventricular fibrillation induced by coronary ligation.

J Pharmacol Exp Ther, 164: 326-340, 1968.

Kohlhardt $M$, Bauer $B$, Krause $H$, Fleckenstein A: Differentiation of the transmembrane $\mathrm{Na}$ and $\mathrm{Ca}$ channels in mammalian cardiac fibers by use of specific inhibitors.

In: Recent advances in studies on cardiac structure and metabolism. Vol 5: Basic functions of cations in myocardial activity. Eds: Fleckenstein A, Dhalla NS, University Park Press, Baltimore, London, Tokyo, 19-33, 1975

Krikler DM, Spurrel RAJ: Verapamil in the treatment of paroxysmal supraventricular tachycardia.

Postgrad Med J, 50: 447-453, 1974.

Melville KI, Shister HE, Huq S: Iproveratril: experimental data on coronary dilation and antiarrhythmic action.

Can Med Assoc J, 90: 761-770, 1964. 
Rosen MR, ITvento JP, Gelband $H$, Merker C: Effects of verapamil on electrophysiological properties of canine cardiac Purkinje fibers. J Pharmacol Exp Ther, 189: 414-422, 1974.

Rosen MR, Wit AL, Hoffman BF: Electrophysiology and pharmacology of cardiac arrhythmias. VI. Cardiac effects of verapamil. Am Heart J, 89: 665-673, 1975.

Schamroth L: Immediate effects of intravenous verapamil on atrial fibrillation.

Cardiovasc Res, 5: 419-424, 1971.

Schamroth L, Krikler DM, Garett C: Immediate effects of intravenous verapamil in cardiac arrhythmias.

Br Med J, 1: 660-662, 1972.

Schmid JR, Hanna C: A comparison of the antiarrhythmic actions of two new synthetic compounds, iproveratrill and MJ 1999, with quinidine and pronethalol.

J Pharmacol Exp Ther, 156: 331-338, 1967.

Singh BN, Vaughan Williams EM: A fourth class of anti-dysrhythmic action. Effect of verapamil on ouabaine toxicity, on atrial and ventricular intracellular potentials, and on other features of cardiac function. Cardiovasc Res, 12: 109-119, 1971.

Wit AL, Cranefield PF: Effect of verapamil on the simoatrial and atrioventricular nodes of the rabbit and the mechanism by which it arrests reentrant atrioventricular nodal tachycardia.

Circ Res, 35: 413-424, 1974.

Zipes DP. Troup PJ: New anti-arrhythmic agents. Amiodarone, aprindine, disopyramide, ethmozin, mexiletine, tocainide, verapamil. Am J Cardiol, 41: 1005-1024, 1978. 


\section{THE EFFECTS OF AMIODARONE}

Amiodarone, a benzofuran derivative, was developed in the laboratories of Labaz Brussels in 1961. Initially it was used as an antianginal agent, but later the antiarrhythmic effects were recognised. Beneficial effects have been noted in the Wolff-Parkinson-White syndrome, both to prevent supraventricular tachycardias (Rosenbaum et al. 1974) and to reduce a high ventricular rate when atrial fibrillation occurs in a patient with WPW (Wellens et al. 1976). It has also been shown to be effective against atrial flutter and fibrillation (Rosenbaum et al. 1974, Rowland and Krikler 1980, Santos et al. 1979, wheeler et al. 1979), and against recurrent ventricular tachycardias (Rosenbaum et a1. 1974, Wheeler et al. 1979). However the electrophysiological mechanisms by which the drug exerts its antiarrhythmic effects are poorly understood. A prolongation of the refractory period has been reported as one of the most important electrophysiological effects of amiodarone, while the conduction velocity should not be affected or only stightly depressed (Singh and Vaughan Williams 1970).

Recent investigations indicate that atrial fibrillation is based on multiple local reentrant circuits (Moe and Abildskor 1959, Allessie et al. 1982). The number of these functionally determined circuits, which are present simultaneously, depends on the size of the circuits relative to the size of the heart. If the dimension of the circuits is small relative to the size of the atria there is room for many circuits. In this situation the statistical chance on termination of fibrillation is sma 7 . On the other hand if the size of the atria is small or the minimal size of a circuit is large, only a limited number of wave fronts can be present at the same time and termination of fibrillation becomes more likely. A drug which prolongs the length of the excitation wave can be expected to act as an antifibrillatory agent. The primary purpose of this study was to verify whether amiodarone -except for its prolongation of the refractory period-also prolonged the length of the excitation wave. If so, this might explain the antifibrillatory action of amiodarone.

\subsection{METHODS}

Since the solubility of amiodarone in Tyrode solution is 1 imited and only allows low concentrations to be studied, we investigated the effects of 
amiodarone after chronic administration to the rabbit. Because the binding of amiodarone after longterm treatment is very strong the heart can be isolated and studied in vitro without further addition of amiadarone to the perfusion solution. Amiodarone (Cordarone, Labaz) was injected intraperitoneally during a period of 4 weeks. 27 Rabbits (New Zealand, both sexes, $1.5 \mathrm{~kg}$ ) were included in the study. Three groups of 9 rabbits were selected at random. During 4 weeks all animals were given one intraperitoneal injection daily; in group 1 only the soivent $(0.8 \mathrm{ml} / \mathrm{kg})$ was injected, group 2 was given $20 \mathrm{mg} / \mathrm{kg}$ amiodarone, whereas group 3 received $40 \mathrm{mg} / \mathrm{kg}$ amiodarone daily. Both amiodarone groups were loaded with $65 \mathrm{mg} / \mathrm{kg}$ amiodarone during the first 3 days.

After 4 weeks of treatment two preparations were isolated: the right atrium to measure the intrinsic rate of the sinus node, and a strip of left atrium to measure the functional refractory period and the conduction velocity of the myocardium. The two preparations were put together in a tissue bath which was perfused at a rate of $100 \mathrm{ml} / \mathrm{min}$. No amiodarone was added to the perfusion solution. There was no evidence that amiodarone or its metabolites were washed-out during the superfusing period after isolation of the heart. The first measurement, done about 25 min after the operation, and the last measurement, one and a half hour later, gave the same results.

Statistical analysis was done using the student t-test.

\subsection{RESULTS}

To evaluate whether the injected amiodarone was absorbed from the peritoneal fluid we determined the amiadarone plasma concentration prior to the operation. The group receiving $20 \mathrm{mg} / \mathrm{kg}$ had a mean $\mathrm{plasma}$ level of 0.43 $\mathrm{mg} / 1( \pm 0.45)$. The group with the high concentration of amiodarone (40 mg/kg) had a mean plasma level of $1.44 \mathrm{mg} / 1( \pm 1.02)$. It may be noted (table $11 . \mathrm{I}$, 11. II and 11. IIl) that the individual plasma levels varied considerably in both groups. It is not clear whether this is caused by differences in absorption or in metabolism.

The weight of the rabbits at the first day of treatment was $1.48( \pm 0.06)$ kg.; there were no differences between the three groups. However at the day 
vof operation the weight of the rabbits having received amiodamone was significantly less than in the placebo group. Obviously the growth of young rabbits is retarded by amiodarone.

The effects of amiodarone on the intrimsic rate of the sinus node.

Figure 11.1 shows the intrinsic rate of the sinus node after 4 weeks of treatment in the 3 groups. The open bar represents the intrinsic rate of the placebo group, the bar with the large circles the group with the low concentration amiodarone, while the bar with the small circles indicates the group treated with the high concentration of amiodarone. In the placebo group $(n=9)$ the mean cycle length was $426 \mathrm{msec}( \pm 41.2 \mathrm{msec})$. Essentially the same value was found in the group $(n=8)$ treated with $20 \mathrm{mg} / \mathrm{kg}$ amiodarome (429 msec \pm $48.1 \mathrm{msec}$ ). A significant prolongation of the cycle length of the sinus node was observed in the group $(n=9)$ with a high concentration of amiodarone (495 msec \pm 75.6 msec).

TABEL 11.I

PLACEBO

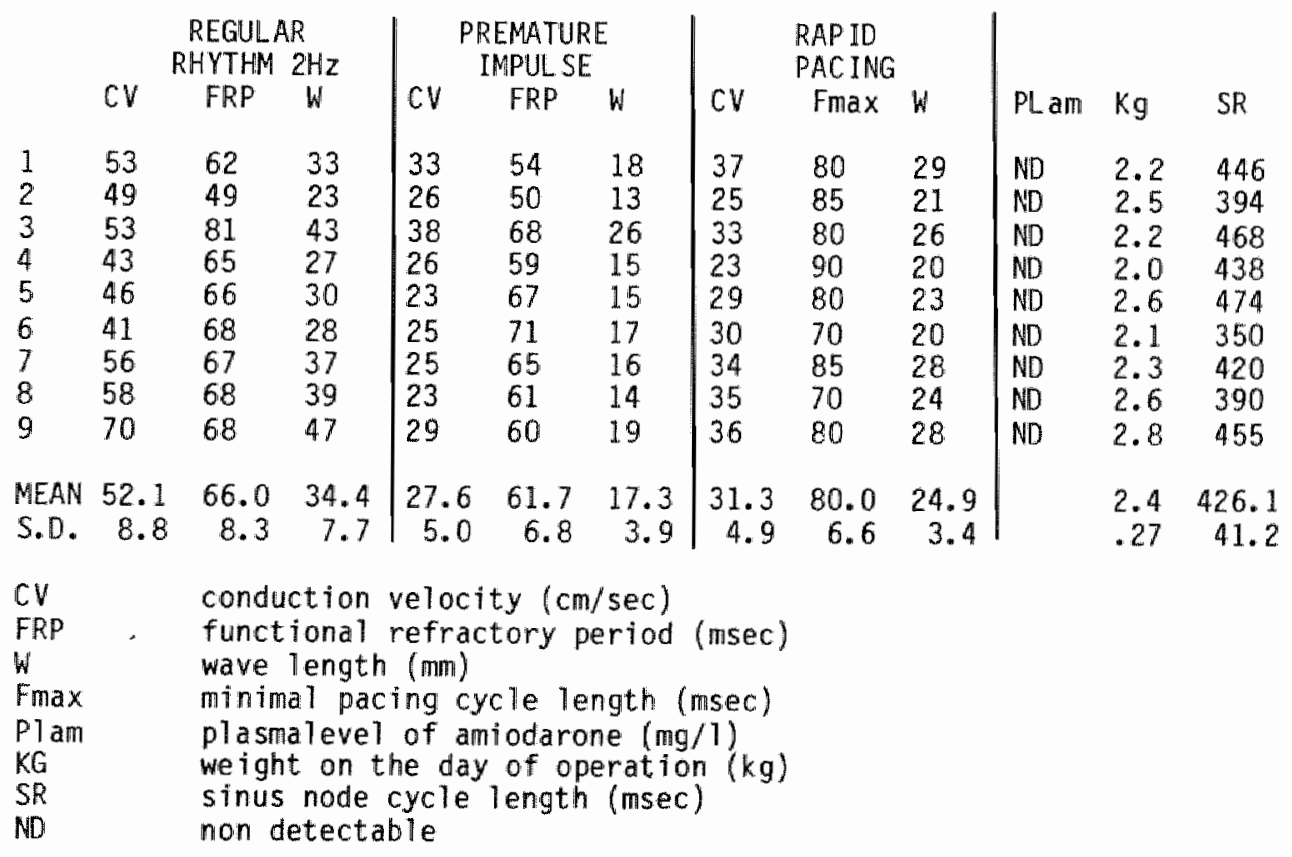


AMIODARONE $20 \mathrm{mg} / \mathrm{kg}$

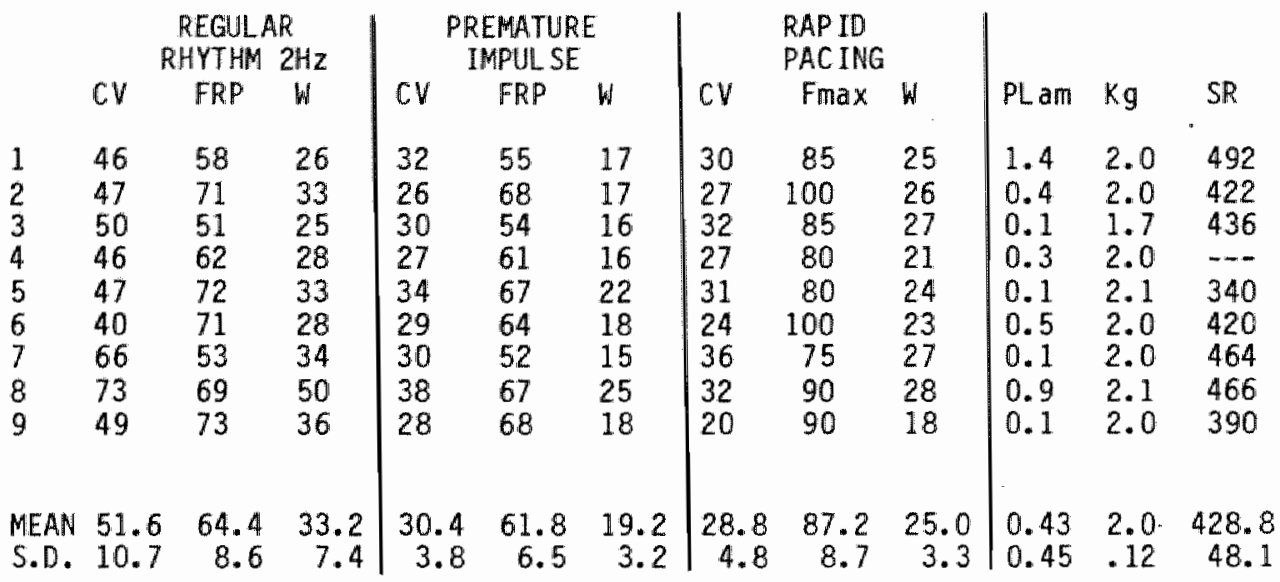

Tabel 11. III

AMIOD ARONE

$40 \mathrm{mg} / \mathrm{kg}$

\begin{tabular}{|c|c|c|c|c|c|c|c|c|c|c|c|c|}
\hline & & $\begin{array}{l}\text { REGULL } \\
\text { RHYTHM }\end{array}$ & $\begin{array}{l}\mathrm{R} \\
2 \mathrm{~Hz}\end{array}$ & & $\begin{array}{l}\text { EMATUR } \\
\text { MPUL SE }\end{array}$ & & & $\begin{array}{l}\text { RAP ID } \\
\text { PACING }\end{array}$ & & & & \\
\hline & CV & FRP & $W$ & $\mathrm{cV}$ & FRP & $w$ & $\mathrm{CV}$ & $F_{\max }$ & $W$ & PL am & $\mathrm{Kg}$ & $S R$ \\
\hline 1 & $\begin{array}{l}48 \\
39 \\
38 \\
45 \\
43 \\
42 \\
31 \\
48 \\
56\end{array}$ & $\begin{array}{r}64 \\
68 \\
100 \\
79 \\
64 \\
84 \\
70 \\
72 \\
81\end{array}$ & $\begin{array}{l}30 \\
26 \\
37 \\
35 \\
27 \\
35 \\
21 \\
34 \\
45\end{array}$ & $\begin{array}{l}31 \\
29 \\
23 \\
25 \\
27 \\
27 \\
23 \\
34 \\
34\end{array}$ & $\begin{array}{r}54 \\
61 \\
107 \\
79 \\
58 \\
77 \\
65 \\
64 \\
67\end{array}$ & $\begin{array}{l}16 \\
17 \\
24 \\
19 \\
15 \\
20 \\
15 \\
21 \\
22\end{array}$ & $\begin{array}{l}30 \\
20 \\
20 \\
26 \\
28 \\
20 \\
20 \\
21 \\
34\end{array}$ & $\begin{array}{r}85 \\
105 \\
160 \\
100 \\
110 \\
120 \\
90 \\
110 \\
90\end{array}$ & $\begin{array}{l}25 \\
21 \\
31 \\
25 \\
30 \\
23 \\
18 \\
23 \\
30\end{array}$ & $\begin{array}{l}1.5 \\
3.1 \\
1.1 \\
0.1 \\
0.9 \\
1.0 \\
1.4 \\
3.1 \\
0.8\end{array}$ & $\begin{array}{l}2.0 \\
2.0 \\
1.9 \\
2.5 \\
2.2 \\
2.3 \\
2.0 \\
1.7 \\
2.0\end{array}$ & $\begin{array}{l}496 \\
490 \\
550 \\
398 \\
406 \\
620 \\
420 \\
550 \\
528\end{array}$ \\
\hline $\begin{array}{l}\text { IEAN } \\
\text {.D. }\end{array}$ & $\begin{array}{r}43.3 \\
7.1\end{array}$ & $\begin{array}{l}75.8 \\
11.6\end{array}$ & $\begin{array}{r}32.9 \\
6.9\end{array}$ & $\begin{array}{r}28.1 \\
4.2\end{array}$ & $\begin{array}{l}70.2 \\
16.0\end{array}$ & $\begin{array}{r}19.7 \\
3.4\end{array}$ & $\begin{array}{r}24.3 \\
5.3\end{array}$ & $\begin{array}{r}107.8 \\
22.7\end{array}$ & $\begin{array}{r}25.7 \\
4.7\end{array}$ & $\begin{array}{l}1.44 \\
1.02\end{array}$ & $\begin{array}{l}2.1 \\
.23\end{array}$ & $\begin{array}{r}495.3 \\
75.6\end{array}$ \\
\hline $\begin{array}{l}C V \\
\text { FRP } \\
\text { W } \\
\text { Fmax } \\
\text { Plam } \\
\text { KG } \\
\text { SR }\end{array}$ & & $\begin{array}{l}\text { cond } \\
\text { func } \\
\text { wave } \\
\text { minit } \\
\text { plas } \\
\text { weig } \\
\text { sinu } \\
\text { non }\end{array}$ & $\begin{array}{l}\text { ction } \\
\text { ional } \\
\text { length } \\
\text { al pad } \\
\text { al eve } \\
t \text { on } \\
\text { node }\end{array}$ & $\begin{array}{l}\text { veloc } \\
\text { refrac } \\
\text { (mm) } \\
\text { ing } \\
\text { of an } \\
\text { he day } \\
\text { cycle }\end{array}$ & $\begin{array}{l}\text { ty (c } \\
\text { toory } \\
\text { rcle } 1 \\
\text { miodar } \\
\text { of } \\
\text { Tengt }\end{array}$ & $\begin{array}{l}\mathrm{sec} \text { ) } \\
\text { riod } \\
\text { gth } \\
\text { ee (mg } \\
\text { ratio } \\
\text { (msec }\end{array}$ & $\begin{array}{l}\text { msec } \\
\text { li) } \\
n(k\end{array}$ & & & & & \\
\hline
\end{tabular}


The effects of amiodarone during slow rate.

In figure 11.2 the effects of amiodarone on conduction velocity, functional refractory period and wave length of the atrial impulse during a regular rhythm of $2 \mathrm{~Hz}$ are plotted. In the placebo group the conduction velocity at a rate of $2 \mathrm{~Hz}$ was $52 \mathrm{~cm} / \mathrm{sec}( \pm 8.8$ ). The functional refractory period was $66 \mathrm{msec}( \pm 8.3)$; thus the length of the excitation wave during this slow rhythm was calculated to be $34 \mathrm{~mm}( \pm 7.7)$. Treatment during 4 weeks with a low concentration of amiodarone $(20 \mathrm{mg} / \mathrm{kg}$ daily) did not affect the conduction velacity $(52 \mathrm{~cm} / \mathrm{sec} \pm 10.7)$, nor the functional refractory periad $(64 \mathrm{msec} \pm 8.6)$. Therefore the wave length of the impulse remained the same $(33 \mathrm{~mm} \pm 7.4)$. However when the rabbits were treated for 4 weeks with a higher dosage of amiodarone $(40 \mathrm{mg} / \mathrm{kg}$ daily), clear electrophysiollagical changes occurred. During slow pacing with $2 \mathrm{~Hz}$ the functional refractory period prolonged from $66 \mathrm{msec}( \pm 8.3)$ to $76 \mathrm{msec}( \pm 11.6)$. If such a prolongation in refractory period was not accompanied by a depression in

\section{SINUS NODE INTERVAL}

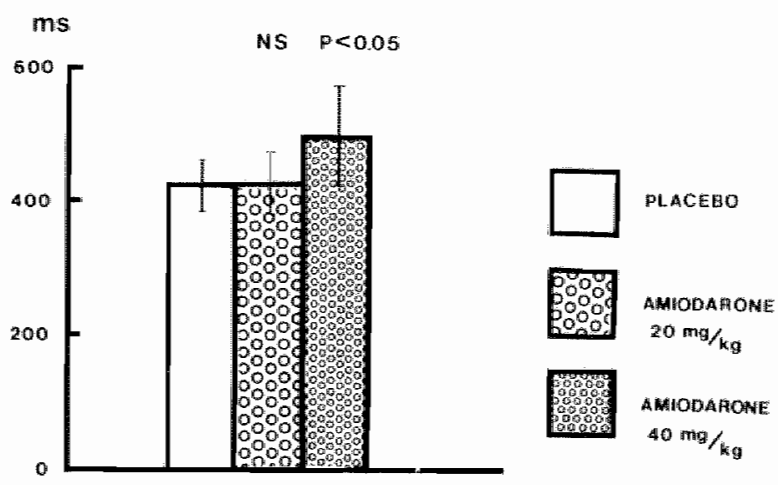

EIGURE 11.1 The effects of amiodarone on the intrinsic rate of the simus node. the open bar represents the placebo group $(n=9)$, the bar with the large circtes is the group with the low concentration amiodarone $120 \mathrm{mg} / \mathrm{kg}, 1 \mathrm{~m}=\mathrm{B}$. and the bar with the mall circlee the group with the high concentration of amiodarone $(40 \mathrm{mg} / \mathrm{kg}, n=9)$. there is no change of the cycle length in the low concentration group if compared with the placebo group, but the group with the high concentration shows a significant increase in the cycle length from $426( \pm 1.2)$ to $495 \mathrm{mbec}( \pm 75.6)$. 
conduction velocity, this would result in a lengthening of the excitation wave. However amiodarone in the high concentration did slow down the speed of propagation from $52 \mathrm{~cm} / \mathrm{sec}( \pm 8.8)$ to $43 \mathrm{~cm} / \mathrm{sec}( \pm 7.1, P<0.05)$. This slowing of the conduction velocity completely neutralized the effect of the prolongation of the refractory period on the length of the excitation wave.

\section{REGULAR RHYTHM $2 \mathrm{HZ}$}

\section{CONDUCTION VELOCITY $Y$}

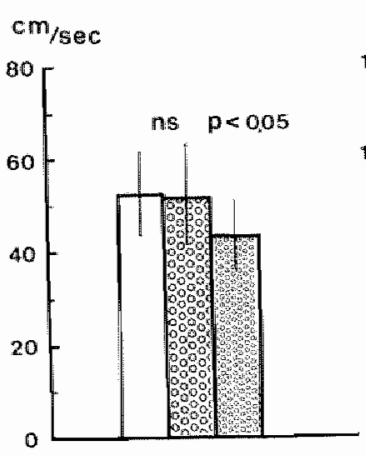

FUNCT. REFR

PERIOD

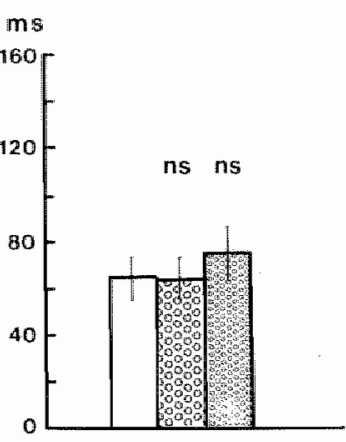

WAVE LENGTH

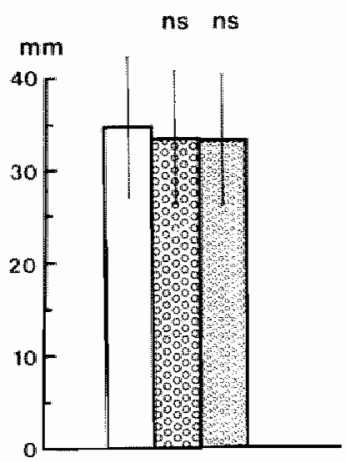

PLACEBO

AMIODARONE $40 \mathrm{mg} / \mathrm{kg}$

FIGURE 11.2 The effects of amiodarone on the wave length of the reguiar impulase. The conduction velactty in the placebo group ( $n=9$, open bar) is 52 $\mathrm{cm} / \mathrm{eec}(+8.8)$. The mean refractory period is 66 mbec $(+8.3)$. The mean wave Zength of the impulae at $2 \mathrm{ha}$ is $34 \mathrm{~mm}(+7.7)$. Aftem chronic treatment with a tow concentration of amiodarone (bar with the large circles), there is no atteration in the conduction velocity $(52 \mathrm{~cm} / \mathrm{sec}+10.7)$ or in the refractory period $(64$ moec $(+8.6))$. The calculated wave length $i s 33 \mathrm{~mm}(+7.4)$. After treatment for 4 weeks with a high concentration of amiodarone $(40 \mathrm{mg} / \mathrm{kg})$ both the conduction velocity and the refractory period are affected. The conduction velocity at $2 \mathrm{hz}$ is depressed to $43 \mathrm{~cm} / \mathrm{sec}( \pm 7.1)$. This would imply that the wave length would be smatier if the refractory period was constant. However this is not the case. The refractory period increased from $66(+8.3)$ to 76 msec $(+11.6)$. Because of the fact that these changes are almost equal and have an opposite effect on the length of the excitation wave, the product of the two remaine unchanged: $33 \mathrm{~mm}( \pm 6.9)$. 
As a result amiodarone had no effect on the wave length of the impulse during a regular rhythm of $2 \mathrm{~Hz}$. The values were $34 \mathrm{~mm}, 33 \mathrm{~mm}$ and $33 \mathrm{~mm}$ for the placebo group, low amiodarone group and high amiodarone group respectively.

The effects of amiodarone on premature beats.

In figure 11.3 the electrophysiological influence of amiodarone on early premature beats is depicted. As can be expected the conduction welocity of a

\section{EARLIEST PREMATURE IMPULSE}

\section{CONDUCTION VELOCITY}

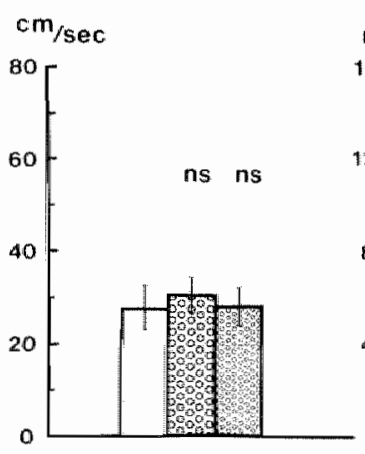

WAVE LENGTH

FUINCT. REFR.

PERIOD
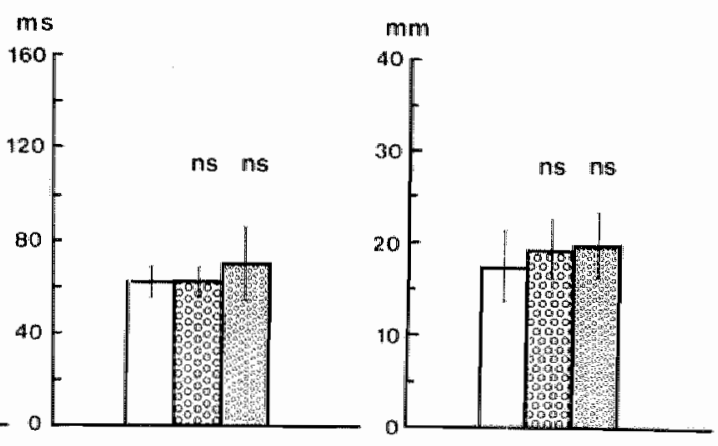

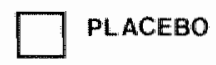

AMIODARONE

$40 \mathrm{mg} / \mathrm{kg}$

FIGUFE 11.3 The effects of amiodarone on the wane length of the earliest premature impulse. The open bars represent the placebo group ( $n=9$ ), the bars with the Earge circles the group with the low concentration amiadarone 120 $m g / k g, n=8)$, the bars with the smalt circles the group with the high concentration amiodarone $(40 \mathrm{mg} / \mathrm{kg}, \mathrm{m}=9)$. The conduction velocity of the earlitest premature impulse in the placebo group is $28 \mathrm{~cm} / \mathrm{sec}(+5.0)$. The excitability is recovered after 62 mbec $(+6.8)$. The mean wave tength of the premature impulse ie $17 \mathrm{~mm}(+3.9)$, half of the length of the excitation wave at $2 \mathrm{~Hz}$. At a low concentration of amiodarone the wave length increases sligthly to $19 \mathrm{~mm}(+3.2)$. At a high concentration the wave length has increased to $20 \mathrm{~mm}(+3.4)$, due to a slight prolongation of the refractory period $(70 \mathrm{msec}+16.05$, the conduction velocity remaining the 8 ame $128 \mathrm{~cm} / \mathrm{sec}$ $\pm 4.21$. 
premature impulse is slower than the speed of propagation during a slow rhythm. In the placebo group the mean conduction velocity of the earliest premature beat was $28 \mathrm{~cm} / \mathrm{sec}( \pm 5.0 \mathrm{~cm} / \mathrm{sec})$, compared to $52 \mathrm{~cm} / \mathrm{sec}$ of the regular impulse. The mean functional refractory period of the earliest premature beat was sightly shorter than during basic rhythm $(62$ msec \pm 6.8 versus $66 \mathrm{msec} \pm 8.3)$. This marked depression of the conduction velocity and the shortening of the refractory period both shortened the excitation wave. As a consequence the length of the excitation wave of the early premature beat was not more than $17 \mathrm{~mm}( \pm 3.9)$.

After chronic administration of $20 \mathrm{mg}$ amiodarone per $\mathrm{kg}$ dally, the conduction velocity and the functional refractory period of the earliest premature impulse were not changed: $30 \mathrm{~cm} / \mathrm{sec}( \pm 3.8)$ and $62 \mathrm{msec}( \pm 6.5)$ respectively. The length of the excitation wave was $19 \mathrm{~mm}( \pm 3.2)$. These values were not statistically different ( $P>0.05$ ) from the placebo group. At the high concentration of amiodarone there was some prolongation of the mean functional refractory period, from $62 \mathrm{msec}$ to $70 \mathrm{msec}( \pm 16.0)$. The mean conduction velocity was the same as in the placebo group (28 cm/sec 44.2$)$. Due to the slight increase in refractary period, the wave length of the early prenature beat was also slightly lengthened (from 17 to $20 \mathrm{~mm}$ ). However these differences did not reach a statistically significant level.

The effects of amiodarone during rapid rate.

Figure 11.4 gives the mean values of the conduction velocity, refractory period and the wave length during the highest possible pacing rate in the three groups. The conduction velocity during the highest pacing rate is much slower than during a regular rhythm of $2 \mathrm{~Hz}(31 \mathrm{~cm} / \mathrm{sec}$ compared to 52 $\mathrm{cm} / \mathrm{sec}$. This distinct slowing of the speed of propagation did cause a marked shartening of the excitation wave (25 versus $34 \mathrm{~mm})$. The length of the excitation wave of the earliest premature impulse is shorter than the wave length at the highest pacing rate (17 versus $25 \mathrm{~mm}$ ), because the functional refractory period of a premature impulse is shorter than the minimal pacing cycle length.

After 4 weeks of treatment with amiodarone $(20 \mathrm{mg} / \mathrm{kg} / \mathrm{day})$ none of the measured electrophysiological parameters were significantly changed. The shortest possible pacing interval prolonged slightly from $80.0 \pm 6.6$ to 87.2 $\pm 8.7 \mathrm{msec}$. The conduction velocities at these rates decreased from 
$31.3+4.9$ to $28.8 \pm 4.8 \mathrm{~cm} / \mathrm{sec}$. The resulting wave length was $24.9 \pm 3.4 \mathrm{~mm}$ during control whereas after treatment with this low dosage of amiodarone the wave length was $25.0 \pm 3.3 \mathrm{~mm}$.

After 4 weeks of treatment with amiodarone $(40 \mathrm{mg} / \mathrm{kg} /$ day) the maximum possible pacing rate of the atrium was clearly diminished; the shortest possible pacing interval proionged from 80 to $108 \mathrm{msec}$. This increase in the minimum time required for recovery of excitability between two succesive

\section{$F_{\text {MAX }}$}

$\begin{array}{ll}\text { CONDUCTION } & F_{\text {MAX }} \\ \text { VELOCITY }\end{array}$
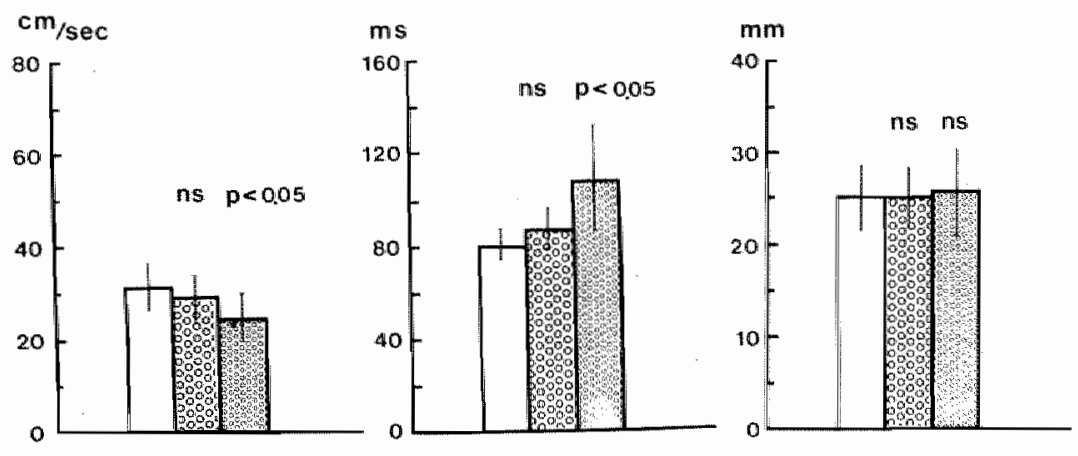

PLACEBO

AMIODARONE

$20 \mathrm{mg} / \mathrm{kg}$
AMIODARONE

$40 \mathrm{mg} / \mathrm{kg}$

FIGURE 11.4 The wrve length at the highest pacing rate. The format is the same as in figure 11.2 and 11.3. The shortest possible pacing interval (max) is in the placebo group 80 meed $(+6.6)$, the conduction velocity at this pacing rate being $31 \mathrm{~cm} / \mathrm{sec}(+4.9)$. The mean length of the excitation wave is $25 \mathrm{~mm}$ $(+3.4)$. The wawe length is atill $25 \mathrm{~mm}(+3.3)$ at a low concentration of amiodarone. In this situation there $i \cdot s$ only a minor increase in the minimum pacing interval $(87 \mathrm{msec}+8.7)$. This effect on the wave length $i_{8}$ counter acted by the decrease in conduction velocity $(29 \mathrm{~cm} / \mathrm{sec}+4.8)$. In the group with the high amiadarone concentration the interval of Fmax inemeased further to 108 meec $(+22.7)$ while the conduction velocity was depressed $(24 \mathrm{~cm} / \mathrm{sec}$ $+5.3)$. Because of the fact that these changes were about equat but opposite amiodarone had no effect on the wave length of the impulse during rapid pacing. 
impulses should have prolonged the length of the excitation wave considerably. However such prolongation of the wave length was not found. In contrast to what was expected, amiodarone did not alter the length of the excitation wave in the atrium. This was caused by the fact that the prolongation of the time for recovery of excitability was accompanied by a concomitant depression in conduction velocity. Thus the slowing of the speed of propagation completely neutralized the effect of the prolongation of the refractory period on the wave length.

\subsection{DISCUSSION}

Effects of amiodarone on heart rate.

One of the beneficial effects of amiodarone in patients with angina pectoris is the slowing of heart rate. In animal studies this bradycardia is found both after chronic and acute administration (Singh and Vaughan Williams 1970, Rosenbaum et al. 1974, Goupil and Lenfant 1976, Lubbe et al. 1979). In clinical studies the bradycardia is also observed after chronic oral treatment, but acute intravenous administration of amiodarone gave controversial results. When amiodarone is injected intravenously a transient tachycardia occurs during the first 3-4 min. This is probably due to the solvent (Tween 80) because Sicart et al. (1977) could show that the same tachycardia occurred after injection of the solvent alone. Apart from this short initial tachycardia, some investigators did not abserve a change in heart rate (Sicart et a1. 1977, Benaim and Uzan 1978, Cote et al. 1979) while others found a bradycardia (Ourbak et al. 1976. Touboul et al. 1979). One of the explanations for the bradycardia is the non competitive beta-blocking properties of amiodarone (Charlier 1970, Polster and Brokkuysen 1976). Besides these beta-blocking effects amiodarone also has a direct suppressive effect on the sinus node. In the present study we confirmed the observations of Singh and Vaughan Williams (1970) and Goupil and Lenfant (1976), that the intrinsic rate of the isolated, denervated sinus node is slowed down under the influence of amiodarone. Thus it seems likely that the bradycardia observed in patients is caused both by a direct suppression of the intrinsic rate of the sinus node and by an indirect effect mediated by the betablocking properties of amiodarone. 
Effects of amiodarone on refractory period, maximum pacing frequency and conduction velocity.

Singh and Vaughan Williams (1970) measured the transmembrane action potential in rabbit atrium after chronic treatment with $20 \mathrm{mg} / \mathrm{kg}$ amiodarone. They observed a prolongation of the action potential duration of $30 \%$, suggesting that the refractory period increased by amiodarone. 01sson et al. (1973) showed that the monophasic action potential in the right atrium of humans was lengthened with about $30 \%$ after chronic administration of amiodarone. Direct measurement of the refractory period of the atrium in patients by programmed electrical stimulation revealed a prolongation varying from $17 \&$ (Wellens et al. 1976) to $28 \%$ (Rowland and Krikler 1980). We found in the rabbit atrium after 4 weeks of treatment with $40 \mathrm{mg} / \mathrm{kg}$ a prolongation of the functional refractory period from 66 to $76 \mathrm{msec}(+15 \%)$. The maximum pacing frequency of the atrium was also clearly diminished by amiodarone. The shortest possible interval of a train of stimuli which still showed a 1:1 response increased from 80 to $108 \mathrm{msec}(+35 \%)$. This means a decrease of the maximum pacing rate from 750 to 555 beats per min.

Less uniform are the results about the effects of amiodarone on the conduction velocity. Singh and Vaughan Williams (1970) found in the rabbit atrium a small but signifficant decrease of the maximum rate of rise of the action potential. Nevertheless they did not measure a difference in conduction velocity in the atrium between the amiodarone treated and control rabbits. In clinical studies no change was found in the intra-atrial and intra-ventricular conduction (Benaim and Uzan 1978, Rosenbaum et a1. 1974). In our studies the conduction velocity in the atrium was clearly depressed after 4 weeks of treatment with $40 \mathrm{mg} / \mathrm{kg}$ amiodarone. During a slow regular rhythm of $2 \mathrm{~Hz}$ the speed of propagation was diminished by $18 \%$. Pacing the atrium with the highest possible rate caused a further depression af the conduction velacity with $22 \%$. Also the conduction velocity of premature beats after treatment with amiodarone was less than in the placebo group.

Effects of amiodarone on the wave length.

In figures $11.2,11.3$ and 11.4 the wave length during a rate of $2 \mathrm{~Hz}$, the wave length of the earliest premature beat and the wave length during the highest pacing rate are depicted. During the highest possible pacing 
frequency the wave length was $26 \%$ shorter than the wave length at $2 \mathrm{~Hz}$. Treatment for 4 weeks with aniodarone $(40 \mathrm{mg} / \mathrm{kg} / \mathrm{day})$ only caused minor changes in this parameter. The wave length of the earliest premature beat prolonged by $14 \%$ compared to the placebo group. However this was not statistically significant. The wave length during a regular rhythm of $2 \mathrm{~Hz}$ and during the highest pacing rate were not changed under influence of amiadarane. This finding can be explained by the fact that the effect of the prolongation of the refractory period on the wave length was totally neutralized by the concomitant depression of the conduction velocity.

The antiarrhythmic effects of amiodarone in relation to reentrant arrhythmias.

Clinical experience with amiodarone in the treatment of atrial fibrillation looks promising. Especially in paroxysmal atrial fibrillation the success rate is high during chronic oral treatment. Rosenbaum et al. (1974) reported reversion to sinus rhythm in 29 out of 30 patients, Rowland and Krikler (1980) 7 out of 8 and Wheeler et al. (1979) 9 out of 15. This means that the overall success rate is 45 out of 53 patients or $85 \%$. Atrial fibrillation with a recent onset also responds well to chronic oral treatment. Santos et al. (1979) reported that $85 \%$ of their patients reverted to sinus rhythm.

Our measurements of the electrophysiological effects of amiodarone in the isolated rabbit atrium do not give a satisfactory explanation for this well documented antifibrillatory action of amiodarone. In contrast with all the other interventions studied in the previaus chapters, in case of amiodarone no correlation between changes in the length of the excitation wave and susceptibility to atrial fibrillation could be demonstrated. We have no good explanation for this discrepancy. The most likely explanation is that in case of amiodarone there are marked species differences. Evidence is accumulating that the complex pharmacokinetics of amiodarone are different in the different species. For instance the metabolite desethyl-amiodarone is found in plasma of humans in concentrations as high as amiodarone itself. It is likely that this metabolite has antiarrhythmic properties itself. In the plasma of the rabbit this metabolite is not found suggesting that differences in pharmacokinetics may indeed play an important role as far as the anti- 
arrhythmic properties are concerned. In the light of the growing clinical application of amiodarone as an antiarrhythmic drug and because of the marked species differences it might be usefull to measure the effects of amiodarone on the length of the excitation wave in the human heart.

\section{ACKNOWL EDGEMENT}

We are grateful to Dr.P Schoenfeld of Labaz Brussels for generously supplying Amiodarone (Cordarome) and the placebo. We also thank Dr. David Holt, Poisons Unit, New Cross Hospital, London for determining the plasma levels of amiodarone.

\section{REFERENCES}

Allessie MA, Lammers WJEP, Smeets JLRM, Bonke FIM, Hollen Su: Total mapping of atrial excitation during acetylchaline-induced atrial flutter and fibrillation in the isolated canine heart.

In: Atrial Fibrillation. Edited by Kulbertus HE, 01sson SB, Schlepper M, Publ Hassle, Molndal Sweden, 44-61, 1982.

Benaim R, Uzan $C$ : Les effects antiarrhythmiques de T'amiodarone injectable (a propos de 153 cas).

Rev Med, 19: 1959, 1978.

Charlier R: Cardiac actions in the dog of a new antagonist of adrenergic excitation which does not produce competitive blockade of adrenoceptors. Br J Pharmacol, 39: 68-74, 1970.

Cote P, Bourassa MG, Delaye J, Janin A, Froment R, David P: Effects of amiodarone on cardiac and coronary hemodynamics and on myocardial metabolism in patients with comary artery disease. Circulation, 59: 1165-1171, 1979. 
Goupil N, Lenfant J: The effects of amiodarone on the simus node activity of the rabbit heart.

Eur J Pharmacol, 39: 23-31, 1976.

Harris L, Mckenna WJ, Rowland E, Storey GCA, Krikler DM, Holt DW: Plasma amiodarone and desethyl amiodarone levels in chronic oral therapy. Circulation, 64, sup1. IV: 263, 1981.

Lubbe WF, McFayden ML, Muller CA, Wothington M, Opie LH: Protective action of amiadarone against ventricular fibrillation in the isolated perfused rat heart.

Am J Cardiol, 43: 533-540, 1979.

Moe GK, Abildskov JA: Atrial fibrillation as a self-sustaining arrhythmia independent of focal discharge.

Am Heart J, 58: 59-70, 1959.

01 sson SB, Brorson L, Varnauskas E: Class 3 antiarrhythmic action in man. observations from monophasic action potential recordings and amiodarone treatment.

Br Heart J, 35: 1255-1259, 1973.

Ourbak P, Rochier R, Aziza J-P, Manin J-P, Vagner D, Leclerc M, Maurice P: Effects hemodynamiques de l'injection intra-veneuse de chlorhydrate d'amiodarone chez le sujet normal et le coronarien.

Arch Ma $]$ Coeur, 69: 293-298, 1976.

Polster $P$, Broekhuysen $\mathrm{J}$ : The adrenergic antagonism of amiodarone. Biochem Pharmaco1, 25: 131-134, 1976.

Rosenbaum MB, Chiale PA, Ryba D, Elizari MV: Control of tachyarrhythmias associated with Wolff-Parkinson-White syndrome by amiodarone hydrochloride.

Am J Cardiol, 34: 215-223, 1974. 
Rowland E, Krikler DM: Electrophysiological assessment of amiodarone in treatment of resistant supraventricular arrhythmias.

Br Heart J, 44: 82-90, 1980.

Santos AL, Aleixo AM, Landeiro J, Luis AS: Conversion of atrial fibrillation to sinus rhythm with amiodarone.

Acta Med Portug , 1: 15-23, 1979.

Sicart M, Besse P, Choussat A, Bricaud H: Action hemodynamique de 7 'amiodarone intra-veneuse chez 1 'home.

Arch Mal Coeur, 70: 219-227, 1977.

Singh BN, Vaughan Williams EM: The effect of amiodarone, a new anti-angimal drug, on cardiac muscle. Er J Pharmaco 1, 39: 657-667, 1970.

Touboul P, Atallah G, Gressard A, Kirkorian G: Effects of amiodarone on the sinus node in man.

Br Heart J, 42: 573-578, 1979.

Wellens HJJ, Lie KI, Bar FW, Wesdorp JC, Dohmen HJ, Duren DR, Durrer D: Effect of amiodarone in the Wolff-Parkinson-White syndrome. Am J Cardiol, 38: 189-194, 1976.

Wheeler PJ, Puritz R, Ingram DV, Chamberlain DA: Amiodarone in the treatment of refractory supraventricular and ventricular arrhythmias. Postgrad Med J, 55: 1-9, 1979. 

SUIMMARY AND CONCLUSIONS.

The aim of this thesis was to investigate whether the length of the excitation wave in cardiac muscle can be used as an indicator for the risk of occurrence of reentrant arrhythmias. Whether an impulse can be trapped in a circuitous route depends both on the inhomogeneity in excltability and conduction and on the size of the reentrant circuit. The delicate interplay between these two electrophysiological properties actually determines the chance of initiation of a functionally determined circuit. If the size of a circuit is small, a small area of conduction block will be sufficient to set the stage for a reentrant arrhythmia. On the other hand if the dimensions of a circuit are large, a large area of conduction block is required for the occurrence of reentry. The size of a functionally determined reentrant circuit is equal to the length of the excitation wave, because a tight fit exists between head and tail of the wave front. Interventions which shorten the wave length of the cardiac impulse will decrease the size of the reentrant circuit. As a consequence the number of circuits which can be simultaneously present in a given mass of heart tissue increases. The chance of spontaneous termination of all circuits at the same time will be low. However if an intervention prolongs the wave length, the size of the reentrant circuit will increase. As a result only a limited number of circuits can be present at the same time, making spontaneous termination likely. If our hypothesis is correct that the length of the excitation wave indicates the risk of occurrence of reentrant arrhythmias we should expect that interventions which are known to facilitate the initiation of reentrant arrhythmias will cause a shortening of the wave length of the cardtac impulse. Interventions which terminate reentrant arrhythmias should be expected to increase the length of the excitation wave.

In chapter 2 a simple method to measure the length of the excitation wave in an isolated strip of left atrial tissue is described. By simultaneously measuring conduction velocity and refractory period of the activation wave under conditions comparable to those during a reentrant tachycardia the length of the excitation wave can be calculated from these two basic electrophysiological parameters. 
A well known method to inftiate reentrant arrhythmias is programmed electrical stimulation of the heart. By either applying a properly timed premature stimulus or by pacing the heart at a rapid rate, reentrant arrhythmias can be inithated as well as terminated. In chapter 3 a description is given of the measurement of the length of the excitation wave during this kind of programmed electrical stimulation. It turmed out that the length of the excitation wave of the earliest possible premature impulse was the shortest. At progressively longer coupling intervals the wave length of the premature beat rapidiy prolonged. It was observed that the wave length was only shortened in a narrow zone of prematurity (30 - $40 \mathrm{msec}$ after the refractory period》. This is consistent with the finding that the reentrant arrhythmias ustally can be initiated by critically timed premature beats. Furthermore it was found that the wave length of the cardiac impulse was also considerably shortened at high pacing rates (faster than $5 \mathrm{fz}$ ). Both the shortening of the wave length of premature impulses and the shortening of the length of the excitation wave during rapid pacing support our hypothesis.

In addition changes in the length of the excitation wave were measured during several interventions which are known to exert an arrhythmogeric or antiarhythmic action. The effects of changes in temperature (chapter 4), in the extracellular potassium concentration (chapter 5), of carbamylcholine and epinephrine (chapter 6) and of antiarrhythmic drugs such as lidocaine (chapter 7), quinidine (chapter 8), ouabain (chapter 9), verapamil (chapter 10) and aniodarone (capter 11) were investigated. In the figure below a summary of the results is presented. In this graph the length of the excitation wave (ordinate) is plotted as a function of the minimal pacing cycle length (abcissa). The effects of various interventions can be divided in three groups: 1) interveritions which shorten the wave length - indicated by the arrows pointing downwards - 2) interventians which do not influence the wave length of the impulse - indicated by the arrows pointing horizontally to the right - and 3) interventions which prolong the wave length indicated by the arrows pointing upwards and to the right.

Ad 1) Both a lowering of the extracellular potassium concentration and administration of carbamylcholine cause a shortening of the wave length (arrows pointing downwards). These interventions are well known for their arrhythmogenic behavior. The observed shortening of the wave length in the 


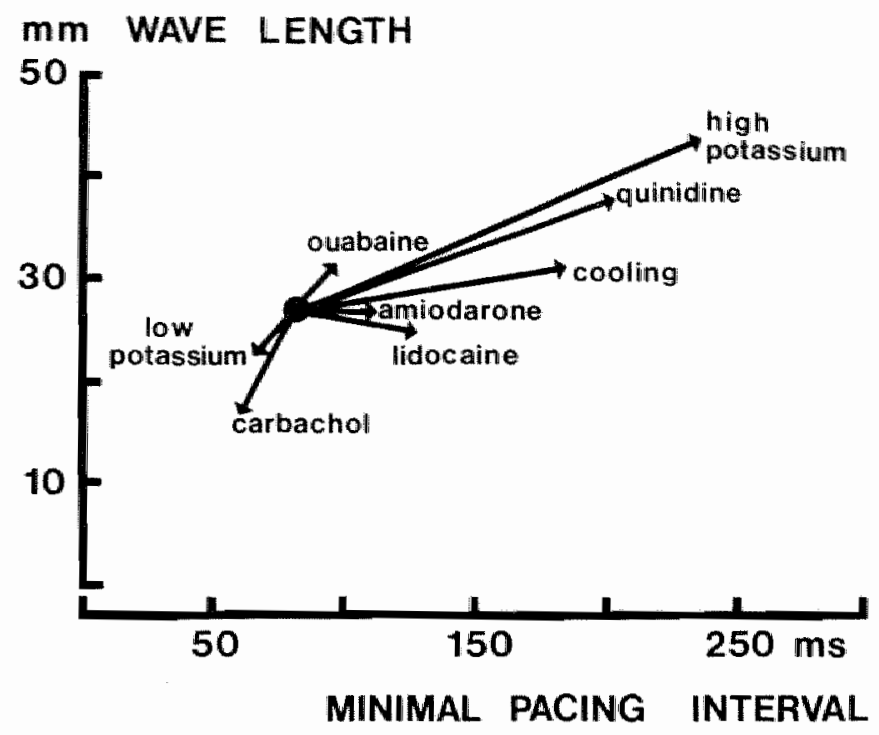

A summary of the effects of different interventions on the wave length and on the minimal paeing interval. Amiodarone (40 $\mathrm{mg} / \mathrm{kg} / \mathrm{gay})$, carbamyichaline $\left(4 \times 10^{-7} \mathrm{~g} / \mathrm{ml}\right)$, Zidocaine $\left(5 \times 10^{-6} \mathrm{~g} / \mathrm{ml}\right)$, owabain $\left(3 \times 10^{-7} \mathrm{M}\right)$. Low potassium $(2.0 \mathrm{mM})$, high potassium $(9.0 \mathrm{mM})$, quinidine (group II), tow temperature $\left(26^{\circ} \mathrm{C}\right)$.

isolated atrial muscle, as measured in this study, indicates that the size of a functionally determined circuit decreases. This is consistent with the arrhythmogenic behavior of these interventions. Furthermore one can expect that the cycle length of the reentrant tachycardia will shorten, as indicated by the fact that the arrow also points to the left.

Ad 2) The effects of lidocaine, amiodarone and moderate cooling are indicated by the arrows pointing almost horizontally to the right. The length of the excitation wave is hardly affected (horizontal position of the arrows), whereas the minimal pacing interval is prolonged (arrows pointing to the right), indicating that the revolution time of a reentrant circuit will increase. The clinical results of the treatment of atrial fibrillation with lidocaine is in agreement with these findings. Moderate cooling during a circus movement based on a functionally determined reentrant circuit, causes a slowing of the rate of the arrhythmia, without a major change in the size of the reentrant circuit. Mot in agreement with our hypothesis is the observation that amiodarone does not prolong the length of the excitation 
wave in the atrial myocardium. This discrepancy between the well documented antifibrillatory action of amiodarone in the human atrium and the finding that the length of the excitation wave in the rabbit atrial muscle is not prolonged, could not be explained. It is possible that the pharmacokinetic behavior of amicdarone differs from species to species.

Ad 3) A third category consisting of hyperkalemia and of the antiarrhythmic drugs ouabain and quinidine is indicated by the arrows pointing upwards and to the right. Ouabain causes a slight prolongation of the minimal pacing cycle length and a small prolongation of the length of the excitation wave. However both quinidine and hyperkalemia caused a pronounced prolongation of the minimal pacing interval, indicated by a large shift to the right. Simultaneously the length of the excitation wave is markedly prolonged. In other words if quinidine is administered or if the potassium concentration is elevated the slowing in the rate of a reentrant arrhythmia is accompanied by a prolongation of the length of the excitation wave indicating that the reentrant circuit will increase in size. As a consequence the chance of spontaneous termination of the arrhythmia becomes more likely. These findings support our hypothesis, since both hyperkalemia and quinidine administration are classical ways to terminate atrial fibrillation.

In conclusion the measurement of the length of the excitation wave in isolated atrial tissue is a rapid and easy method which can unravel the direct effects of different drugs on the wave length of the cardiac impulse. A shortening of the wave length indicates an increased risk of occurrence of reentrant arrhythmias if the inhomogeneity in excitability and conduction is unchanged, whereas an increase in the wave length will make initiation of a reentrant circuit more difficult and spontaneous termination mare likely. The results obtained in this thesis support the hypothesis that the length of the excitation wave can be used as an indicator for the risk of occurrence of reentrant arrhythmias. 
SAMENVATTING EN CONCLUSIES

Een regelmatige samentrekking van de hartspier is van evident belang voor het functioneren van het menselijk lichaam. Deze samentrekking wordt veroorzaakt door een electrische activatiegolf, die zich gelijkmatig en met grote snelheid $(50-100 \mathrm{~cm} / \mathrm{sec})$ in de hartspier voortplant. Een dergelijke activatiegolf wordt in rust 70 - 80 keer per minut gegenereerd. Onder bepaalde omstandigheden echter kan een verstoring in dit ritme plats winden waarbij zowel eel vertraging als een versnelling van de hartfrekwentie kan ontstaan. Sommige ritmestoornissen kunnen zo snel zijn 1600 - 700 "slagen" per minuut) dat ze de normale pompfunctie van het hart verstoren wardoor de bloedvoorziening in het lichaam stagneert.

Deze snelle ritmestoormissen kunnen worden veroorzaakt door het feit dat de hartspier voortdurend geactiveerd wordt. Nader onderzoek heeft angetoond dat de activatiegolf zich dan in een cirkelvormig pad voortplant. Een wan de factoren die het onstaan van cirkelgeleiding kan bepalen is de grootte van het circuit. Als het circuit klein is in verhouding tot de grootte van het hart kunnen meerdere circuits tegelijkertijd aanwezig zijn. De kans dat deze circuits allemal op hetzelfde moment stoppen is klein. Wanneer het circuit echter groot is kunnen er slechts een beperkt aantal tegelijk aanwezig zijn en neemt de kans op spontaan stoppen evenredig toe. Ook bij het starten van deze ritmestoornis is de grootte wan het circuit van belang. Hoe kleiner het circuit des te gemakkelijker dit past in de hartspier, hoe groter het circuit des te maeilijker.

De grootte van een dergelijk circuit is gelijk aan de golflengte wan het activatiefront. In hoofdstuk 2 wordt een envoudige methode beschreven warmee de golflengte gemeten kan worden. In deze studie herd de geisoleerde linker hartboezen wan het konijin gebruikt. Centraal staat de gedachte dat verkorting van de golflengte de kans op het ontstaan en voortdurem van deze cirkelgeleiding werhoogt. Daarentegen zal een langere golflengte de kans op het ontstaań en vaortduren verminderen. De golflengte werd gemetem onder omstandigheden, die het optreden van cirkelgeleiding bevorderen en onder amstandigheden die dit tegengaan. Hanneer de golflengte inderdaad een van de factoren is die de kans op het optreden van cirkelgeleiding weergeeft verwachten wij dat deze interwenties de golflengte op corresponderende wijze zullen veranderen. 
Een van de methoden om cirkelgeleiding in het hart op te wekken is geprogrammeerde electrische stimulatie. Door het toedienen van electrische prikkells op bepalde tijdstippen of door het snel prikkelen van het hart kan cirkelgeleiding opgewekt worden. Het bleek dat beide vormen van electrische stimulative een verkorting van de golflengte teweegbrachten (hoofdstuk 3). Deze bewinding is in overeenstemming met de gedachte dat een verkorting wan de golflengte het optreden van cirkelgeleiding bevordert.

ook werden twee andere interventies bestudeerd die bekend staan om hun arrhythmogene (=ritmestoornis bevarderende) eigenschappen; $n i$. een lage kalium concentratie (hoofdstuk 5) en een hoge concentratie acetylcholine (hoofdstuk 6). Ook onder deze omstandigheden werd de golflengte aanmerkelijk korter, geheel in overeensteming met bovenvermelde hypothese.

Een tweede methode om de hypothese te toetsen bestond uit het toepassen van interventies die de kans op het optreden van deze varm van ritmestoornis niet of nauwellijks beinvloeden. Voombeelden hiervan zijn matige afkoeling (hoofdstuk 4), lichte hyperkalemie (hoofdstuk 5) en de antiarrhythmica 1 udocaine (hoofdstuk 7) en verapamil (hoofdstuk 10). De golflengte werd zoals verwacht doar deze interventies niet noemenswardig beinvloed.

Tenslotte werd het effect van een aantal anti-arrhythmica bestudeerd warwan bekend is dat ze deze vorm wan cirkelgeleiding bestrijden. Twee vam deze middelen zijn quimidine (hoofdstuk 8) en ouabaine (hoofdstuk 9). Deze veroorzakten inderdaad een verlenging wan de golflengte. Een derde geneesmidde1, amilodarone (hoofdstuk 11), bleek geen effect te hebben op de golflengte. Dit resultat is niet in overeensteming met onze hypothese. Een duidelijke verklaring woor dit verschil werd niet gevonden. Een mogelijke verklaring zou kunnen iggen in thet felt dat het metabolisme vam amiodarone bij het konijn anders verloopt als bij de mens.

Concluderend kumnen we stellen dat meting van de golflengte in het geisoleerde hartspierweefsel een eenvoudige methode is, warmee de directe effecten van allerlei interventies op de lengte wan de activatiegolf gemeten kumnen worden. De resultaten van de in dit proefschrift beschreven interwenties ondersteunen de mypothese dat de golflengte een belangrijke factor is bij het onstaan en het voortduren van deze vorm var ritmestoornissen. 


\section{NAMOORD}

Met zeer veel genoegen kjjk ik terug op de afgelopen 4 jaren. Niet alleen de aard van het wetenschappelijk werk, maar ook de kameraadschappelijke sfeer, warin door de sectie ritme en ritmestoornissen van de capaciteitsgroep Fysiolagie wardt gewerkt, is darbij bepalend geweest.

Dr. Allessie, beste Maurits, jouw nooit aflatende enthousiasme en bereidheid het werk kritisch te beoordelen zijn essentieel geweest voor het welslagen van dit onderzoek. De vele late discussies aver de inhoud van dit proefschrift zijn bijzonder stimulerend geweest en bovendien onmisbaar bij miljn wetenschappelijke vorming. Het feit, dat door dit werk tussen ons een hechte vriendschap is ontstaan, die ook op sportief terrein tot uiting kont, is voor mij een woortdurende bron van genoegen.

Dr. Bonke, beste Wic, ondanks het feit dat je als vaorzitter van de capaciteitsgroep Fysiologie een druk bezette agenda hebt, heb je desalniettemin met grote nauwgezetheid dit proefschrift gelezen en met raad en daad ondersteund.

Tevens wil ik de referenten prof. dr. H.d.J. Wellens, dr. M. Janse en prof. A.L. Wit hartelijk danken voor het feit dat zij in korte tijd dit proefschrift gelezen en van kritische kommentaren hebben voorzien.

Bij deze wil ik ook mijn collega en paranymf $W$. Lammers bedanken. Beste Wim, veel heb ik gehad aan de discussies die we in de afgelopen jaren hebben gevoerd. Ook in deze laatste, soms wel hectische fase van de totstandkoming van dit proefschrift, heb je een wezenlijk aandeen in de uiteindelijke vorngeving gehad. Je deed dit op de jou eigen accurate wijze.

Bij het uitwoemen van de experimenten, die in deze studie beschreven staan, heb ik steun gekregen wan velle mensen. Met name Jan Hollen heeft aan deze proeven een belangrijke bijdrage geleverd. Zijn mimmer falende technisiche ondersteuming was wan veel betekenis voor het wels slagen van menig experiment. Astrid Dingjan, Jan Corsel, Eugene Herens en Victor Kaiser wil ik bedamken voor hun aandeel in een aantal van de experimenten.

Het grootste deel van het type werk werd verricht door Marie Louise Coenen. Ze werd hierbij geholpen door Ronna Le Doux. De schoomprimts van de figuren in dit proefschrift werden werzorgd door Roland Kengen.

Tenslotte wil ik dr. Reneman bedanken. Beste Rob, je hebt alls oprichter en eerste voorzitter van de capaciteitsgroep Fysiologie een goed kl imat voar wetenschappelijk werk geschapen. Hiervoor ben ik je zeer erkentelijk. 

CURR ICULUM VITAE:

30 maart 1952

geboren te heerlen

$1964-1971$

Gymmasium b gevolgd aan het Veldeke college te Maastricht.

$1971-1978$

studie geneeskunde aan de Rijksuniversiteit Groningen.

$1978-1983$

Wetenschappe]ijk ambtenaar bij de capaciteitsgroep Fysiologie, Rijksuniversiteit Limburg.

1 maart 1983

In dienst getreden als arts-assistent bij de capaciteitsgroep Interne Geneeskunde, Rijksuniversiteit Limburg, in het kader van de opleiding cardiologie. 